\title{
WestVirginiaUniversity
}

THE RESEARCH REPOSITORY @ WVU

Graduate Theses, Dissertations, and Problem Reports

2007

\section{Advanced modeling for small glass furnaces}

Heath A. Morris

West Virginia University

Follow this and additional works at: https://researchrepository.wvu.edu/etd

\section{Recommended Citation}

Morris, Heath A., "Advanced modeling for small glass furnaces" (2007). Graduate Theses, Dissertations, and Problem Reports. 1803.

https://researchrepository.wvu.edu/etd/1803

This Thesis is protected by copyright and/or related rights. It has been brought to you by the The Research Repository @ WVU with permission from the rights-holder(s). You are free to use this Thesis in any way that is permitted by the copyright and related rights legislation that applies to your use. For other uses you must obtain permission from the rights-holder(s) directly, unless additional rights are indicated by a Creative Commons license in the record and/ or on the work itself. This Thesis has been accepted for inclusion in WVU Graduate Theses, Dissertations, and Problem Reports collection by an authorized administrator of The Research Repository @ WVU. For more information, please contact researchrepository@mail.wvu.edu. 


\author{
Heath A. Morris
}

Thesis submitted to the College of Engineering and Mineral Resources at West Virginia University in Partial Fulfillment of the Requirements for the Degree of

\author{
Master of Science \\ in \\ Mechanical Engineering \\ Larry E. Banta, Ph.D., Chair \\ Giampiero Campa, Ph.D. \\ Kenneth H. Means, Ph.D. \\ Department of Mechanical Engineering \\ Morgantown, WV \\ 2007
}

Keywords: Glass Furnace, Modeling, Control 


\title{
Abstract ADVANCED MODELING FOR SMALL GLASS FURNACES
}

\author{
Heath Morris
}

One of the most pressing issues facing the glass industry is improving energy efficiency. The largest energy user in any glass company is the melting furnace or furnaces. While large float glass and container glass companies have developed sophisticated control systems, little work has been done until recently for small glass furnaces. This thesis extends the work of Holladay (2005), in which an observer was developed to estimate the temperature of glass in a small day-tank furnace. The current work eliminates the assumption of homogeneous glass melt and refractory temperatures, and develops a furnace model suitable for implementation with a real-time controller.

A state space model of an end-fired furnace was developed in which the furnace was divided longitudinally into two zones. Zone 1 contains the burner flame "cylinder", while Zone 2 is beyond the end of the flame cylinder. Separate states are identified for the temperatures of the refractory in the crown, the walls above the glass melt, the walls adjacent to the two primary melt zones, and the floor of the furnace. The furnace ends are also divided into similar zones constituting discrete states. The glass melt itself contains a thin, surface layer and two thicker layers of stratification. In all, 24 state variables are included in the model. The inputs are the net thermal power provided by the flame and the ambient temperature.

Simulations were performed in Simulink and Matlab and were used to predict the temperatures of all 24 state variables. The results were verified using data collected from a similar tank furnace at Fenton Art Glass Company. The results showed a significant stratification in the vertical axis of the furnace but very nearly uniform temperatures in the length and width directions. The model was used to study various melting strategies. Preliminary results suggest that using the estimated glass temperature and feedback from thermocouples in the wall and floor of the furnace could lead to significant energy savings in the melt cycle. Suggestions are made for using the model within a real-time control system implementable on a small glass furnace. 


\section{Table of Contents}

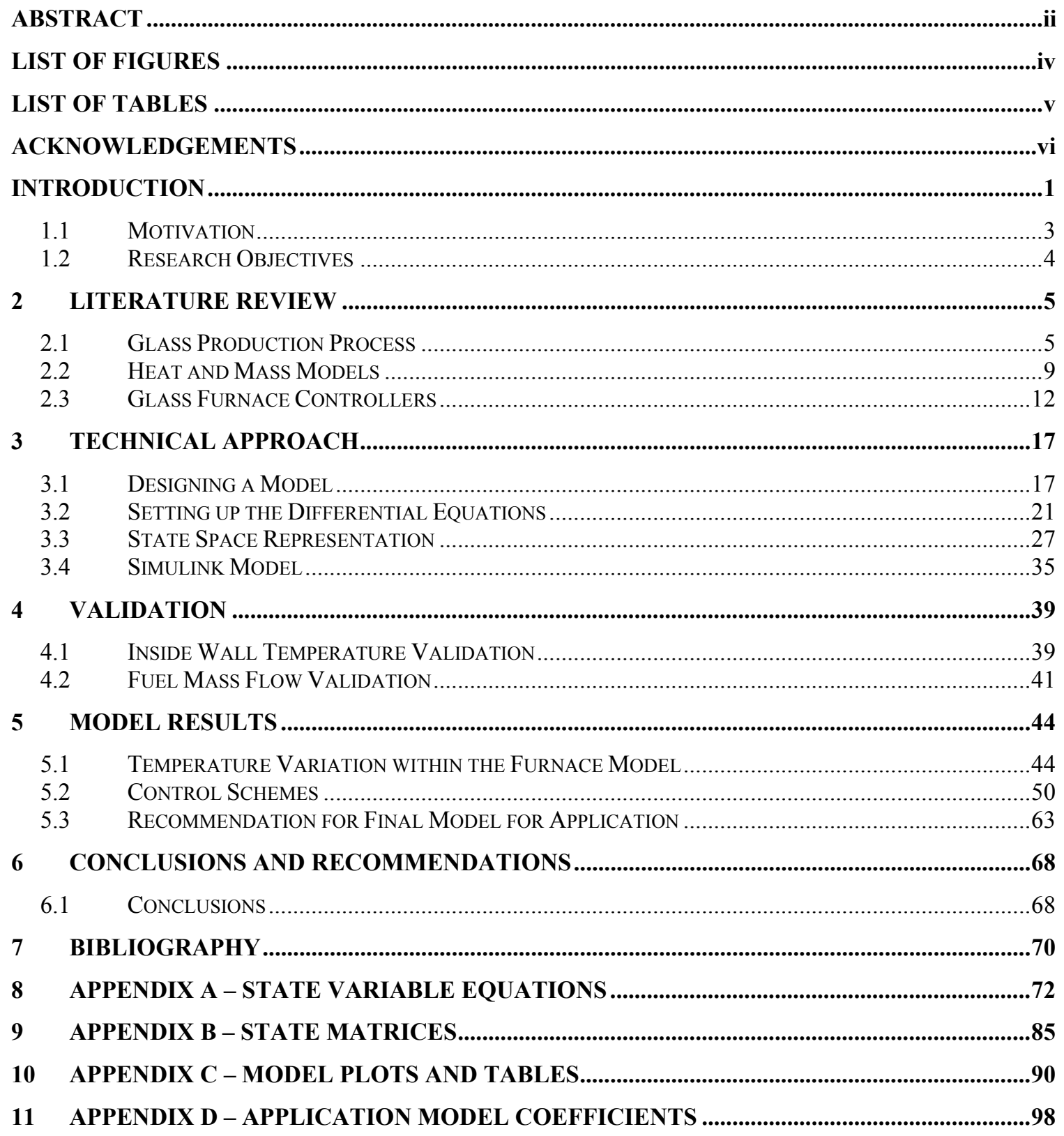




\section{List of Figures}

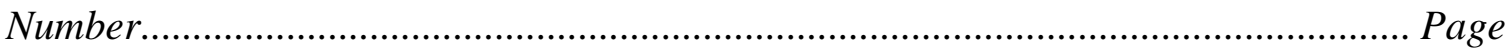

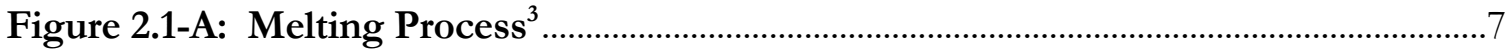

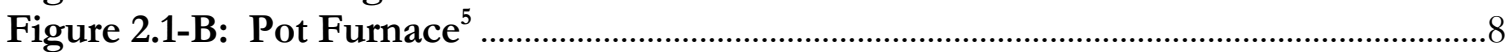

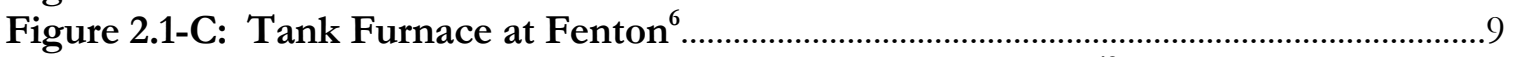

Figure 2.2-A: Temperature Distribution along a Large Furnace ${ }^{12}$.................................... 11

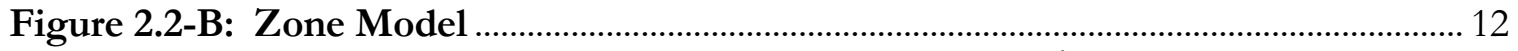

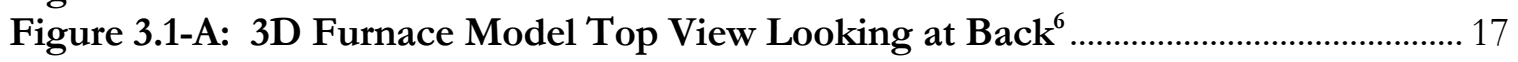

Figure 3.1-B: 3-View Drawing of Furnace Model Volume ................................................. 18

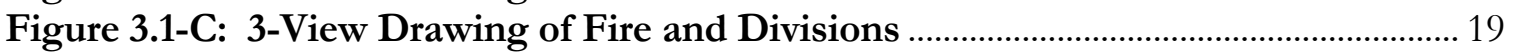

Figure 3.1-D: Side View of Furnace Division with Labels .................................................. 19

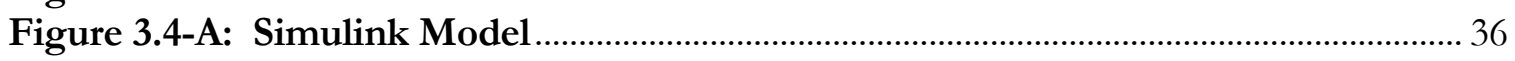

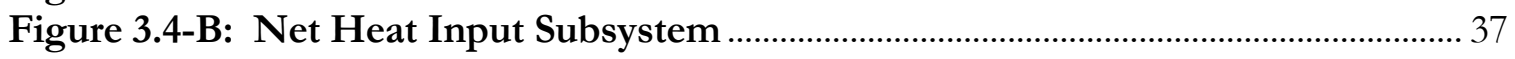

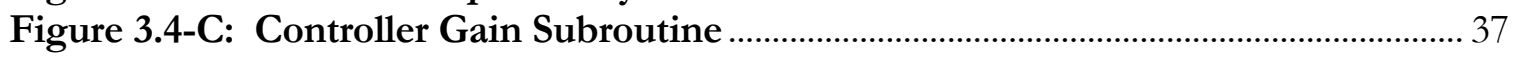

Figure 4.1-A: Internal Wall Temperatures During Idle at 1338K ........................................ 40

Figure 4.2-A: Fuel Usage during Operation of the Model .................................................. 42

Figure 5.1-A: Glass Temperatures near the Flame during the Melt Cycle ........................ 45

Figure 5.1-B: Glass Temperatures away from the Flame during the Melt Cycle ........... 46

Figure 5.1-C: Profile Glass Temperatures during the Melt Cycle ........................................ 49

Figure 5.2-A: Feedback Glass Temperature during the Full Melt Cycle ........................... 52

Figure 5.2-B: Fuel Rate during Operation with Glass Temperature Feedback ............. 53

Figure 5.2-C: Feedback Crown Temperature during the Full Melt Cycle......................... 56

Figure 5.2-D: Fuel Rate during Operation with Crown Temperature Feedback............ 57

Figure 5.2-E: Feedback Floor Temperature during the Full Melt Cycle .......................... 58

Figure 5.2-F: Fuel Rate during Operation with Floor Temperature Feedback .............. 59

Figure 5.2-G: Feedback Crown Temperature and Others during the Full Melt Cycle 61

Figure 5.2-H: Feedback Floor Temperature and Others during the Full Melt Cycle .. 62

Figure 10-A: Back Profile Temperatures during the Melt Cycle ....................................... 90

Figure 10-B: Front Profile Temperatures during the Melt Cycle .......................................... 91

Figure 10-C: Side Profile Temperatures near the Flame during the Melt Cycle............. 92

Figure 10-D: Side Profile Temperatures away from the Flame during the Melt Cycle 93

Figure 10-E: Glass Temperatures near the Flame during the Melt Cycle ......................... 94

Figure 10-F: Glass Temperatures away from the Flame during the Melt Cycle............. 95

Figure 10-G: Profile Temperatures during the Melt Cycle ............................................... 96

Figure 10-H: Profile Glass Temperatures during the Melt Cycle ......................................... 97 


\section{List of Tables}

Number.

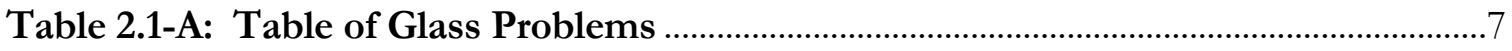

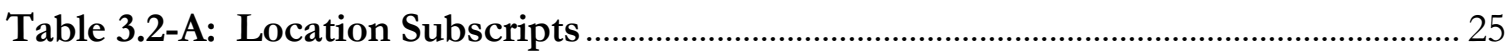

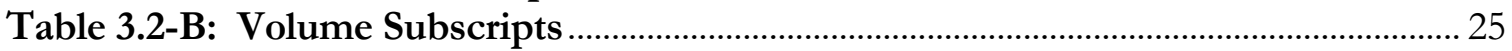

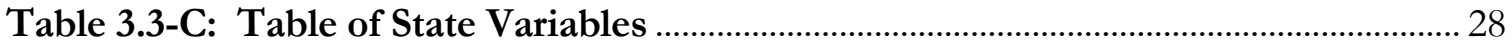

Table 3.3-D: Table of Areas and Shape Factors ...................................................................... 29

Table 3.3-E: Table of Masses, Specific Heats, and Capacitances...................................... 31

Table 3.3-F: Mass, Specific Heat, and Capacitance of Gas Volumes ................................. 33

Table 3.3-G: Table of Heat Transfer Resistances between Different Materials.............. 33

Table 3.3-H: Heat Transfer Resistances between Volumes of the Same Material........ 34

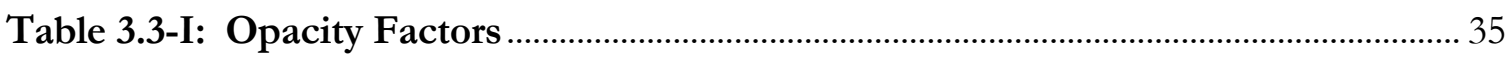

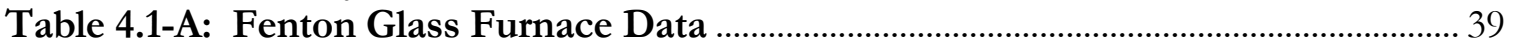

Table 4.1-B: Steady State Model Furnace Data and Error Percentage ................................ 40

Table 4.2-C: Steady State Model Fuel Data and Error Percentage ..................................... 43

Table 5.1-A: Glass Temperatures near the Flame at Steady State ...................................... 45

Table 5.1-B: Glass Temperatures away from the Flame at Steady State ............................ 46

Table 5-C: Profile Temperatures during the Melt Cycle ................................................. 47

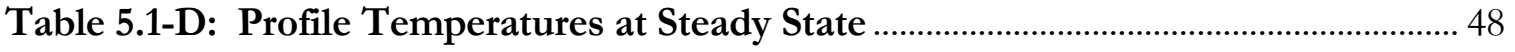

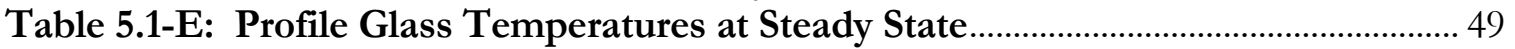

Table 5.2-F: Steady State Temperatures with 1500K Set Point ............................................... 51

Table 5.2-G: Fuel Usage and Glass Temperature for Glass Feedback Controller .......... 53

Table 5.2-H: Fuel Usage and Glass Temperature for Crown Feedback Controller...... 57

Table 5.2-I: Fuel Usage and Glass Temperature for Floor Feedback Controller............ 59

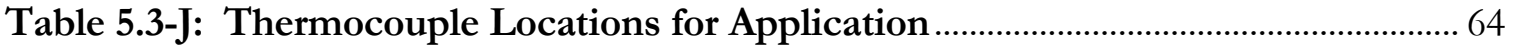

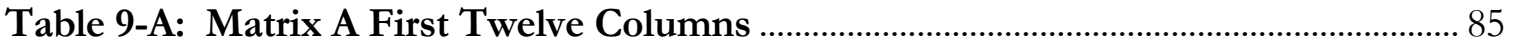

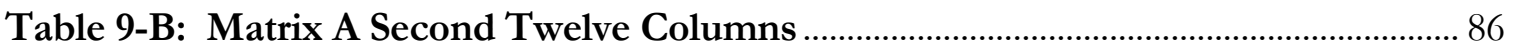

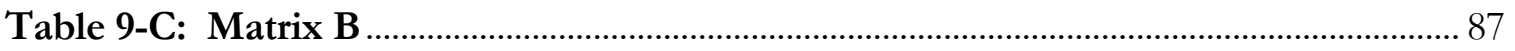

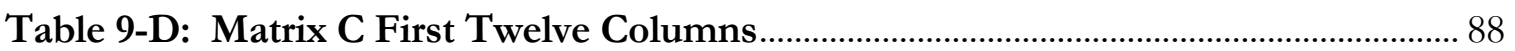

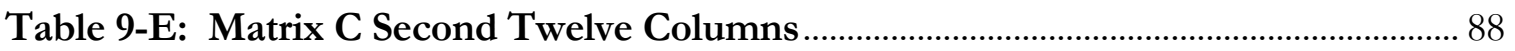

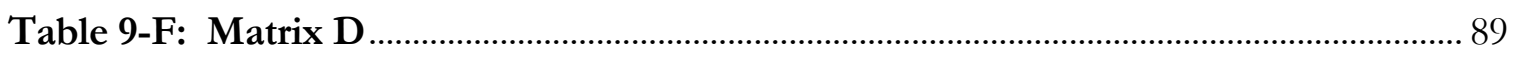

Table 10-A: Back Profile Temperatures at Steady State ........................................................ 90

Table 10-B: Front Profile Temperatures at Steady State .................................................. 91

Table 10-C: Side Profile Temperatures near the Flame at Steady State ............................ 92

Table 10-D: Side Profile Temperatures away from the Flame at Steady State ................ 93

Table 10-E: Glass Temperatures near the Flame at Steady State ........................................ 94

Table 10-F: Glass Temperatures away from the Flame at Steady State.............................. 95

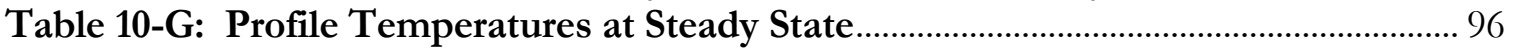

Table 10-H: Profile Glass Temperatures at Steady State ................................................... 97

Table 11-A: Table of Areas and Shape Factors for Application ............................................. 98

Table 11-B: Table of Masses, Specific Heats, and Capacitances for Application .......... 99

Table 11-C: Mass, Specific Heat, and Capacitance for Gas Volume for Application.... 99

Table 11-D: Heat Transfer Resistances between Different Materials for Application 100

Table 11-E: Table of Resistances between Glass Volumes for Application 100 


\section{Acknowledgements}

I would like to thank all of my friends and family who helped me get through these five years of hard work. I am so grateful for you, Cheryl, for helping me keep on track and being supportive as things got busy. I would like to thank my parents, Rick and Sharon Morris. You did all that you could and more to help me get the education that you always wanted me to have. Thanks also to my sister, Jessica, who always was there if I needed her.

I would like to express gratitude for my committee members, Dr. Kenneth Means and Dr. Giampiero Campa. Thank you for your time reading and evaluating my thesis. Thank you for also answering those seemingly simple questions that I got tripped up on along the way.

Most of all, I would like to thank Dr. Larry Banta for all he has done for me. As my research advisor, committee chair, and friend you have given me more than I could ever ask. You have helped me strive to achieve my fullest potential. Your influence will always carry with me as I continue practicing engineering in industry. 
List of Variables

A Area

A State matrix

B Control matrix

C Capacitance

C Output matrix

$c_{p} \quad$ Specific heat

D Noise matrix

g Acceleration of gravity

h Heat transfer coefficient

m Mass

P Pressure

Q Heat transfer

R Resistance

R Gas constant

SF Shape Factor

OF Opacity Factor

T Temperature

V Volume

x State vector

$\varepsilon \quad$ Emissivity

$\rho \quad$ Density

$\sigma \quad$ Stephan-Boltzmann constant 


\section{Introduction}

Tremendous opportunity for improvement of process efficiency and product quality is available to the hand glass industry through better control of the furnaces. Control systems can monitor and regulate fuel to keep the combustion process within the furnace as efficient as possible. For example a furnace operating at $2400 \mathrm{~F}$ with $25 \%$ excess air could experience $24 \%$ fuel savings by reducing excess combustion air to $10 \%$. High efficiency combustion decreases melt cycles with maximized heat/fuel ratios. Keeping a stable glass temperature decreases defects such as cords, seeds, and other inclusions. Glass temperature control allows for glass viscosity control for forming operations. $^{1}$

Most glass furnaces use simple, single-loop control of the firing rate based on the temperature of the refractory in the furnace crown. Air/fuel ratios are usually controlled by open-loop ratio controllers sensing either pressure in the combustion air manifold, flow rate of fuel, or mechanical position of a damper linkage. These controllers only monitor a single parameter in order to approximate the fuel needed for operation. A system monitoring multiple parameters has more understanding of the furnace temperatures and can better judge the needs of the furnace's fuel input.

Multiple furnace control schemes have been designed over the years using different approaches. The earliest and most common are PID controllers. These control systems monitor either a single sensor or multiple sensors and adjust the fuel flow based on a predetermined relationship between inputs and outputs. Adaptive control has been 
added recently to PID controllers to provide more flexibility. These systems are better able to adjust to the dynamic changes within the glass furnace system through the incorporation of parameter estimation. The new adaptive systems are usually designed for specific (usually large) furnaces. They usually incorporate multiple PID controllers working together to monitor several parameters such as fuel flow, glass temperature, refractory temperatures, furnace pressure, and stack gas temperatures. The cost of such a complex control system that is specially designed for the furnace is usually greater than what a small hand glass company can afford.

The first step in any control design is modeling. The accuracy and robustness of a control system is entirely dependent on the quality of the underlying mathematical model of the process and its environment. Modeling means describing a physical element or system using mathematical equations. These equations can be used to predict how a system will behave in response to any feasible set of inputs, and thus a controller can be designed to provide a series of control signals which will result in the system producing the desired outputs - or at least a set of outputs that is acceptably close to the desired set.

Most of the early PID controllers were designed using this basic modeling procedure. A "lumped parameter" approach was utilized in order to simplify the computations. "Lumped parameters" refer to a set of assumptions that are only approximately true. Examples of this include a well stirred batch or corner effects not existing. More advanced modeling, involving finite element analysis, has come about with the idea of creating subsystems within a system. The whole system is broken up 
into partial volumes on which transfer functions are created. These partial volumes, or zones, are solved using computer algorithms creating a more detailed understanding of the whole system. Linear dynamic systems can easily be expressed in state space form. State space combines the complex mathematical expressions of transfer functions with vector representation of the same relationships. The vector calculations of computational solutions are easier to reach which saves time and money. State space also utilizes this combination of multiple parameters for estimating noisy or incomplete parameters. These unknown parameters are approximated from the measurable parameters to which they are related by transfer functions. State space also allows the ability to implement control sequences based on multiple streams of information, to design for complex and time-varying control objectives and to optimize control strategies for more complex objectives than are possible with single-variable classical PID controllers. Modeling of glass furnaces has been only conducted on a case by case basis. Models are specific for the furnace to be controlled and little effort has been put forth on a global furnace model.

\subsection{Motivation}

This research provides the tools needed to implement complex controls systems in small glass furnaces allowing for cost savings, improved product quality and possible extended furnace life. An accurate yet flexible furnace model has been constructed so it will be applicable for as many furnaces in the glass industry as possible. The furnace model takes advantage of existing technology and applies it in such a way that results can be reached in more detail than ever before with low cost equipment. 


\subsection{Research Objectives}

The main objective of this research is to develop an advanced model suitable for use in small glass furnaces, particularly of the day tank variety. The research will include the following tasks:

- Expand earlier work creating a generic furnace model suitable for a wide range of furnace sizes and geometries.

- Improve model accuracy by eliminating assumptions of homogeneous melt properties and wall/crown/floor temperature profiles.

- Verify model using temperature data from real furnaces.

- Develop a plan for implementation 


\section{Literature Review}

Glass furnace control requires the consideration of four concepts: the glass production process, glass furnace heat and mass flow models, furnace parameter estimation, and glass furnace controllers.

\subsection{Glass Production Process}

Glass production includes the techniques and furnace designs used to produce glass. The processes in glass formation include batch mixing, furnace charging, melting, and glass forming. Furnace designs vary based on firing direction and location of furnace entry ports.

Batch mixing is the preparation of raw materials for introduction into the furnace. The raw materials are selected based on the type of glass to be produced. The base ingredient in batches is the glass former. Common glass formers include silica $\left(\mathrm{SiO}_{2}\right)$, boric oxide $\left(\mathrm{B}_{2} \mathrm{O}_{3}\right)$, and phosphoric oxide $\left(\mathrm{P}_{2} \mathrm{O}_{5}\right)$. Additional ingredients are added to the batch to modify the glass properties or the process reactions. Flux is added to the batch to lower the temperature at which melting occurs. Common fluxes include soda ash $\left(\mathrm{Na}_{2} \mathrm{O}\right)$, sodium carbonate $\left(\mathrm{Na}_{2} \mathrm{CO}_{3}\right)$, limestone $\left(\mathrm{CaCO}_{3}\right)$, and potassium carbonate $\left(\mathrm{K}_{2} \mathrm{CO}_{3}\right)$. Flux not only lowers the melting temperature but also weakens the glass. An addition of alumina $\left(\mathrm{Al}_{2} \mathrm{O}_{3}\right)$ helps strengthen the chemical structure of the glass and 
counteract the effects of the flux. Additional colorants are added to give the glass the desired shade and color. Finally fining agents are added to the mix to help with removal of bubbles and provide some mixing action. Fining agents are not always added to the initial batch and may be added later once the furnace has been charged. ${ }^{2}$

Furnace charging is simply the adding of batch materials to the furnace. Furnace charging may be either: continuous or batch. Continuous charging is the process of adding the batch ingredients at a more or less constant rate to the furnace. An automated process dumps the batch materials into one end of the furnace and the melting process begins. Continuous charging is mainly used for large furnaces with capacities above 10 tons per day.

Batch charging is merely the addition of all of the materials for a "batch" of glass at once. Typically, the furnace is worked down until it is nearly empty and then a new batch is put into the furnace for a melt cycle to begin. Most small glass furnaces use batch feeding. ${ }^{3}$

Glass melting actually consists of four processes: melting, fining, homogenizing and conditioning. Four different processes occur during the melting process. Melting is what the term implies - the physical transformation of the batch materials from solid to liquid phase. This stage includes several chemical reactions in addition to the heat transfer process. Gases are evolved from the batch and from the fining agents, and bubble to the surface, promoting mixing and homogenization of the melt. The fining 
process continues until all of the gas bubbles have escaped from the surface. Each of these processes occurs in a near sequential but overlapping order as shown below in Figure 2-A.

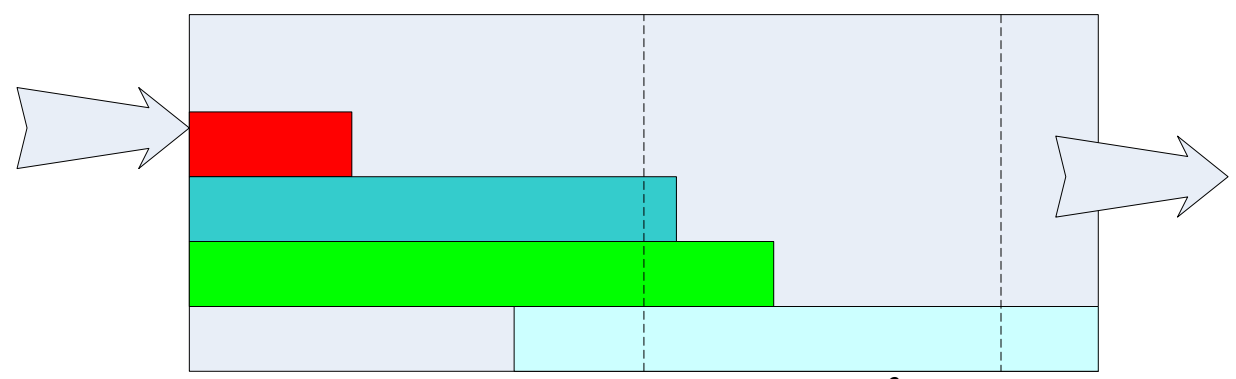

Figure 2.1-A: Melting Process ${ }^{3}$

The final process in glass production is glass forming, and this occurs outside the furnace. Different types of glass forming include hand blowing, floating, molding, and glass fiber extrusion. Defects found after glass forming are almost always attributed to the glass melting process. A table of problems that can occur during the glass melting cycle is shown below.

Table 2.1-A: Table of Glass Problems

\begin{tabular}{|c|c|}
\hline Problem & Effect \\
\hline Insufficient Refining & Seeds or bubbles within the glass \\
\hline Insufficient Homogenizing & Areas of inconsistent glass \\
\hline Inconsistent Batch Size & Areas of inconsistent glass \\
\hline Atmospheric Pollution Infiltration & Discoloration of glass \\
\hline Poor Temperature Control & All of the above \\
\hline
\end{tabular}


Control of the melting process helps reduce the number of defects found later in the glass forming process.

The most important piece of equipment in a glass factory is the furnace. In small glass factories two types of furnaces are most common, pot and tank furnaces. Pot furnaces are refractory structures built around a ceramic crucible. The crucible is usually closed, and shields the batch materials from the furnace atmosphere. Pot furnaces are often used for colored glasses. Tank furnaces are slightly larger and are constructed of refractory brick. The brick refractory is the melt container in a tank furnace. The glass melt lies on the bottom of the furnace after charging until melting is complete. These furnaces can be batch or continuous fed depending on the rate of glass production desired. A tank furnace is heated by internal flames arranged either to fire the length of the furnace (end fired) or firing across the width of the furnace (cross fired). The position of the batch loading port can also be on the side (side port) or on the end (end port). Below is a picture of both a pot and an end port tank furnace.

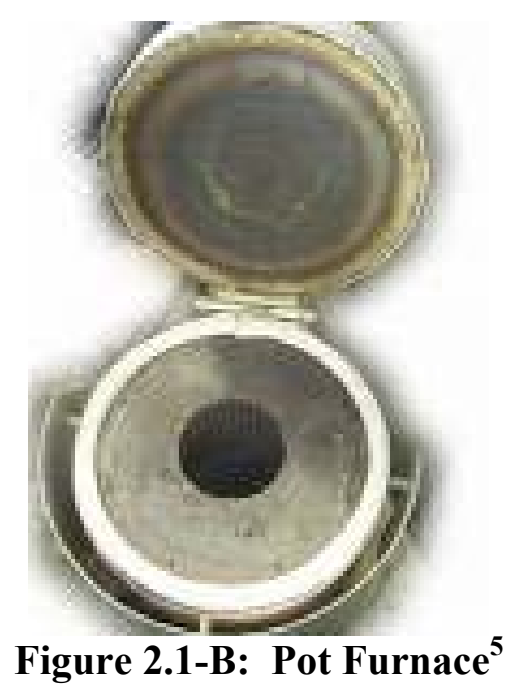




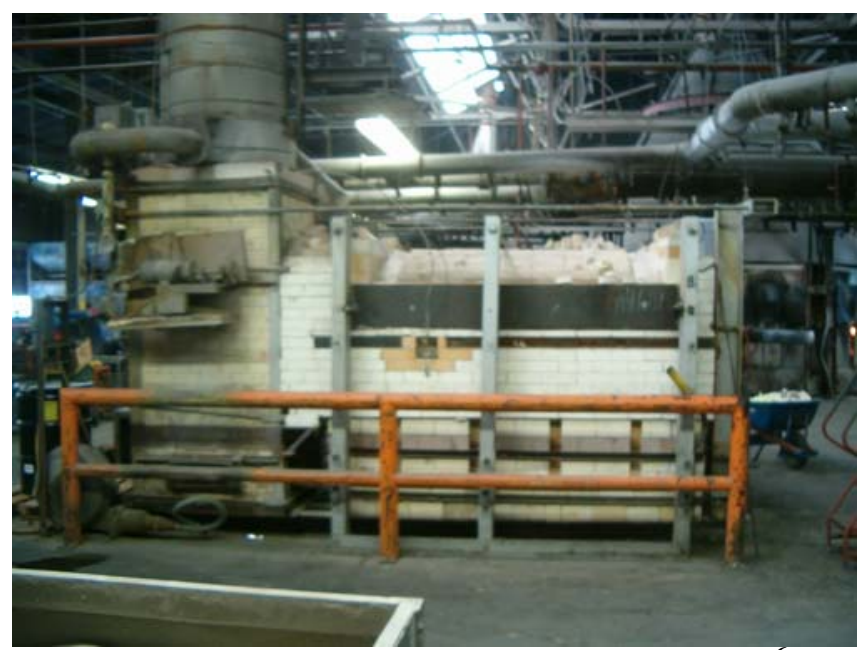

Figure 2.1-C: Tank Furnace at Fenton ${ }^{6}$

\subsection{Heat and Mass Models}

Heat and mass flow models have been developed to try to understand the processes that occur within the glass furnace. The first computer models were constructed in the 1960s just after invention of the computer. These first models were one dimensional heat flow models showing the temperature variance through multilayered refractory walls. The initial models allowed engineers to design refractory walls based on these temperatures to prevent material failure due to temperature. Not until the 1970 s when the energy crisis began, did engineers start to use models to better understand energy usage. Since then many complex highly specific models have been designed and put into operation. ${ }^{7}$

Models are designed to incorporate combustion, molten glass flow, temperature variance, and radiation heat transfer modeling. Most models have put more emphasis on 
one specific area rather than trying to incorporate all of them. It has been realized that for a complete model all of these elements of furnace operation must be included. ${ }^{8}$

Flame structures vary from furnace to furnace according to firing direction and flame shape. However, complex flame structures can be simplified within models to heat generation zones. The total heat generation by the combustion process is calculated by the rate of fuel burned. The heat generation can be distributed within the model by using a function of flame length. Dzuyzer ${ }^{9}$ divided the flame length into 5 sections and assigned corresponding percents of the total heat generation of 50,30, 15, 5, and 0 . His model was effective in showing a variation of temperatures in the walls and glass along the direction of the flame. The distribution of wall and melt temperatures along the length of the furnace can be seen in other models. Varner and Trochta ${ }^{10}$ modeled the temperature distribution within the depth of a batch. Choudhary ${ }^{12}$ modeled the molten glass temperature with temperature gradients. In these cross fired furnaces, both horizontal and vertical gradients exist ${ }^{11}$. Choudhary ${ }^{12}$ shows these temperature variances in the diagram below: 


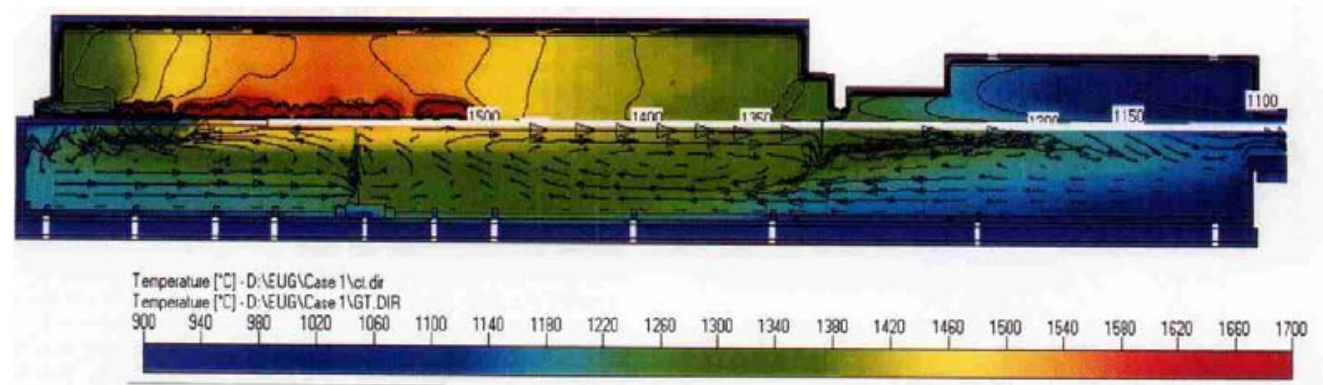

Figure 2.2-A: Temperature Distribution along a Large Furnace ${ }^{12}$

Mathematical modeling requires in depth understanding of static and dynamic mathematic equations that represent the object under observation. The equations used in glass furnace modeling are found within the laws of physics and heat transfer. The main mode of heat transfer to the glass in a furnace is radiation from the flame ${ }^{13}$. The radiation from the flame is absorbed by the walls, glass, and crown. Absorption of this energy in the glass varies with glass properties based on the emissivity of the glass.

With so much variance within the furnace, assuming uniform temperatures has been proven inaccurate. Dzyuzer ${ }^{9}$ produced a zonal model in which the entire furnace was broken into equal cubes with each volume and surface having its own set of governing equations. The grand total of volumes and surfaces reached were 75 and 110 . 


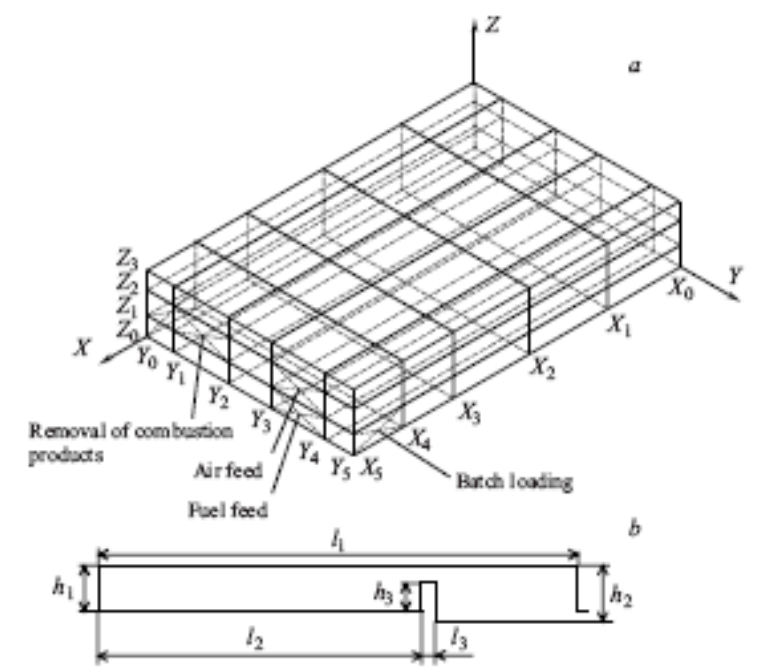

Fig. 1. Approximated zonal model of the working space of the glass-melting fumace with horseshoe flame direction (a) and longitudinal section of the melting tank $(b)$.

Figure 2.2-B: Zone Model

This allowed the model to still use the simplicity of uniform temperatures within each block, but allowed accuracy to increase as the number of blocks was increased since temperatures could be different from block to block. This allowed him to accurately predict flow patterns and temperature profiles within the glass furnace.

\subsection{Glass Furnace Controllers}

Glass furnace control has been approached not as a problem but as an application for control schemes. Four different control schemes were found to be in use today in glass furnaces. These controllers include PID, fuzzy logic, adaptive control, and observer control. 
PID controllers were one of the first types of controllers used in glass furnaces, and are still the most common type used today. PID stands for proportional, integral, derivative. The control process reads the set point temperature and responds with a control signal that is the weighted sum of the error, the derivative of the error, and the integral of the error. The error is the difference between the set point and measured temperature of the crown. Nixon ${ }^{14}$ reported using PID controllers for furnace operation more than 20 years ago. In his control system, he used PIDs in a cascade system with one response feeding the next. The sensors monitored oxygen, crown temperature, and wall temperatures. The system could react to the removal of glass from the furnace, and cut the fuel back so that the furnace didn't over heat.

PIDs are still heavily used today. Moon ${ }^{15}$ describes a multiloop system that works very similarly to Nixon's ${ }^{14}$, with "feed forward, cascade, override, selective, and decoupling" loops. His work dates only back to 2000. This reflects the current problem with the glass furnace industry. The control schemes have not been updated with the progression of technology. Moon's work was conducted on a large TV glass furnace whose financial revenue could afford more advanced controls. Small glass furnaces today are stuck with using only conventional PIDs due to the higher development costs normally associated with more complex controllers.

Fuzzy logic has been applied to different areas such as classification, pattern recognition, decision making, optimization, signal processing and control. The idea behind fuzzy logic is the imitation of human action. Processes that are nonlinear, 
complex, or poorly understood are often approached using fuzzy logic. Moon ${ }^{16}$ performed tests using fuzzy logic on the same TV glass furnaces as mentioned earlier. In these furnaces he set his system up to monitor the human operator and the PID controllers. The operator had the option to control the furnace either manually or with the fuzzy logic. The human operator would operate the furnace first, and the fuzzy logic would monitor and "learn" the control logic used by the operator. Once the fuzzy logic had gathered enough data, the human operator could switch control to the fuzzy logic and the controller would try to mimic the human control logic. The PID controller was still in use to control the furnace fuels and air however the fuzzy logic controller was setting the set points that the PID needed to reach.

This form of fuzzy logic is more of a form of automation than a form of pure control. The controller in this case is a combination of the fuzzy logic and the PID. The older simpler PID is still making adjustments to fuel and air while the fuzzy logic sets temperature set points for the PID to follow. The fuzzy logic controller was observing other inputs such as pull rate, ambient conditions, or glass temperature that the PID may not have been measuring.

Adaptive control theory is the incorporation of parameter estimation in order to adapt to the control scheme to maintain performance despite changes in process parameters. Wertz ${ }^{17}$ introduced the idea of parameter estimation with the use of a PID controller. Wertz also approached the PID controller from a new direction with the incorporation of a bottom temperature reading. Wertz claims there is a strong 
relationship between glass quality and the stability of the bottom temperature of the furnace. The more common placement of a crown temperature gauge was found inefficient since the time constants between the air and crown were much smaller than the air and the glass melt. With the incorporation of the furnace bottom temperature, a new feedback measurement with a time constant close to the actual melt could be monitored and used for control. The goal shifted from controlling the temperature of the combustion gas to controlling the temperature of the furnace bottom.

The incorporation of parameter estimation came about for several reasons for Wertz. He saw that the operating conditions of the furnace varied from time to time and a good example is a change in glass color. The heat transfer properties are different in white and colored glass. The addition of electrical heating that can vary depending on the furnace operators was also mentioned. And finally the wear in the furnace and sensors over the time of its life were motivations for adaptive control. ${ }^{17}$

In 2005 it was suggested to use an observer based control model for small glass furnaces. In her thesis, Holladay ${ }^{2}$ developed two ideas for an observer control scheme. The first was based on the already installed crown thermocouples. The second was designed around additional inputs of wall temperatures and floor temperatures.

An observer control system mathematically estimates the unknown states of a system. The observer uses the measured system states along with known system dynamics and control inputs to provide estimates on these unknowns. The modeling for 
an observer is the same as any other system with only the inclusion of a feedback term. This feed back is used to determine an estimation error which the system tries to drive to zero.

The crown temperature observer was found insufficient. Holladay ${ }^{2}$ noted the same time constants found by Wertz ${ }^{17}$ and came up with a similar solution. The second observer control system incorporated both the wall and floor temperatures of the system. Using these additional measurable states, a steady state system error could be driven to zero in a matter of minutes. This system provided a highly mathematical, yet electronically simple design for the use in smaller glass furnaces. The system, however, is still only theoretical and contains many simplifying assumptions such as uniform glass and wall temperatures. 


\section{Technical Approach}

\subsection{Designing a Model}

The tank furnace is one of the most common types of furnaces used within the glass industry by small companies. A furnace from Fenton Glass $^{6}$ was chosen for its common size and shape. A 3-D model of the furnace can be seen below.

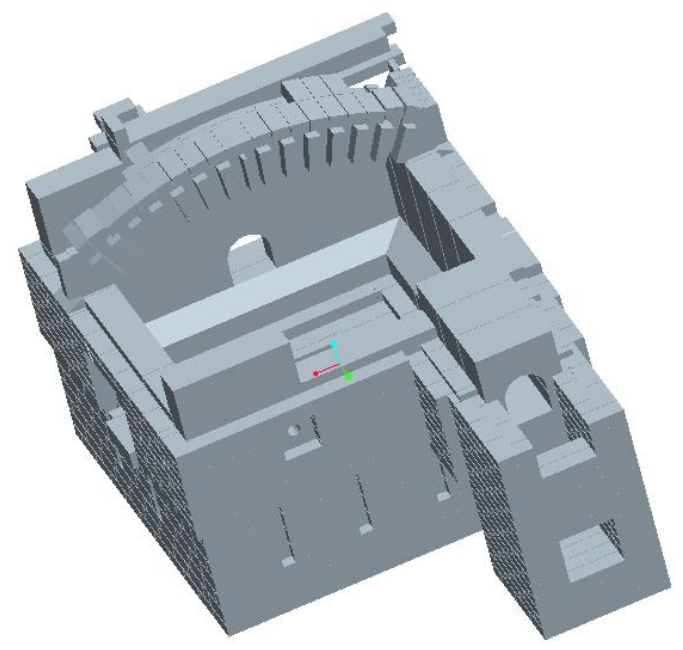

Figure 3.1-A: 3D Furnace Model Top View Looking at Back 6

The dimensions of the furnace were approximated as $1.83 \times 1.83 \times .915$ meters $\left(6^{\prime} \times 6^{\prime} \times 3^{\prime}\right)$. A three view drawing of the tank is shown below. 


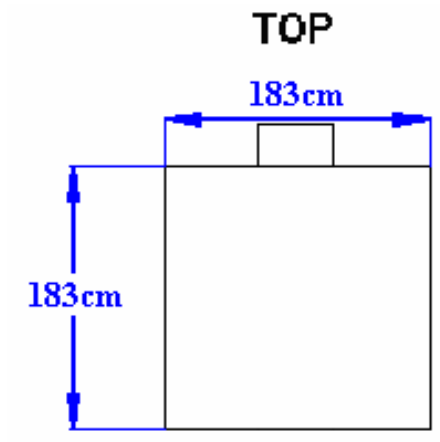

FRONT

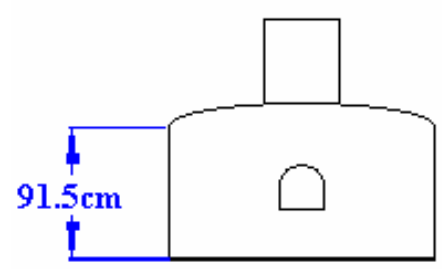

RIGHT

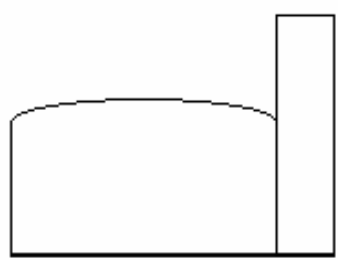

Figure 3.1-B: 3-View Drawing of Furnace Model Volume

Considering flame length and glass level, the furnace can be broken up into zones. The top rectangular volumes consist of combustion gases containing the flame and combustion gases without flame in them. These two volumes are labeled alpha. The numerical 1 or 2 corresponds directly to flame and no flame. This separation is kept consistent as the furnace is further divided throughout the depth of the glass. Beta consists of the glass surface. The thickness is half an inch. The small thickness allows the assumption of no lateral heat transfer. The next volume, chi, is the top half of the glass volume. The final volume, delta, is the bottom of the glass in the tank. Figure 3.1C shows how the 3 view drawing is divided. 

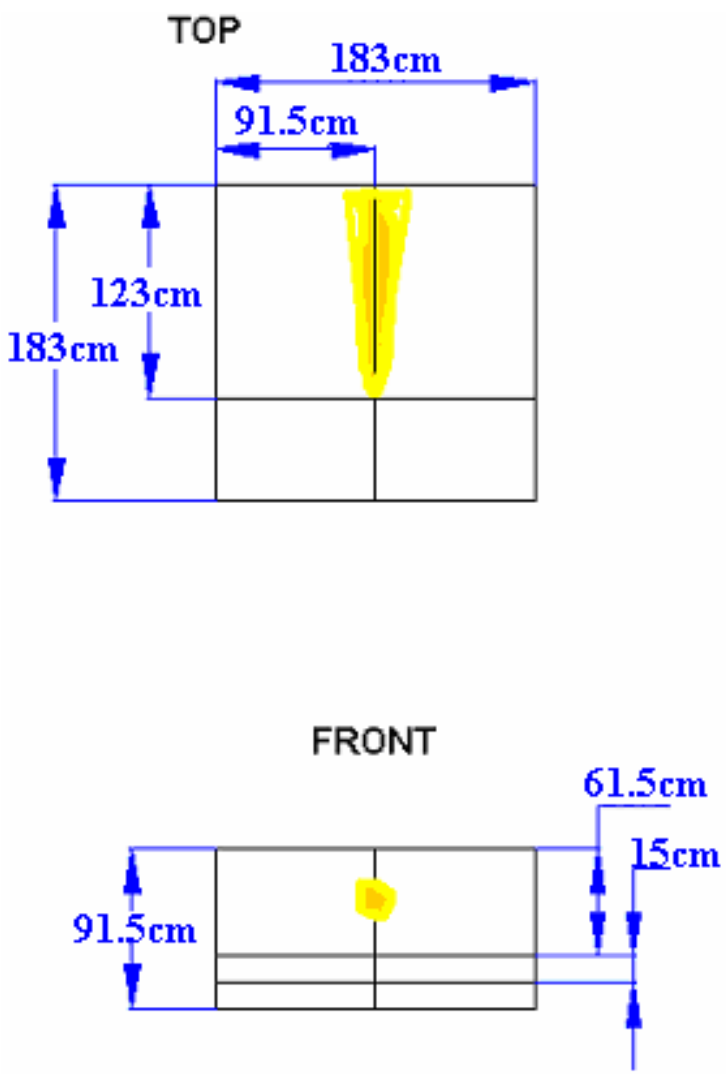

RIGHT

Figure 3.1-C: 3-View Drawing of Fire and Divisions

Figure 3.1-D shows the right hand view with its labeled volumes.

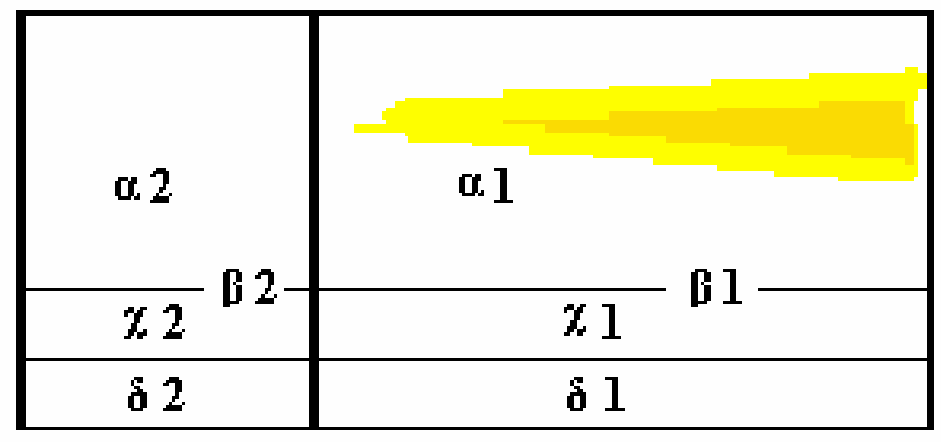

Figure 3.1-D: Side View of Furnace Division with Labels

A set of assumptions must be made now for the final model to be set up. 
- The flame is fired along the center of the furnace

- The stack outlet is in the center as well, removing gases from the same volume that the flame is heating. These assumptions allow for symmetry along the width of the furnace. With symmetry only one side of the furnace needs to be solved since the furnace has uniform temperature across its width.

- Heat in is calculated as a net input. Flame heat addition is calculated then the net losses from stack, conduction loss through the skin, infiltration/exfiltration and radiative losses through openings are subtracted to calculate a net heat input.

- The temperature is uniform within each volume of glass, refractory, or gas however different volumes have different temperatures. This assumption allows for variations in temperature along the length and height of the furnace. Keeping each volume a uniform temperature allows for simpler heat transfer equations and fewer temperature states within the furnace.

- Refractory volumes consist of only the inner high temperature layer. A furnace is constructed using two layers of refractory. The inner layer is a high temperature refractory that is designed to resist the corrosion of the glass. The outer shell consists of a lighter, insulating refractory. Rather than create more state variables, the convective and radiative resistances at the outer shell are adjusted to simplify the shell model to a single layer with equivalent thermal resistance to the composite shell. 


\subsection{Setting up the Differential Equations}

Since a glass furnace operates at high temperatures (around 1500K), the primary mode of heat transfer from the flame to the glass is radiation. It has been shown that convection is two orders of magnitude smaller than radiation at temperatures above $1200 \mathrm{~K}$ and can therefore be neglected between the combustion air and the glass ${ }^{18}$. Conduction is the primary mode of heat transfer within the glass but some models have included convection. The convection effects have been shown to be negligible for the sake of simplifying computation ${ }^{13}$. The equation for heat transfer by radiation has the form:

$$
\dot{Q}=\sigma \varepsilon A(S F)\left(T_{1}^{4}-T_{2}^{4}\right)
$$

This equation can be linearized by using a mean operation temperature. The linearized form is shown below:

$$
\dot{Q}=4 \sigma \varepsilon A(S F) \bar{T}^{3}\left(T_{1}-T_{2}\right)
$$

This method was shown by Holladay ${ }^{2}$ to be accurate for temperatures over 1300K. This form is further simplified by finding a generalized heat transfer resistance R. The final form of the equation is shown below:

$$
\dot{Q}=\frac{1}{R} A(S F)\left(T_{1}-T_{2}\right)
$$

The resistance between the combustion gases and glass can be calculated by:

$$
R a g=1 / 4 \sigma \varepsilon \bar{T}_{a g^{3}}
$$

The resistance between the combustion gases and walls can be calculated by: 


$$
R_{a w}=1 / 4 \sigma \varepsilon \bar{T}_{a w^{3}}
$$

In these equations each variable can be defined as:

$\sigma=$ Stephen-Boltzman constant of $5.67 \times 10^{-8} \mathrm{~W} / \mathrm{K}^{4} \mathrm{~m}^{2}$

$\varepsilon=$ emissivity used for all objects within the furnace from Holladay ${ }^{2}=.3$

$\bar{T}=$ average temperature

$\mathrm{A}=$ area of combustion gas, wall, or glass.

$\mathrm{SF}=$ shape factor relating to radiation heat transfer

The equations for calculating the average temperature used in the resistance equations are shown below.

$$
\begin{aligned}
& T_{a g}=.5\left(T_{a}+T_{g}\right) \\
& T_{a w}=.5\left(T_{a}+T_{w}\right)
\end{aligned}
$$

$T_{a}=$ temperature of the combustion gases

$T_{g}=$ temperature of the glass

$T_{w}=$ temperature of the refractory wall

The radiative energy is partially transmitted through the glass is partially absorbed by the glass. The energy is absorbed and re-radiated from the floor refractory and from the glass itself, and is internally reflected from the air/glass interface. Thus the energy impinging on the surface of the melt is not all absorbed at the surface, once the batch materials have melted and become translucent/transparent. This phenomenon is considered in the model by including an Opacity Factor (OF). The opacity factor can be 
adjusted for each furnace and type of glass. The opacity factor was determined by trial and error to make the temperature gradients in the melt agree with estimates of those found in the prototype furnace at Fenton Art Glass. Conversations with the plant engineer placed the typical temperature difference between surface and floor of the melt to be about $25 \mathrm{C}$, and the opacity factors were adjusted to make the model mimic this data.

Another factor is introduced into the heating of glass volumes. Opacity is the amount of radiation absorbed by a semi clear solid, liquid, or gas. The opacity factor (OF) is an approximation and can be adjusted for each furnace and type of glass. The value of this factor for my model is approximated from industry data.

The 3D model below shows the heat transfer related to the combustion gas in alpha 1.

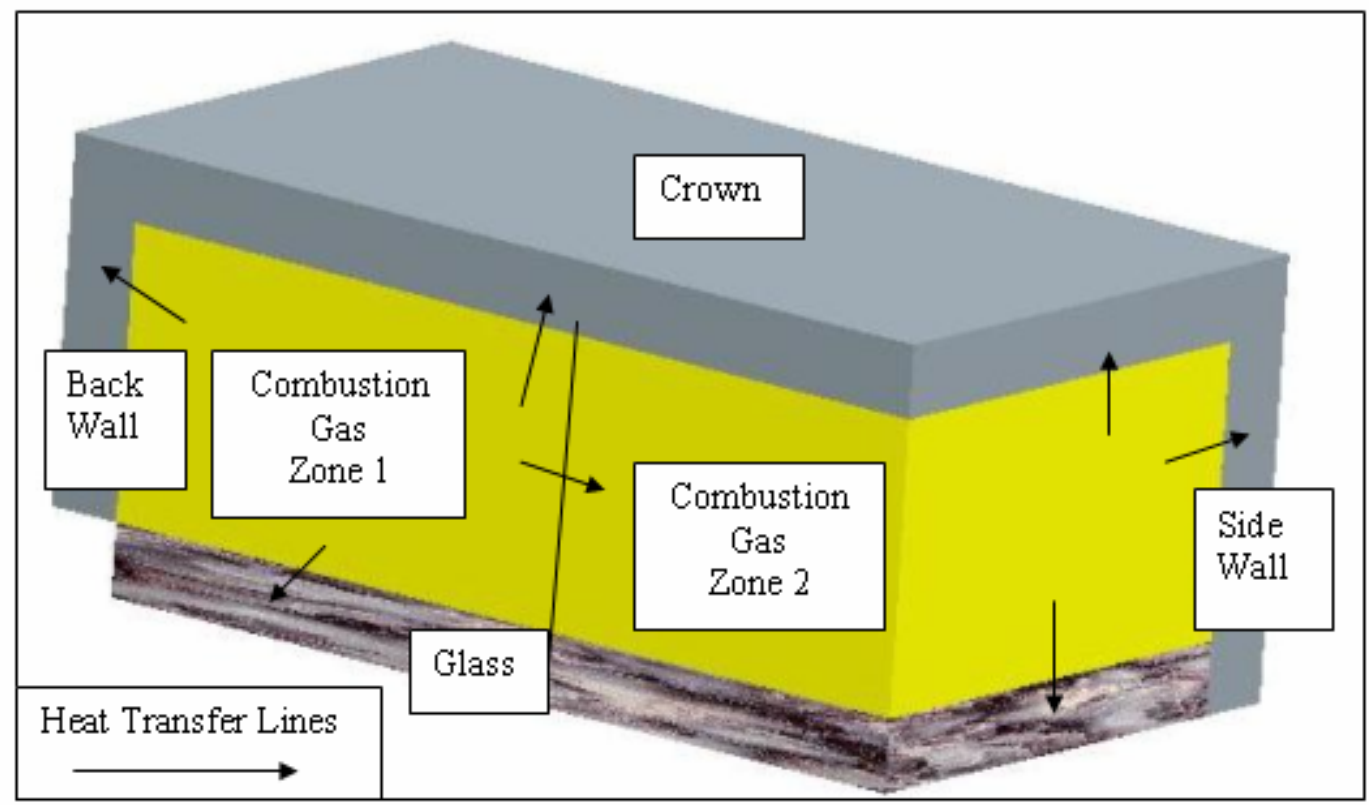

Figure 3.2-A: Heat Transfer within Combustion Gas in Zone 1 
The energy balance for the volume of combustion gas in Zone 1 is shown below:

$$
\dot{Q} a_{\alpha 1}=C a_{\alpha 1} \frac{d T a_{\alpha 1}}{d t}
$$

$$
\begin{aligned}
C a_{\alpha 1} \frac{d T a_{\alpha 1}}{d t}= & \dot{Q} b w_{\alpha 1}+\dot{Q} c_{\alpha 1}+\dot{Q} s w_{\alpha 1}+\dot{Q} a_{\alpha 2}+\dot{Q} g_{\beta 1} \\
& +\dot{Q} g_{\beta 2}+\dot{Q} g_{\chi 1}+\dot{Q} g_{\chi 2}+\dot{Q} g_{\delta 1}+\dot{Q} g_{\delta 2}+\dot{Q}_{i n}
\end{aligned}
$$

$$
\begin{aligned}
C a_{\alpha 1} \frac{d T a_{\alpha 1}}{d t}= & \frac{A b w_{\alpha 1}}{R b w_{\alpha 1}}\left(T a_{\alpha 1}-T b w_{\alpha 1}\right)+\frac{A c_{\alpha 1}}{R c_{\alpha 1}}\left(T a_{\alpha 1}-T c_{\alpha 1}\right) \\
& +\frac{A s w_{\alpha 1}}{R s w_{\alpha 1}}\left(T a_{\alpha 1}-T s w_{\alpha 1}\right)+\frac{A a_{\alpha 2}}{R a_{\alpha a}}\left(T a_{\alpha 1}-T a_{\alpha 2}\right) \\
& +\frac{O F_{\beta} A g_{\beta 1}}{R g_{\beta 1}}\left(T a_{\alpha 1}-T g_{\beta 1}\right)+\frac{(S F) O F_{\beta} A g_{\beta 2}}{R g_{\beta 2}}\left(T a_{\alpha 1}-T g_{\beta 2}\right) \\
& +\frac{O F_{\chi} A g_{\chi 1}}{R g_{\chi 1}}\left(T a_{\alpha 1}-T g_{\chi 1}\right)+\frac{(S F) O F_{\chi} A g_{\chi 2}}{R g_{\chi 2}}\left(T a_{\alpha 1}-T g_{\chi 2}\right) \\
& +\frac{O F_{\delta} A g_{\delta 1}}{R g_{\delta 1}}\left(T a_{\alpha 1}-T g_{\delta 1}\right)+\frac{(S F) O F_{\delta} A g_{\delta 2}}{R g_{\delta 2}}\left(T a_{\alpha 1}-T g_{\delta 2}\right)+\dot{Q}_{i n}
\end{aligned}
$$

After expansion and rearrangement the heat transfer equation for the combustion gases in alpha 1 is: 


$$
\begin{aligned}
\frac{d T a_{\alpha 1}}{d t}= & -\frac{1}{C a_{\alpha 1}}\left[\frac{A s w_{\alpha 1}}{R s w_{\alpha 1}}+\frac{A b w_{\alpha 1}}{R b w_{\alpha 1}}+\frac{A c_{\alpha 1}}{R c_{\alpha 1}}+\frac{A a_{\alpha 2}}{R a_{\alpha 2}}+\frac{O F_{\beta} A g_{\beta 1}}{R g_{\beta 1}}+\frac{(S F) O F_{\beta} A g_{\beta 2}}{R g_{\beta 2}}\right. \\
& \left.+\frac{O F_{\chi} A g_{\chi 1}}{R g_{\chi 1}}+\frac{(S F) O F_{\chi} A g_{\chi 2}}{R g_{\chi 2}}+\frac{O F_{\delta} A g_{\delta 1}}{R g_{\delta 1}}+\frac{(S F) O F_{\delta} A g_{\delta 2}}{R g_{\delta 2}}\right] T a_{\alpha 1} \\
& +\frac{A b w_{\alpha 1}}{\left(C a_{\alpha 1}\right) R b w_{\alpha 1}} T b w_{\alpha 1}+\frac{A c_{\alpha 1}}{\left(C a_{\alpha 1}\right) R c_{\alpha 1}} T c_{\alpha 1}+\frac{A s w_{\alpha 1}}{\left(C a_{\alpha 1}\right) R s w_{\alpha 1}} T s w_{\alpha 1} \\
& +\frac{A a_{\alpha 2}}{\left(C a_{\alpha 1}\right) R a_{\alpha a}} T a_{\alpha 2}+\frac{O F_{\beta} A g_{\beta 1}}{\left(C a_{\alpha 1}\right) R g_{\beta 1}} T g_{\beta 1}+\frac{(S F) O F_{\beta} A g_{\beta 2}}{\left(C a_{\alpha 1}\right) R g_{\beta 2}} T g_{\beta 2} \\
& +\frac{O F_{\chi} A g_{\chi 1}}{\left(C a_{\alpha 1}\right) R g_{\chi 1}} T g_{\chi 1}+\frac{(S F) O F_{\chi} A g_{\chi 2}}{\left(C a_{\alpha 1}\right) R g_{\chi 2}} T g_{\chi 2}+\frac{O F_{\delta} A g_{\delta 1}}{\left(C a_{\alpha 1}\right) R g_{\delta 1}} T g_{\delta 1} \\
& +\frac{(S F) O F_{\delta} A g_{\delta 2}}{\left(C a_{\alpha 1}\right) R g_{\delta 2}} T g_{\delta 2}+\frac{\dot{Q}_{i n}}{C a_{\alpha 1}}
\end{aligned}
$$

In this equation the new variables are:

$O F=$ the absorption factor based on opacity

$C a_{\alpha 1}=$ the capacitance of the combustion gases in alpha 1

$\underline{d T a_{\alpha 1}}$

$d t$ = time rate of change of the temperature of the combustion gases in alpha 1

NOTE: Each variable has two subscripts, one for noting the location of the variable and a second to represent the type of variable.

Subscripts used:

Table 3.2-A: Location Subscripts

Table 3.2-B: Volume Subscripts

\begin{tabular}{|c|}
\hline Location Subscripts \\
\hline$\alpha 1$ \\
\hline$\alpha 2$ \\
\hline$\beta 1$ \\
\hline$\beta 2$ \\
\hline$\chi 1$ \\
\hline$\chi 2$ \\
\hline$\delta 1$ \\
\hline$\delta 2$ \\
\hline
\end{tabular}

\begin{tabular}{|c|c|}
\hline Volume Subscript & Type of Variable \\
\hline a & combustion gas \\
\hline c & furnace crown \\
\hline bw & furnace back wall \\
\hline fw & furnace front wall \\
\hline sw & furnace side wall \\
\hline g & glass \\
\hline fl & furnace floor \\
\hline o & outside \\
\hline
\end{tabular}


This energy balance is continued for each volume created by the division noted earlier. The remaining equations for the volumes in alpha 1 are shown below:

$$
\begin{aligned}
& \frac{d T b w_{\alpha 1}}{d t}=\frac{A b w_{\alpha 1}}{\left(C b w_{\alpha 1}\right) R b w_{\alpha 1}} T a_{\alpha 1}-\frac{1}{C b w_{\alpha 1}}\left[\frac{A b w_{\alpha 1}}{R b w_{\alpha 1}}+\frac{A b w_{\alpha 1-\chi 1}}{R b w_{\alpha 1-\chi 1}}+\frac{A b w_{\alpha 1-o}}{R b w_{\alpha 1-o}}\right. \\
& +\frac{(S F) O F_{\beta} A g_{\beta 1}}{R g_{\beta 1}}+\frac{(S F) O F_{\beta} A g_{\beta 2}}{R g_{\beta 2}}+\frac{(S F) O F_{\chi} A g_{\chi 1}}{R g_{\chi 1}} \\
& \left.+\frac{(S F) O F_{\chi} A g_{\chi^{2}}}{R g_{\chi 2}}+\frac{(S F) O F_{\delta} A g_{\delta 1}}{R g_{\delta 1}}+\frac{(S F) O F_{\delta} A g_{\delta 2}}{R g_{\delta 2}}\right] T b w_{\alpha 1} \\
& +\frac{(S F) O F_{\beta} A g_{\beta 1}}{\left(C b w_{\alpha 1}\right) R g_{\beta 1}} T g_{\beta 1}+\frac{(S F) O F_{\beta} A g_{\beta 2}}{\left(C b w_{\alpha 1}\right) R g_{\beta 2}} T g_{\beta 2}+\frac{(S F) O F_{\chi} A g_{\chi 1}}{\left(C b w_{\alpha 1}\right) R g_{\chi 1}} T g_{\chi 1} \\
& +\frac{A b w_{\alpha 1-\chi 1}}{\left(C b w_{\alpha 1}\right) R b w_{\alpha 1-\chi 1}} T b w_{\chi 1}+\frac{(S F) O F_{\chi} A g_{\chi^{2}}}{\left(C b w_{\alpha 1}\right) R g_{\chi^{2}}} T g_{\chi^{2}}+\frac{(S F) O F_{\delta} A g_{\delta 1}}{\left(C b w_{\alpha 1}\right) R g_{\delta 1}} T g_{\delta 1} \\
& +\frac{(S F) O F_{\delta} A g_{\delta 2}}{\left(C b w_{\alpha 1}\right) R g_{\delta 2}} T g_{\delta 2}+\frac{A b w_{\alpha 1-o}}{\left(C b w_{\alpha 1}\right) R b w_{\alpha 1-o}} T o \\
& \frac{d T c_{\alpha 1}}{d t}=\frac{A c_{\alpha 1}}{\left(C c_{\alpha 1}\right) R c_{\alpha 1}} T a_{\alpha 1}-\frac{1}{C c_{\alpha 1}}\left[\frac{A c_{\alpha 1}}{R c_{\alpha 1}}+\frac{A c_{\alpha 1-\alpha 2}}{R c_{\alpha 1-\alpha 2}}+\frac{A c_{\alpha 1-o}}{R c_{\alpha 1-o}}+\frac{(S F) O F_{\beta} A g_{\beta 1}}{R g_{\beta 1}}\right. \\
& +\frac{(S F) O F_{\beta} A g_{\beta 2}}{R g_{\beta 2}}+\frac{(S F) O F_{\chi} A g_{\chi 1}}{R g_{\chi 1}}+\frac{(S F) O F_{\chi} A g_{\chi 2}}{R g_{\chi 2}}+\frac{(S F) O F_{\delta} A g_{\delta 1}}{R g_{\delta 1}} \\
& \left.+\frac{(S F) O F_{\delta} A g_{\delta 2}}{R g_{\delta 2}} T c_{\alpha 1}+\frac{A c_{\alpha 1-\alpha 2}}{\left(C c_{\alpha 1}\right) R c_{\alpha 1-\alpha 2}}\right] T c_{\alpha 2}+\frac{(S F) O F_{\beta} A g_{\beta 1}}{\left(C c_{\alpha 1}\right) R g_{\beta 1}} T g_{\beta 1} \\
& +\frac{(S F) O F_{\beta} A g_{\beta 2}}{\left(C c_{\alpha 1}\right) R g_{\beta 2}} T g_{\beta 2}+\frac{(S F) O F_{\chi} A g_{\chi 1}}{\left(C c_{\alpha 1}\right) R g_{\chi 1}} T g_{\chi 1}+\frac{(S F) O F_{\chi} A g_{\chi 2}}{\left(C c_{\alpha 1}\right) R g_{\chi 2}} T g_{\chi^{2}} \\
& +\frac{(S F) O F_{\delta} A g_{\delta 1}}{\left(C c_{\alpha 1}\right) R g_{\delta 1}} T g_{\delta 1}+\frac{(S F) O F_{\delta} A g_{\delta 2}}{\left(C c_{\alpha 1}\right) R g_{\delta 2}} T g_{\delta 2}+\frac{A c_{\alpha 1-o}}{\left(C c_{\alpha 1}\right) R c_{\alpha 1-o}} T o
\end{aligned}
$$




$\begin{aligned} \frac{d T s w_{\alpha 1}}{d t}= & \frac{A s w_{\alpha 1}}{\left(C s w_{\alpha 1}\right) R s w_{\alpha 1}} T a_{\alpha 1}-\frac{1}{C s w_{\alpha 1}}\left[\frac{A s w_{\alpha 1}}{R s w_{\alpha 1}}+\frac{A s w_{\alpha 1-2}}{R s w_{\alpha 1-2}}+\frac{A s w_{\alpha 1-\chi 1}}{R s w_{\alpha 1-\chi 1}}\right. \\ & +\frac{A s w_{\alpha 1-o}}{R s w_{\alpha 1-o}}+\frac{(S F) O F_{\beta} A g_{\beta 1}}{R g_{\beta 1}}+\frac{(S F) O F_{\beta} S F A g_{\beta 2}}{R g_{\beta 2}}+\frac{(S F) O F_{\chi} A g_{\chi 1}}{R g_{\chi 1}} \\ & \left.+\frac{(S F) O F_{\chi} S F A g_{\chi 2}}{R g_{\chi 2}}+\frac{(S F) O F_{\delta} A g_{\delta 1}}{R g_{\delta 1}}+\frac{(S F) O F_{\delta} S F A g_{\delta 2}}{R g_{\delta 2}}\right] T s w_{\alpha 1}\end{aligned}$

The entire set of 24 equations used to describe the furnace can be found in Appendix 1 .

\subsection{State Space Representation}

State space representation consists of a system of equations. These equations are comprised of state vectors and allow for multivariable control. The formal equations are shown below:

$$
\begin{aligned}
& \dot{\mathbf{x}}=\underline{A} \mathbf{x}+\underline{B} \mathbf{u} \\
& \mathbf{y}=\underline{C} \mathbf{x}+\underline{D} \mathbf{u}
\end{aligned}
$$

In this representation $\underline{\mathrm{A}}$ is the state matrix. $\underline{\mathrm{B}}$ represents the input matrix. $\underline{\mathrm{C}}$ is the output matrix and $\underline{D}$ is the feed through matrix. The states in our model are each of the individual temperatures of the volumes. The input matrix consists of the heat input into 
the furnace and the ambient air temperature outside of the furnace. The output of the system is the glass temperatures desired for prediction and control. The D matrix is zero since there is no direct connection between glass temperature and inputs.

The list of state variables used in this state space model is shown below.

Table 3.3-A: Table of State Variables

\begin{tabular}{|c|c|}
\hline $\begin{array}{c}\text { Numbered } \\
\text { Order }\end{array}$ & $\begin{array}{c}\text { State } \\
\text { Variable }\end{array}$ \\
\hline 1 & $\mathrm{Ta}_{\alpha 1}$ \\
\hline 2 & $\mathrm{Tbw}_{\alpha 1}$ \\
\hline 3 & $\mathrm{Tc}_{\alpha 1}$ \\
\hline 4 & $\mathrm{Tsw}_{\alpha 1}$ \\
\hline 5 & $\mathrm{Ta}_{\alpha 2}$ \\
\hline 6 & $\mathrm{Tc}_{\alpha 2}$ \\
\hline 7 & $\mathrm{Tsw}_{\alpha 2}$ \\
\hline 8 & $\mathrm{Tfw}_{\alpha 2}$ \\
\hline 9 & $\mathrm{Tg}_{\beta 1}$ \\
\hline 10 & $\mathrm{Tg}_{\beta 2}$ \\
\hline 11 & $\mathrm{Tg}_{\chi 1}$ \\
\hline 12 & $\mathrm{Tbw}_{1}$ \\
\hline
\end{tabular}

\begin{tabular}{|c|c|}
\hline $\begin{array}{c}\text { Numbered } \\
\text { Order }\end{array}$ & $\begin{array}{c}\text { State } \\
\text { Variable }\end{array}$ \\
\hline 13 & $\mathrm{Tsw}_{\chi_{1}}$ \\
\hline 14 & $\mathrm{Tg}_{\chi_{2}}$ \\
\hline 15 & $\mathrm{Tsw}_{2}$ \\
\hline 16 & $\mathrm{Tfw}_{2}$ \\
\hline 17 & $\mathrm{Tg}_{\delta 1}$ \\
\hline 18 & $\mathrm{Tbw}_{\delta 1}$ \\
\hline 19 & $\mathrm{Tsw}_{\delta 1}$ \\
\hline 20 & $\mathrm{Tfl}_{\delta 1}$ \\
\hline 21 & $\mathrm{Tg}_{\delta 2}$ \\
\hline 22 & $\mathrm{Tsw}_{\delta 2}$ \\
\hline 23 & $\mathrm{Tfw}_{\delta 2}$ \\
\hline 24 & $\mathrm{Tfl}_{\delta 2}$ \\
\hline
\end{tabular}

All of the state variables are temperatures and correspond to all of the volumes within the glass furnace identified in the previous section.

The inputs and outputs for this system are shown in the table below. 


\section{Table 3.3-B: Inputs and Outputs}

\begin{tabular}{|c|c|}
\hline Inputs & Outputs \\
\hline $\mathrm{T}_{\mathrm{amb}}$ & $\mathrm{Tg}_{\mathrm{b} 1}$ \\
\hline $\mathrm{Q}_{\mathrm{in}}$ & $\mathrm{Tg}_{\mathrm{x} 1}$ \\
\hline & $\mathrm{Tg}_{\mathrm{d} 1}$ \\
\hline & $\mathrm{Tfl}_{\mathrm{d} 1}$ \\
\hline
\end{tabular}

In order to simulate this system, numerical coefficients must be calculated for the differential equations from furnace dimensions and material properties. Furnace dimensions can be found on the 3 view drawing of the furnace. The areas for heat transfer and shape factors have been calculated and are shown in the table below:

Table 3.3-C: Table of Areas and Shape Factors

\begin{tabular}{|c|c|c|c|c|}
\hline $\begin{array}{c}\text { Volume } \\
\mathbf{1}\end{array}$ & $\begin{array}{c}\text { Volume } \\
\mathbf{2}\end{array}$ & $\begin{array}{c}\text { Area of Contact } \\
\left(\mathbf{m}^{\mathbf{2}}\right)\end{array}$ & $\begin{array}{c}\text { Shape } \\
\text { Factor }\end{array}$ & $\mathbf{S F}^{*} \mathbf{A}$ \\
\hline $\mathrm{a}_{\alpha 1}$ & $\mathrm{bw}_{\alpha 1}$ & 0.563 & 1.000 & 0.563 \\
\hline $\mathrm{a}_{\alpha 1}$ & $\mathrm{c}_{\alpha 1}$ & 1.125 & 1.000 & 1.125 \\
\hline $\mathrm{a}_{\alpha 1}$ & $\mathrm{sw}_{\alpha 1}$ & 0.756 & 1.000 & 0.756 \\
\hline $\mathrm{a}_{\alpha 1}$ & $\mathrm{a}_{\alpha 2}$ & 0.563 & 1.000 & 0.563 \\
\hline $\mathrm{a}_{\alpha 1}$ & $\mathrm{~g}_{\beta 1}$ & 1.125 & 1.000 & 1.125 \\
\hline $\mathrm{a}_{\alpha 1}$ & $\mathrm{~g}_{\beta 2}$ & 0.563 & 0.043 & 0.024 \\
\hline $\mathrm{bw}_{\alpha 1}$ & $\mathrm{bw}_{1}$ & 0.279 & 1.000 & 0.279 \\
\hline $\mathrm{bw}_{\alpha 1}$ & $\mathrm{o}$ & 0.563 & 1.000 & 0.563 \\
\hline $\mathrm{bw}_{\alpha 1}$ & $\mathrm{~g}_{\beta 1}$ & 0.563 & 0.269 & 0.151 \\
\hline $\mathrm{bw}_{\alpha 1}$ & $\mathrm{~g}_{\beta 2}$ & 0.563 & 0.012 & 0.007 \\
\hline $\mathrm{c}_{\alpha 1}$ & $\mathrm{c}_{\alpha 2}$ & 0.279 & 1.000 & 0.279 \\
\hline $\mathrm{c}_{\alpha 1}$ & $\mathrm{o}$ & 1.125 & 1.000 & 1.125 \\
\hline $\mathrm{c}_{\alpha 1}$ & $\mathrm{~g}_{\beta 1}$ & 1.125 & 0.363 & 0.408 \\
\hline $\mathrm{c}_{\alpha 1}$ & $\mathrm{~g}_{\beta 2}$ & 1.125 & 0.066 & 0.074 \\
\hline $\mathrm{sw}_{\alpha 1}$ & $\mathrm{sw}_{\alpha 2}$ & 0.188 & 1.000 & 0.188 \\
\hline $\mathrm{sw}_{\alpha 1}$ & $\mathrm{sw}_{1}$ & 0.375 & 1.000 & 0.375 \\
\hline $\mathrm{sw}_{\alpha 1}$ & $\mathrm{o}$ & 0.756 & 1.000 & 0.756 \\
\hline $\mathrm{sw}_{\alpha 1}$ & $\mathrm{~g}_{\beta 1}$ & 0.756 & 0.274 & 0.207 \\
\hline $\mathrm{sw}_{\alpha 1}$ & $\mathrm{~g}_{\beta 2}$ & 0.756 & 0.098 & 0.074 \\
\hline $\mathrm{a}_{\alpha 2}$ & $\mathrm{sw}_{\alpha 2}$ & 0.369 & 1.000 & 0.369 \\
\hline & & & & \\
\hline
\end{tabular}




\begin{tabular}{|c|c|c|c|c|}
\hline$a_{\alpha 2}$ & $\mathrm{fw}_{\alpha 2}$ & 0.563 & 1.000 & 0.563 \\
\hline$a_{\alpha 2}$ & $\mathrm{c}_{\alpha 2}$ & 0.549 & 1.000 & 0.549 \\
\hline$a_{\alpha 2}$ & $\mathrm{~g}_{\beta 1}$ & 0.563 & 0.116 & 0.065 \\
\hline $\mathrm{a}_{\alpha 2}$ & $\mathrm{~g}_{\beta 2}$ & 0.549 & 1.000 & 0.549 \\
\hline $\mathrm{c}_{\alpha 2}$ & 0 & 0.549 & 1.000 & 0.549 \\
\hline $\mathrm{c}_{\alpha 2}$ & $\mathrm{~g}_{\beta 1}$ & 0.549 & 0.135 & 0.074 \\
\hline $\mathrm{c}_{\alpha 2}$ & $\mathrm{~g}_{\beta 2}$ & 0.549 & 0.247 & 0.136 \\
\hline $\mathrm{sW}_{\alpha 2}$ & $\operatorname{sw} \chi_{2}$ & 0.183 & 1.000 & 0.183 \\
\hline $\mathrm{sW}_{\alpha 2}$ & o & 0.369 & 1.000 & 0.369 \\
\hline $\mathrm{sW}_{\alpha 2}$ & $\mathrm{~g}_{\beta 1}$ & 0.369 & 0.061 & 0.022 \\
\hline $\mathrm{sW}_{\alpha 2}$ & $\mathrm{~g}_{\beta 2}$ & 0.369 & 0.220 & 0.081 \\
\hline $\mathrm{fw}_{\alpha 2}$ & $f w \chi_{2}$ & 0.279 & 1.000 & 0.279 \\
\hline $\mathrm{fw}_{\alpha 2}$ & $\mathrm{O}$ & 0.563 & 1.000 & 0.563 \\
\hline $\mathrm{fw}_{\alpha 2}$ & $\mathrm{~g}_{\beta 1}$ & 0.369 & 0.058 & 0.021 \\
\hline $\mathrm{fw}_{\alpha 2}$ & $\mathrm{~g}_{\beta 2}$ & 0.369 & 0.223 & 0.082 \\
\hline $\mathrm{g}_{\beta 1}$ & $\mathrm{~g}_{\chi 1}$ & 1.125 & 1.000 & 1.125 \\
\hline $\mathrm{g}_{\beta 2}$ & $\mathrm{~g}_{\chi 2}$ & 0.549 & 1.000 & 0.549 \\
\hline $\mathrm{g}_{\chi 1}$ & $\operatorname{sw} \chi_{1}$ & 0.185 & 1.000 & 0.185 \\
\hline $\mathrm{g}_{\chi 1}$ & $\mathrm{bw} \chi_{1}$ & 0.137 & 1.000 & 0.137 \\
\hline $\mathrm{g}_{\chi 1}$ & $g_{\chi 2}$ & 0.137 & 1.000 & 0.137 \\
\hline $\mathrm{g}_{\chi 1}$ & $\mathrm{~g}_{\delta 1}$ & 1.125 & 1.000 & 1.125 \\
\hline $\mathrm{bw} \chi_{1}$ & $\mathrm{bw}_{\delta 1}$ & 0.279 & 1.000 & 0.279 \\
\hline $\mathrm{bw} \chi_{1}$ & 0 & 0.137 & 1.000 & 0.137 \\
\hline$s w \chi_{1}$ & sw $\chi_{2}$ & 0.046 & 1.000 & 0.046 \\
\hline sw $\chi_{1}$ & $\mathrm{SW}_{\delta 1}$ & 0.375 & 1.000 & 0.375 \\
\hline $\mathrm{sw} \chi_{1}$ & $\mathrm{O}$ & 0.185 & 1.000 & 0.185 \\
\hline$g_{x^{2}}$ & $\operatorname{sw} \chi_{2}$ & 0.090 & 1.000 & 0.090 \\
\hline$g_{x^{2}}$ & $f w \chi_{2}$ & 0.137 & 1.000 & 0.137 \\
\hline $\mathrm{g}_{\chi_{2}}$ & $\mathrm{~g}_{\delta 2}$ & 0.549 & 1.000 & 0.549 \\
\hline $\mathrm{sw} \chi_{2}$ & $\mathrm{SW}_{\delta 2}$ & 0.183 & 1.000 & 0.183 \\
\hline $\operatorname{sw} \chi_{2}$ & o & 0.090 & 1.000 & 0.090 \\
\hline fw $\chi_{2}$ & $\mathrm{fw}_{\delta 2}$ & 0.279 & 1.000 & 0.279 \\
\hline$f w \chi_{2}$ & 0 & 0.137 & 1.000 & 0.137 \\
\hline $\mathrm{g}_{\delta 1}$ & $\mathrm{SW}_{\delta 1}$ & 0.185 & 1.000 & 0.185 \\
\hline $\mathrm{g}_{\delta 1}$ & $\mathrm{bw}_{\delta 1}$ & 0.137 & 1.000 & 0.137 \\
\hline $\mathrm{g}_{\delta 1}$ & $\mathrm{~g}_{\delta 2}$ & 0.137 & 1.000 & 0.137 \\
\hline $\mathrm{g}_{\delta 1}$ & $\mathrm{fl}_{\delta 1}$ & 1.125 & 1.000 & 1.125 \\
\hline $\mathrm{bw}_{\delta 1}$ & $\mathrm{O}$ & 0.137 & 1.000 & 0.137 \\
\hline $\mathrm{SW}_{\delta 1}$ & $\mathrm{SW}_{\delta 2}$ & 0.046 & 1.000 & 0.046 \\
\hline $\mathrm{SW}_{\delta 1}$ & $\mathrm{O}$ & 0.185 & 1.000 & 0.185 \\
\hline $\mathrm{fl}_{\delta 1}$ & $\mathrm{fl}_{\delta 2}$ & 0.137 & 1.000 & 0.137 \\
\hline $\mathrm{fl}_{\delta 1}$ & $\mathrm{O}$ & 1.125 & 1.000 & 1.125 \\
\hline $\mathrm{g}_{\delta 2}$ & $\mathrm{SW}_{\delta 2}$ & 0.090 & 1.000 & 0.090 \\
\hline
\end{tabular}




\begin{tabular}{|c|c|c|c|c|}
$\mathrm{g}_{\delta 2}$ & $\mathrm{fw}_{\delta 2}$ & 0.137 & 1.000 & 0.137 \\
\hline $\mathrm{g}_{\delta 2}$ & $\mathrm{fl}_{\delta 2}$ & 0.549 & 1.000 & 0.549 \\
\hline $\mathrm{sw}_{\delta 2}$ & $\mathrm{O}$ & 0.090 & 1.000 & 0.090 \\
\hline $\mathrm{fW}_{\delta 2}$ & $\mathrm{o}$ & 0.137 & 1.000 & 0.137 \\
\hline $\mathrm{fl}_{\delta 2}$ & $\mathrm{O}$ & 0.549 & 1.000 & 0.549 \\
\hline
\end{tabular}

Shape factor calculations were done using Mills's ${ }^{19} \mathrm{rad} 1$ program.

The capacitances for each material can be found from the equation:

$$
C=m c_{p}
$$

In this equation $\mathrm{m}$ is the mass of the volume and $\mathrm{c}_{\mathrm{p}}$ is the specific heat of the volume. The mass of each volume must be found by calculating the volume and multiplying by the density of the material. The density of refractory can be estimated as $3810 \mathrm{~kg} / \mathrm{m}^{3}$ assuming the use of an inner refractory like Monofrax ${ }^{\circledR}$ CS-3 Alumina-Zirconia-Silica (AZS) Fused Cast Refractory ${ }^{20}$. The specific heat value of the refractory was estimated by Holladay ${ }^{2}$ and was found to be $1.18 \mathrm{~kJ} / \mathrm{kg} \cdot \mathrm{K}$. The density of glass can be found as $2430 \mathrm{~kg} / \mathrm{m}^{3}{ }^{21}$ and the specific heat was averaged by Holladay ${ }^{2}$ to be $1.24 \mathrm{~kJ} / \mathrm{kg} \cdot \mathrm{K}$ over the range of $1000 \mathrm{~K}-1800 \mathrm{~K}$. A table of masses, specific heats, and capacitances are shown below for all volumes.

\section{Table 3.3-D: Table of Masses, Specific Heats, and Capacitances}

\begin{tabular}{|c|c|c|c|c|c|}
\hline $\begin{array}{l}\text { Volume } \\
\text { Name }\end{array}$ & $\begin{array}{c}\text { Volume } \\
\left(\mathbf{m}^{3}\right)\end{array}$ & $\begin{array}{l}\text { Density } \\
\left(\mathrm{kg} / \mathrm{m}^{3}\right)\end{array}$ & $\begin{array}{c}\text { Mass } \\
(\mathrm{kg})\end{array}$ & $\begin{array}{c}\begin{array}{c}\text { Specific Heat } \\
\left(\mathbf{k J} / \mathbf{k g} \mathbf{g}^{*} \mathbf{K}\right)\end{array} \\
\end{array}$ & $\begin{array}{c}\text { Capacitance } \\
(\mathbf{k J} / \mathbf{k g})\end{array}$ \\
\hline $\mathrm{bw}_{\alpha 1}$ & 0.172 & 3810 & 654 & 1.18 & 772 \\
\hline $\mathrm{c}_{\alpha 1}$ & 0.343 & 3810 & 1308 & 1.18 & 1543 \\
\hline
\end{tabular}




\begin{tabular}{|c|c|c|c|c|c|}
$\mathrm{sw}_{\alpha 1}$ & 0.231 & 3810 & 879 & 1.18 & 1037 \\
\hline $\mathrm{c}_{\alpha 2}$ & 0.167 & 3810 & 638 & 1.18 & 753 \\
\hline $\mathrm{sw}_{\alpha 2}$ & 0.113 & 3810 & 429 & 1.18 & 506 \\
\hline $\mathrm{fw}_{\alpha 2}$ & 0.172 & 3810 & 654 & 1.18 & 772 \\
\hline $\mathrm{g}_{\beta 1}$ & 0.014 & 2430 & 34 & 1.24 & 42 \\
\hline $\mathrm{g}_{\beta 2}$ & 0.007 & 2430 & 17 & 1.24 & 21 \\
\hline $\mathrm{g}_{\chi 1}$ & 0.169 & 2430 & 410 & 1.24 & 508.7 \\
\hline $\mathrm{bw}_{1}$ & 0.418 & 381 & 159 & 1.18 & 188 \\
\hline $\mathrm{sw}_{1}$ & 0.056 & 3810 & 214 & 1.18 & 253 \\
\hline $\mathrm{g}_{\chi 2}$ & 0.082 & 2430 & 200 & 1.24 & 248 \\
\hline $\mathrm{Sw}_{2}$ & 0.027 & 3810 & 104 & 1.18 & 123 \\
\hline $\mathrm{fw}_{2}$ & 0.042 & 3810 & 159 & 1.18 & 188 \\
\hline $\mathrm{g}_{\delta 1}$ & 0.169 & 2430 & 410 & 1.24 & 508 \\
\hline $\mathrm{bw}_{\delta 1}$ & 0.042 & 3810 & 159 & 1.18 & 188 \\
\hline $\mathrm{sw}_{\delta 1}$ & 0.056 & 3810 & 214 & 1.18 & 253 \\
\hline $\mathrm{f}_{\delta 1}$ & 0.343 & 3810 & 1308 & 1.18 & 1543 \\
\hline $\mathrm{g}_{\delta 2}$ & 0.082 & 2430 & 200 & 1.24 & 248 \\
\hline $\mathrm{sw}_{\delta 2}$ & 0.027 & 3810 & 104 & 1.18 & 123 \\
\hline $\mathrm{fw}_{\delta 2}$ & 0.042 & 3810 & 159 & 1.18 & 188 \\
\hline $\mathrm{f}_{\delta 2}$ & 0.167 & 3810 & 638 & 1.18 & 753 \\
\hline
\end{tabular}

The combustion gas mass is found differently. The ideal gas law can be used to calculate the mass of the combustion gas as shown below.

$$
m_{a}=\frac{P_{a} V_{a}}{\underline{R_{a} \overline{T_{a}}}}
$$

In this case $R_{a}$ is the gas constant for the combustion gases present. $P_{a}$ is the internal pressure of the furnace (assumed atmospheric). $V_{a}$ is the volume of the combustion gases. $\bar{T}_{a}$ is the mean combustion gas temperature. The specific heat of the combustion gas can be estimated as $1.025 \mathrm{~kJ} / \mathrm{kg} \cdot \mathrm{K}^{22}$. The table below shows the mass and capacitance of the two combustion gas volumes. 
Table 3.3-E: Mass, Specific Heat, and Capacitance of Gas Volumes

\begin{tabular}{|c|c|c|c|c|c|c|c|}
\hline $\begin{array}{c}\text { Volume } \\
\text { Name }\end{array}$ & $\begin{array}{c}\text { Pressure } \\
\left(\mathbf{N} / \mathbf{m}^{\mathbf{2}} \mathbf{)}\right.\end{array}$ & $\begin{array}{c}\text { Volume } \\
\left.\mathbf{( m}^{\mathbf{3}}\right)\end{array}$ & $\begin{array}{c}\text { Gas } \\
\text { Constant }\end{array}$ & $\begin{array}{c}\text { Temperature } \\
(\mathbf{K})\end{array}$ & $\begin{array}{c}\text { Mass } \\
(\mathbf{k g})\end{array}$ & $\begin{array}{c}\text { Specific } \\
\mathbf{\text { Heat }} / \mathbf{k g} \text { *K) }\end{array}$ & $\begin{array}{c}\text { Capacitance } \\
(\mathbf{k J} / \mathbf{k g})\end{array}$ \\
\hline $\mathrm{a}_{\alpha 1}$ & 101325 & 0.687 & 274.57 & 1300 & 0.195 & 1.025 & 0.2 \\
\hline $\mathrm{a}_{\alpha 2}$ & 101325 & 0.344 & 274.57 & 1300 & 0.098 & 1.025 & 0.1 \\
\hline
\end{tabular}

Calculations for the resistances between materials where the mode of heat transfer is radiation were taken from Holladay's ${ }^{2}$ work using an initial mean temperature of 1300K. A table of these values is shown below:

Table 3.3-F: Table of Heat Transfer Resistances between Different Materials

\begin{tabular}{|c|c|}
\hline Resistance & $\begin{array}{c}\text { Value } \\
\left(\mathbf{m}^{2} \mathbf{K} / \mathbf{k W}\right)\end{array}$ \\
\hline Raw & 6.7 \\
\hline Rag & 6.7 \\
\hline Rgw & 2 \\
\hline Rwo & 139 \\
\hline
\end{tabular}

Within each material, conduction is the primary source of heat transfer. The thermal conductivity value of glass is estimated as $1.2 \mathrm{~W} / \mathrm{m} \cdot \mathrm{K}{ }^{23}$ at a mean temperature of $1300 \mathrm{~K}$. The thermal conductivity value of the Monofrax ${ }^{20}$ refractory is $2.1 \mathrm{~W} / \mathrm{m} \cdot \mathrm{K}$. The thermal conductivity value of the combustion gas is estimated as near the value of air and is taken from $\mathrm{ASHRAE}^{24}$ as $.0926 \mathrm{~W} / \mathrm{m} \cdot \mathrm{K}$. The overall resistance can be found using the equation below. 


$$
R=\frac{A}{K / \Delta x}
$$

$\mathrm{A}=$ area of heat transfer

$\mathrm{K}=$ thermal conductivity

$\Delta \mathrm{x}=$ the distance of heat transfer by conduction

A table of resistances based on $\mathrm{K}$ values and distance between volume centers was calculated.

Table 3.3-G: Heat Transfer Resistances between Volumes of the Same Material

\begin{tabular}{|c|c|c|c|c|}
\hline $\begin{array}{c}\text { Volume } \\
\mathbf{1}\end{array}$ & $\begin{array}{c}\text { Volume } \\
\mathbf{2}\end{array}$ & $\begin{array}{c}\mathbf{K} \\
(\mathbf{k W} / \mathbf{m K})\end{array}$ & $\begin{array}{c}\text { Distance } \\
(\mathbf{m})\end{array}$ & $\begin{array}{c}\text { Resistance } \\
\left(\mathbf{m}^{2} \mathbf{K} / \mathbf{k W}\right)\end{array}$ \\
\hline $\mathrm{a}_{\alpha 1}$ & $\mathrm{a}_{\alpha 2}$ & 0.093 & 0.915 & 9.881 \\
\hline $\mathrm{bw}_{\alpha 1}$ & $\mathrm{bw}_{\chi_{1}}$ & 2.100 & 0.383 & 0.182 \\
\hline $\mathrm{c}_{\alpha 1}$ & $\mathrm{c}_{\alpha 2}$ & 2.100 & 0.915 & 0.436 \\
\hline $\mathrm{sw}_{\alpha 1}$ & $\mathrm{sw}_{\alpha 2}$ & 2.100 & 0.915 & 0.436 \\
\hline $\mathrm{sw}_{\alpha 1}$ & $\mathrm{sw}_{1}$ & 2.100 & 0.383 & 0.182 \\
\hline $\mathrm{sw}_{\alpha 2}$ & $\mathrm{sw} \chi_{2}$ & 2.100 & 0.383 & 0.182 \\
\hline $\mathrm{fw}_{\alpha 2}$ & $\mathrm{fw}_{2}$ & 2.100 & 0.383 & 0.182 \\
\hline $\mathrm{g}_{\beta 1}$ & $\mathrm{~g}_{\chi 1}$ & 1.200 & 0.075 & 0.063 \\
\hline $\mathrm{g}_{\beta 2}$ & $\mathrm{~g}_{\chi 2}$ & 1.200 & 0.075 & 0.063 \\
\hline $\mathrm{g}_{\chi 1}$ & $\mathrm{~g}_{\chi 2}$ & 1.200 & 0.150 & 0.125 \\
\hline $\mathrm{g}_{\chi 1}$ & $\mathrm{~g}_{\delta 1}$ & 1.200 & 0.150 & 0.125 \\
\hline $\mathrm{bw}_{\chi_{1}}$ & $\mathrm{bw}_{\delta 1}$ & 2.100 & 0.150 & 0.071 \\
\hline $\mathrm{sw}_{\chi_{1}}$ & $\mathrm{sw}_{2}$ & 2.100 & 0.915 & 0.436 \\
\hline $\mathrm{sw}_{\chi_{1}}$ & $\mathrm{sw}_{\delta 1}$ & 2.100 & 0.150 & 0.071 \\
\hline $\mathrm{sw}_{2}$ & $\mathrm{sw}_{\delta 2}$ & 2.100 & 0.150 & 0.071 \\
\hline $\mathrm{fw}_{\chi_{2}}$ & $\mathrm{fw}_{\delta 2}$ & 2.100 & 0.150 & 0.071 \\
\hline $\mathrm{sw}_{\delta 1}$ & $\mathrm{sw}_{\delta 2}$ & 2.100 & 0.915 & 0.436 \\
\hline $\mathrm{f}_{\delta 1}$ & $\mathrm{f}_{\delta 2}$ & 2.100 & 0.915 & 0.436 \\
\hline
\end{tabular}

The final factors needed are the opacity factors. Industry suggests a variation of approximately 25 degrees Celsius within the melt. Since glass is mostly clear at high 
temperatures with some bubble formation on top, the majority of radiation absorption occurs at the bottom and top surface. The opacity factor is a scaling factor to proportion the amount of energy absorbed by each of the three "layers" of the glass melt. So, of the radiant energy incident on the surface, it is assumed that the thin top layer absorbs $18 \%$, the middle layer absorbs $15 \%$, and the bottom layer absorbs $67 \%$. The values for each of these factors were from multiple model simulations with attempts to reach a 25 degree variation.

\section{Table 3.3-H: Opacity Factors}

\begin{tabular}{|c|c|}
\hline Opacity Factor & Value \\
\hline OFb & 0.18 \\
\hline OFx & 0.15 \\
\hline OFd & 0.67 \\
\hline
\end{tabular}

Using all of these values, the final A, B, C, and D matrices can be created. These matrices can be found in Appendix 2.

\subsection{Simulink Model}

Using Matlab and Simulink, a model can be created for simulation. The four state matrices are used in Simulink to construct a working model. In the figure below is the state space model representation within Simulink. 


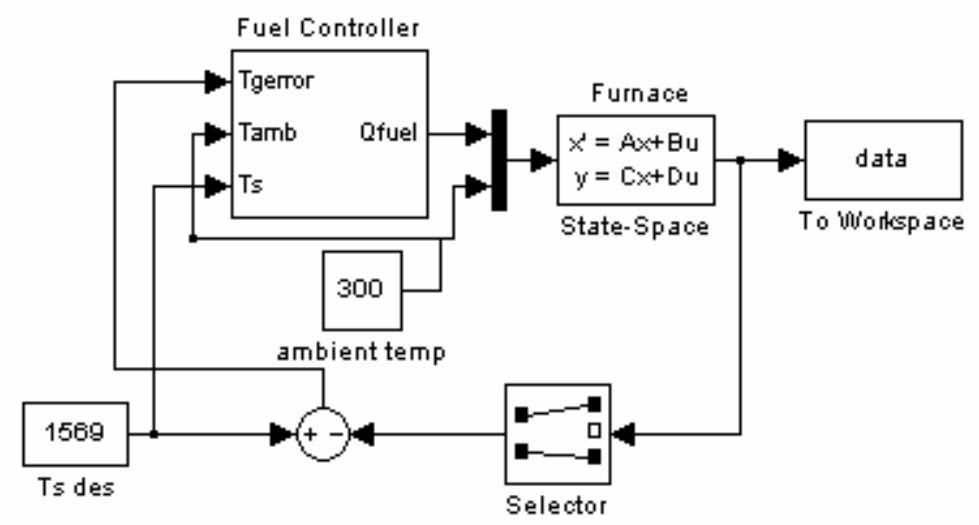

Figure 3.4-A: Simulink Model

Within the model there are two constants, the ambient air temperature and the glass set point temperature. The ambient air temperature is the air temperature outside of the furnace. The glass set point temperature is the desired steady state temperature of the glass. For melting conditions, this temperature is approximately $1500 \mathrm{~K}$.

The first large block is a fuel flow controller. This specific controller is a subroutine based on Holladay's ${ }^{2}$ work. She designed this controller for a much simpler state space model. The gains within the controller have been modified for optimal performance for my model.

The second block is labeled the state space model block. Within this block Simulink accepts the model's inputs and then outputs the model's outputs. The output needed for furnace control is routed back to the fuel controller and the remaining outputs are collected in a data file for observation and plotting. 
The first subroutine is shown in the figure below.

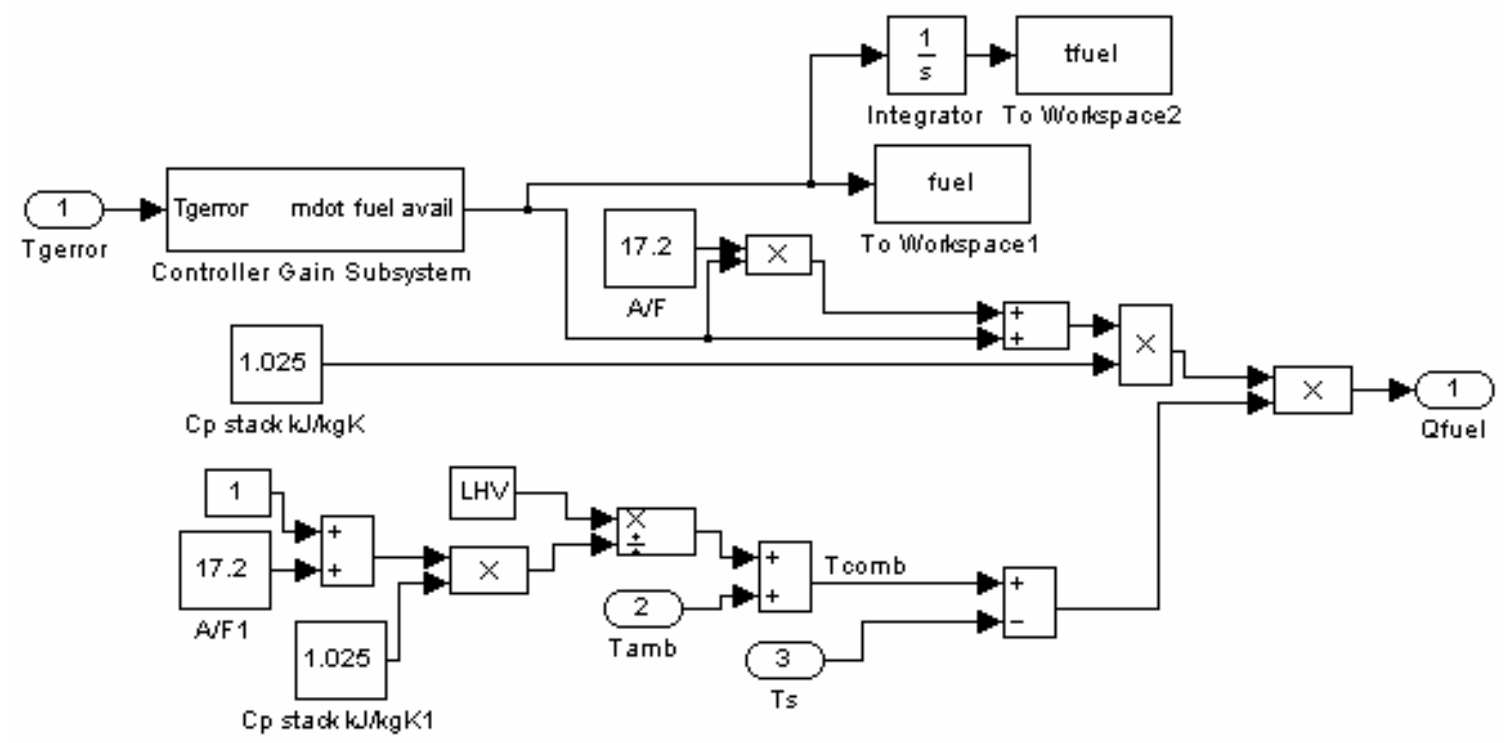

Figure 3.4-B: Net Heat Input Subsystem

The largest block in this routine is the true fuel controller subroutine. The rest of this routine calculates the net heat input using the fuel flow from the controller routine, the LHV of the fuel, and the ambient air temperature. The model could be simplified using a constant; however the model was left expanded so that the variables like LHV and $\mathrm{A} / \mathrm{F}$ ratio could be easily changed.

The controller gain subroutine is shown below.

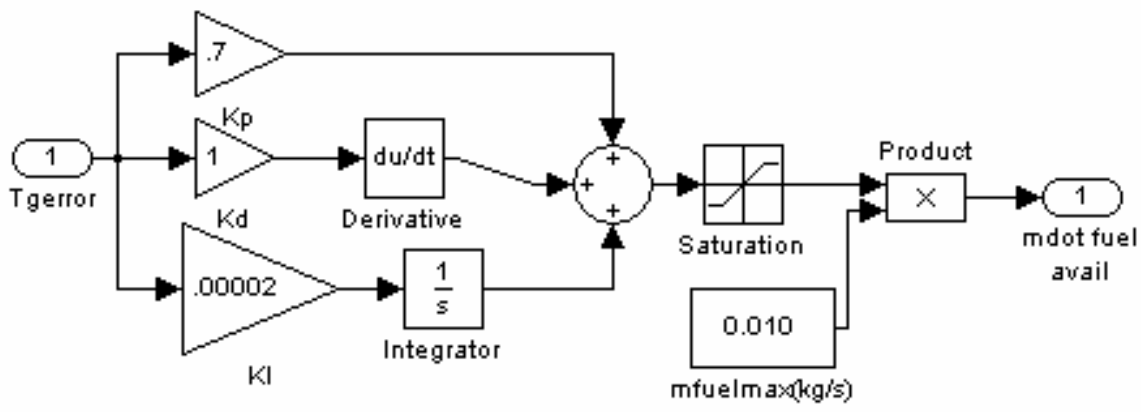

Figure 3.4-C: Controller Gain Subroutine 
A PID controller was chosen for simplicity. The three gains (Kp, Kd, Ki) were adjusted for a quick melt time with minimal combustion gas temperature and minimal glass temperature overshoot. These gains are .7, 1, and .00002 respectively. With these gains the controller has adequate properties including a small overshoot and quick settling time when controlling the state space model. 


\section{Validation}

In order to consider the results from a model as valid, a set of tests was run comparing the theoretical model to an actual furnace. Two validation tests were conducted. The first test compares the inside wall temperatures of an operating furnace to those predicted by the model. The second test compares the predicted and actual fuel rates at steady state operation.

\subsection{Inside Wall Temperature Validation}

Fenton Art Glass Company ${ }^{6}$ provided the information needed to model one of their glass tank furnaces. A set of data was collected from the furnace while the furnace had been idling nearly empty of glass. Though the furnace did not have glass in it, the temperatures of the walls and crown above the glass would be unaffected because each of these volumes is considered independently uniform in temperature. Below is the set of data collected from the real furnace and the model.

Table 4.1-A: Fenton Glass Furnace Data

\begin{tabular}{|c|c|}
\hline \multicolumn{2}{|c|}{ Fenton Glass Furnace Data } \\
\hline \multicolumn{2}{|c|}{} \\
\hline Temperature Set Point (K) & 1338 \\
\hline Side Wall Temperature (K) & 1355 \\
\hline Back Wall Temperature (K) & 1316 \\
\hline Crown Temperature (K) & 1350 \\
\hline
\end{tabular}




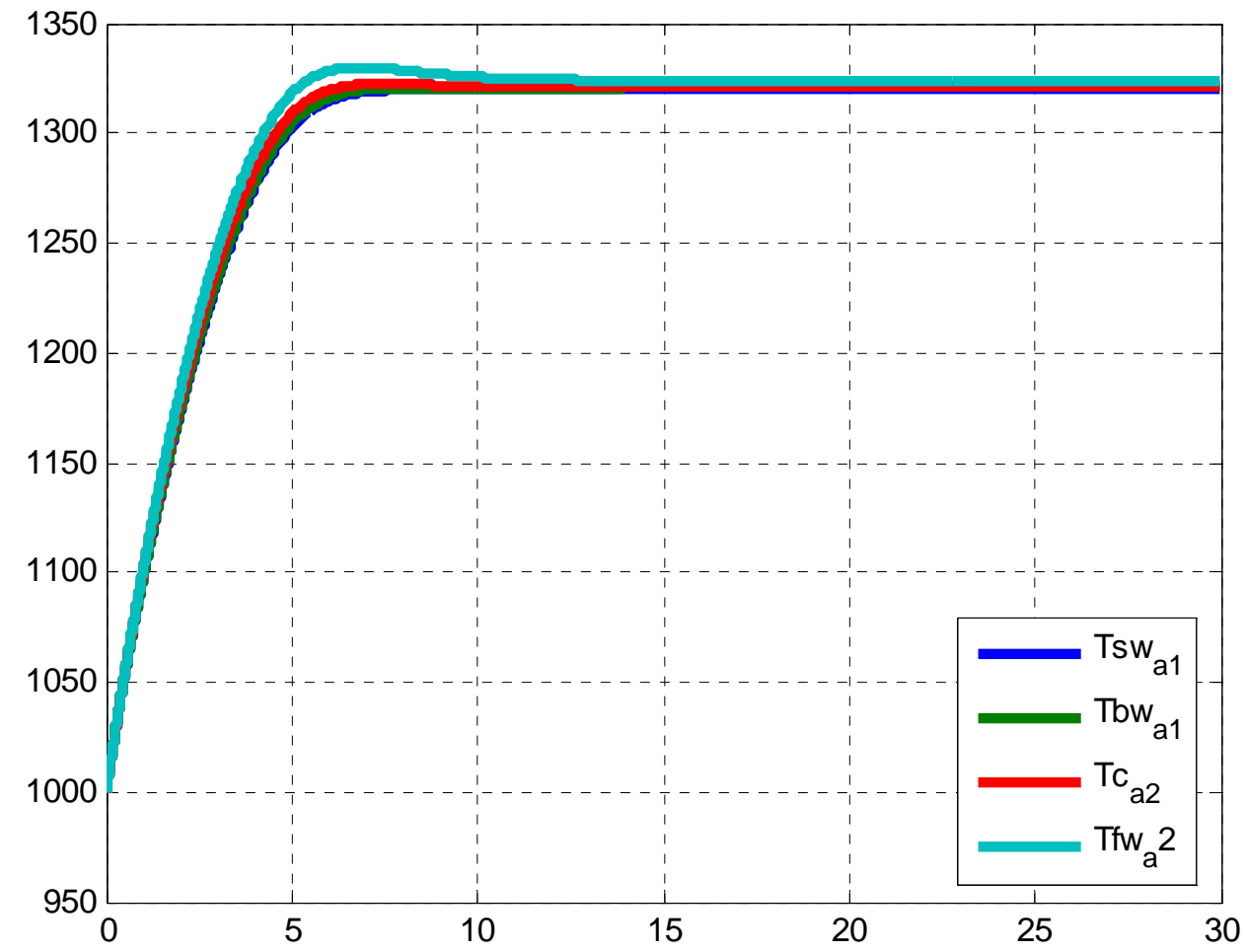

Figure 4.1-A: Internal Wall Temperatures During Idle at 1338K

Table 4.1-B: Steady State Model Furnace Data and Error Percentage

\begin{tabular}{|c|c|}
\hline Model Furnace Data & \\
\hline Temperature Set Point $(\mathrm{K})$ & 1338 \\
\hline Side Wall Temperature $(\mathrm{K})$ & 1337 \\
\hline Back Wall Temperature (K) & 1339 \\
\hline Crown Temperature $(\mathrm{K})$ & 1337 \\
\hline Front Wall Temperature $(\mathrm{K})$ & 1341 \\
\hline
\end{tabular}

\% Error

\begin{tabular}{|c|}
\hline 1.33 \\
\hline-1.75 \\
\hline 0.96 \\
\hline NA \\
\hline
\end{tabular}


Comparing the data, the error is less than $2 \%$. The set points of both furnaces are

different due to the controller in use for each. Fenton controls their furnace by monitoring a combustion gas temperature and allowing the furnace to fire for a set amount of time on high fire. This time period has been determined from traditional melting procedures. At the end of this time period, the glass is considered nearly equal to this temperature and fully melted. The model proposed in this work directly predicts the glass temperature and uses that value as a set point for the controller. Temperature error between the data is reasonably low and validates the model's accuracy in determining the internal wall temperatures at a given temperature set point for the glass using the new controller.

\subsection{Fuel Mass Flow Validation}

The second model validation compares the predicted and actual fuel usage at the same steady state temperature. The same furnace was recorded at a steady fuel flow of $400 \mathrm{ft}^{3} / \mathrm{hr}$. For comparison purposes this volumetric flow rate must be converted to a mass flow rate. This conversion has been done assuming methane as an ideal gas. The assumption is valid under low pressure situations. The equation is shown below.

$$
\dot{m}=\frac{\dot{V} P}{\underline{R} \bar{T}}
$$

Where: 
$\dot{V}=$ volumetric flow rate $\left(\mathrm{ft}^{3} / \mathrm{hr}\right)$

$\mathrm{P}=$ pressure (14.2 psia)

$\underline{\mathrm{R}}=$ the gas constant of methane $(96.32 \mathrm{ft} \bullet \mathrm{lbf} / \mathrm{lbm} \cdot \mathrm{R})$

$\bar{T}=$ temperature in Rankin $(80 \mathrm{~F}$ or $540 \mathrm{R})$

$\dot{m}=\frac{400 \mathrm{ft} / \mathrm{hr} * 14.2 \mathrm{lbf} / \mathrm{in}^{2} * 144 \mathrm{in}^{2} / \mathrm{ft}^{2}}{96.32 \mathrm{ft} \cdot \mathrm{lbf} / \mathrm{lbm} \cdot R}=15.73 \mathrm{lbm} / \mathrm{hr}=7.132 \mathrm{~kg} / \mathrm{hr}=1.98 \times 10^{-3} \mathrm{~kg} / \mathrm{sec}$

Mass flow from the model is presented in the plot below.

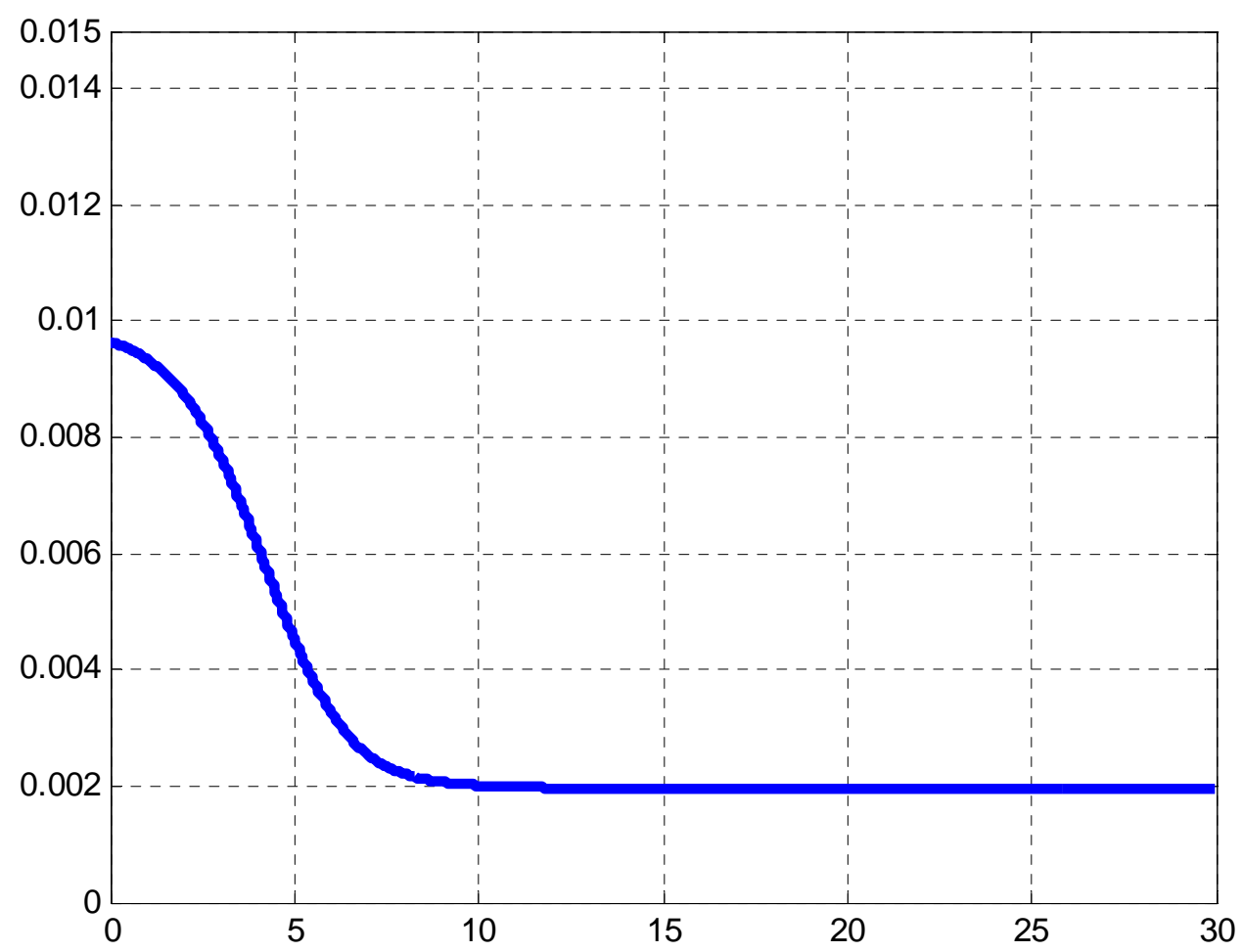

Figure 4.2-A: Fuel Usage during Simulation of the Model during Validation 


\section{Table 4.2-A: Steady State Model Fuel Data and Error Percentage}

Mass Flow of Fuel
\begin{tabular}{|c|c|c|}
\hline Furnace & Model & $\%$ Error \\
\hline 0.00198 & 0.00196 & 1.01 \\
\hline
\end{tabular}

The table above shows that the error is only $1.01 \%$. This error is very small and shows that the model representation of the fuel consumption due to heat loss is very accurate.

Having a realistic fuel flow at steady state also speaks well for the model's representation of losses to the environment. With fuel flow being the only addition of energy within a furnace, having an accurate prediction of the net energy needed as an input can only result from having an accurate prediction of the net energy out.

These results provide some confidence in the validity of the model. The comparison data suggests that temperatures and fuel flow are accurately represented in the furnace model. Having an accurate prediction of these two parameters allows for better glass temperature control which is the ultimate goal of this model. 


\section{Model Results}

\subsection{Temperature Variation within the Furnace Model}

Eliminating the assumption of homogeneous melt temperatures was one of the primary goals of this research. Research has shown that temperature variations exist in large glass furnaces and it seems reasonable to believe they exist in small glass furnaces. For model investigation the final stages of the melt cycle was chosen as a useful transition to view within a furnace. The glass temperatures were initialized at $1300 \mathrm{~K}$. The upper refractory was set at $1500 \mathrm{~K}$ and the lower refractory was initialized at $1400 \mathrm{~K}$. The ambient air temperature was assumed to be $300 \mathrm{~K}$.

After 15 hours of furnace operation was simulated, the data was collected in both dynamic and static states. The dynamic temperatures are shown below as plots and the final temperatures at steady states are given in tables.

The two most important figures display the vertical stratification of temperature within the glass melt. The temperatures of the glass volume directly below the flame are shown in Figure 5.1-A. 


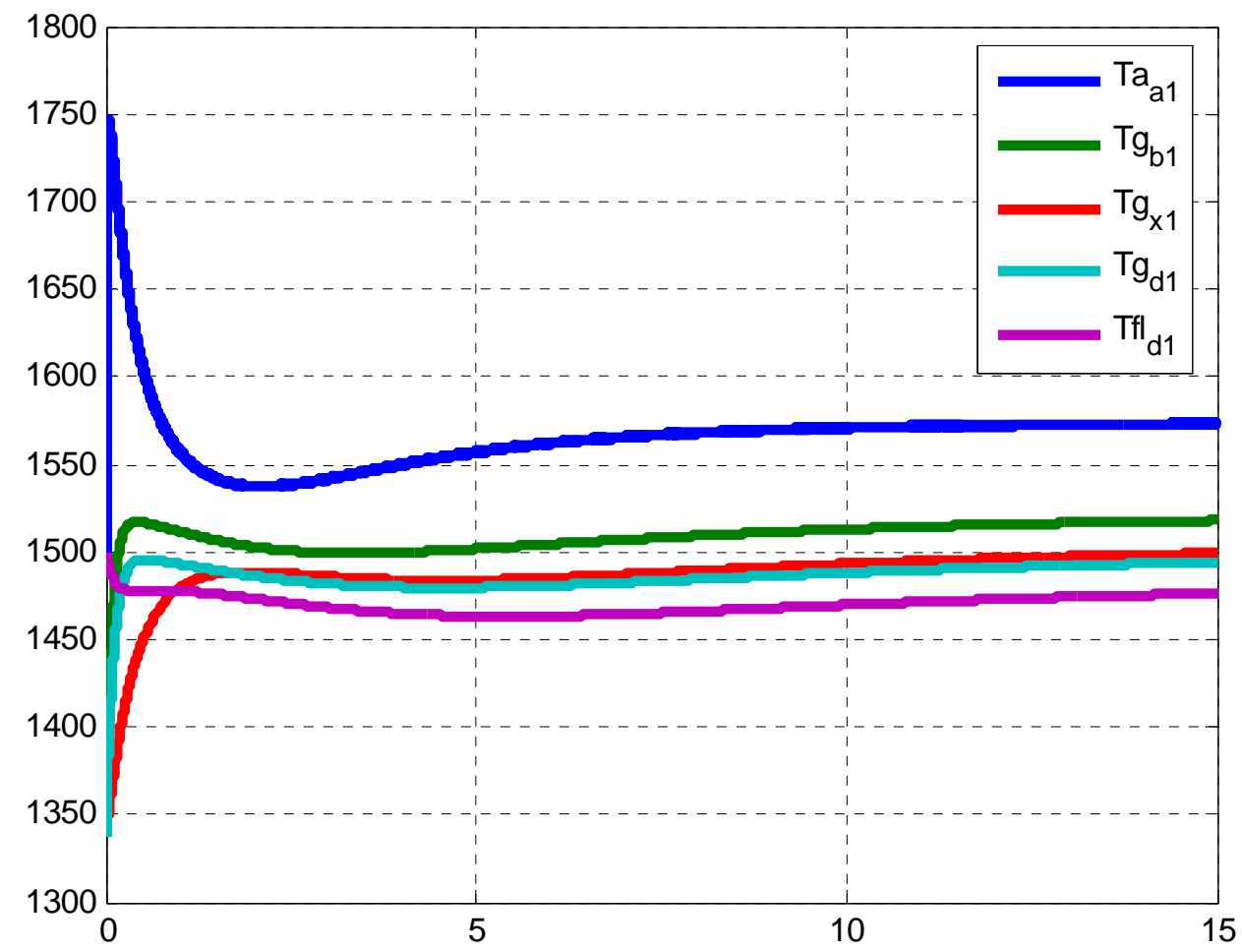

Figure 5.1-A: Glass Temperatures near the Flame during the Melt Cycle

Looking at the table below the final steady state temperatures are given.

Table 5.1-A: Glass Temperatures near the Flame at Steady State

\begin{tabular}{|c|c|}
\hline Location & $\begin{array}{c}\text { Temperature } \\
(\mathbf{K})\end{array}$ \\
\hline $\mathrm{Ta}_{\alpha 1}$ & 1573 \\
\hline $\mathrm{Tg}_{\beta 1}$ & 1518 \\
\hline $\mathrm{Tg}_{\chi 1}$ & 1499 \\
\hline $\mathrm{Tg}_{\delta 1}$ & 1494 \\
\hline $\mathrm{Tfl}_{\delta 1}$ & 1476 \\
\hline
\end{tabular}

The glass temperature variation was only 24 degrees at steady state. This variation was similar to industry experiences. 
The glass temperatures away from the flame (the " 2 " volumes) were also taken. The dynamic representation is shown below in Figure 5.1-B.

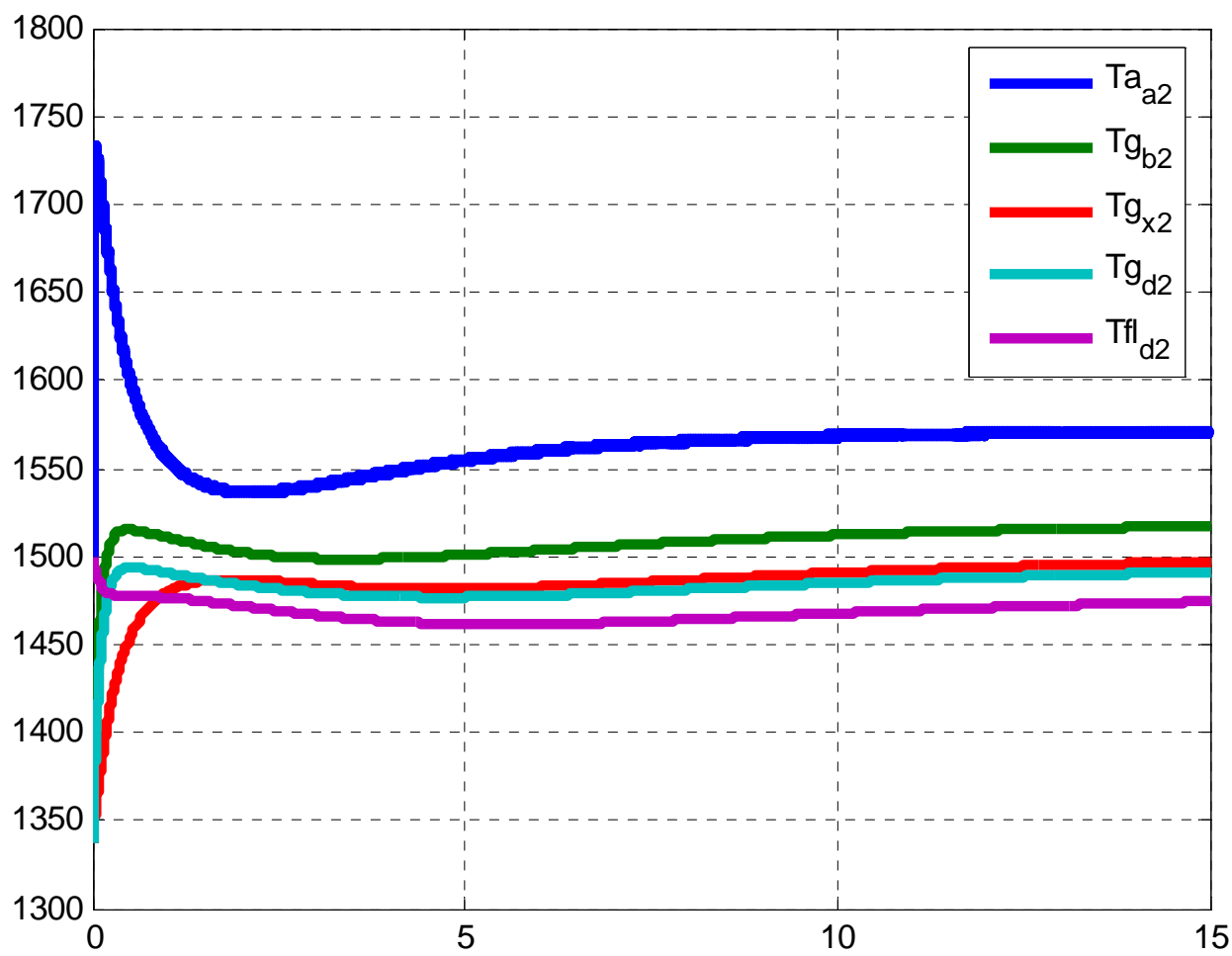

Figure 5.1-B: Glass Temperatures away from the Flame during the Melt Cycle

A similar glass temperature profile was present in the front of the furnace. The steady state temperatures are shown below.

Table 5.1-B: Glass Temperatures away from the Flame at Steady State

\begin{tabular}{|c|c|}
\hline Location & $\begin{array}{c}\text { Temperature } \\
(\mathbf{K})\end{array}$ \\
\hline $\mathrm{Ta}_{\alpha 2}$ & 1570 \\
\hline $\mathrm{Tg}_{\beta 2}$ & 1517 \\
\hline $\mathrm{Tg}_{\chi 2}$ & 1497 \\
\hline $\mathrm{Tg}_{\delta 2}$ & 1491 \\
\hline $\mathrm{Tfl}_{\delta 2}$ & 1475 \\
\hline
\end{tabular}


The final steady state temperatures had a similar variation as before.

All of the temperatures of the furnace walls have been plotted and their steady state temperatures recorded in Appendix C. These plots were under the same conditions as the two earlier plots and show the same temperature variation along the vertical axis of the furnace.

Examination of the other two furnace axes led to different conclusions. Along the width of the furnace there was no temperature gradient. The furnace was assumed symmetrical and no temperature variation could exist under this condition. The remaining axis was the length of the furnace. This examination can be described as comparing the temperatures in zones 1 and 2. In the figure below, the crown, combustion gas, side walls and floor temperatures are all plotted on one graph.

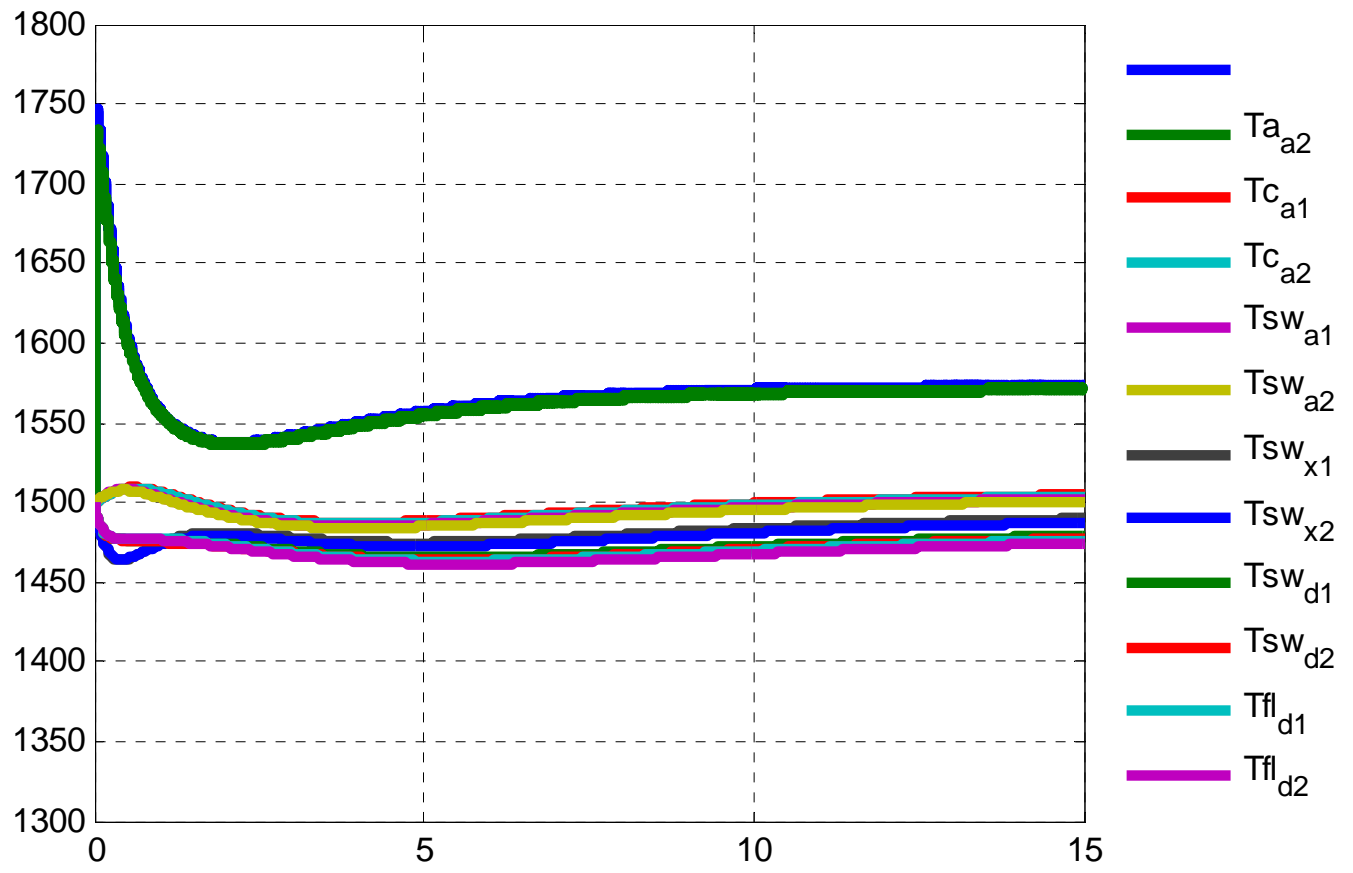

Table 5.1-C: Profile Temperatures during the Melt Cycle 
Each of the temperature lines for volumes that are located at the same height in the furnace appeared to overlap. In the table below, the final steady state temperatures are shown.

\section{Table 5.1-D: Profile Temperatures at Steady State}

\begin{tabular}{|r|c|c|c|}
\cline { 2 - 4 } \multicolumn{1}{c|}{} & \multicolumn{2}{c|}{$\begin{array}{c}\text { Temperatures } \\
\text { (K) }\end{array}$} & \multicolumn{1}{c}{} \\
\cline { 2 - 4 } \multicolumn{1}{c|}{} & $\mathbf{1}$ & $\mathbf{2}$ & \% Difference \\
\hline $\mathbf{T a}_{\boldsymbol{\alpha}}$ & 1573 & 1570 & 0.19 \\
\hline $\mathbf{T c}_{\boldsymbol{\alpha}}$ & 1505 & 1504 & 0.07 \\
\hline $\mathbf{T s w}_{\boldsymbol{\alpha}}$ & 1502 & 1501 & 0.07 \\
\hline $\mathbf{T s w}_{\boldsymbol{\chi}}$ & 1490 & 1487 & 0.20 \\
\hline $\mathbf{T s w}_{\boldsymbol{\delta}}$ & 1479 & 1477 & 0.14 \\
\hline $\mathbf{T f l}_{\boldsymbol{\delta}}$ & 1476 & 1475 & 0.07 \\
\hline
\end{tabular}

The data suggested that the assumption of negligible temperature difference along the length is reasonable. The temperatures of the walls at steady state seemed to be almost equal from end to end. The interesting temperatures, however, were the glass temperatures. The dynamic glass temperatures are shown in the figure below. 


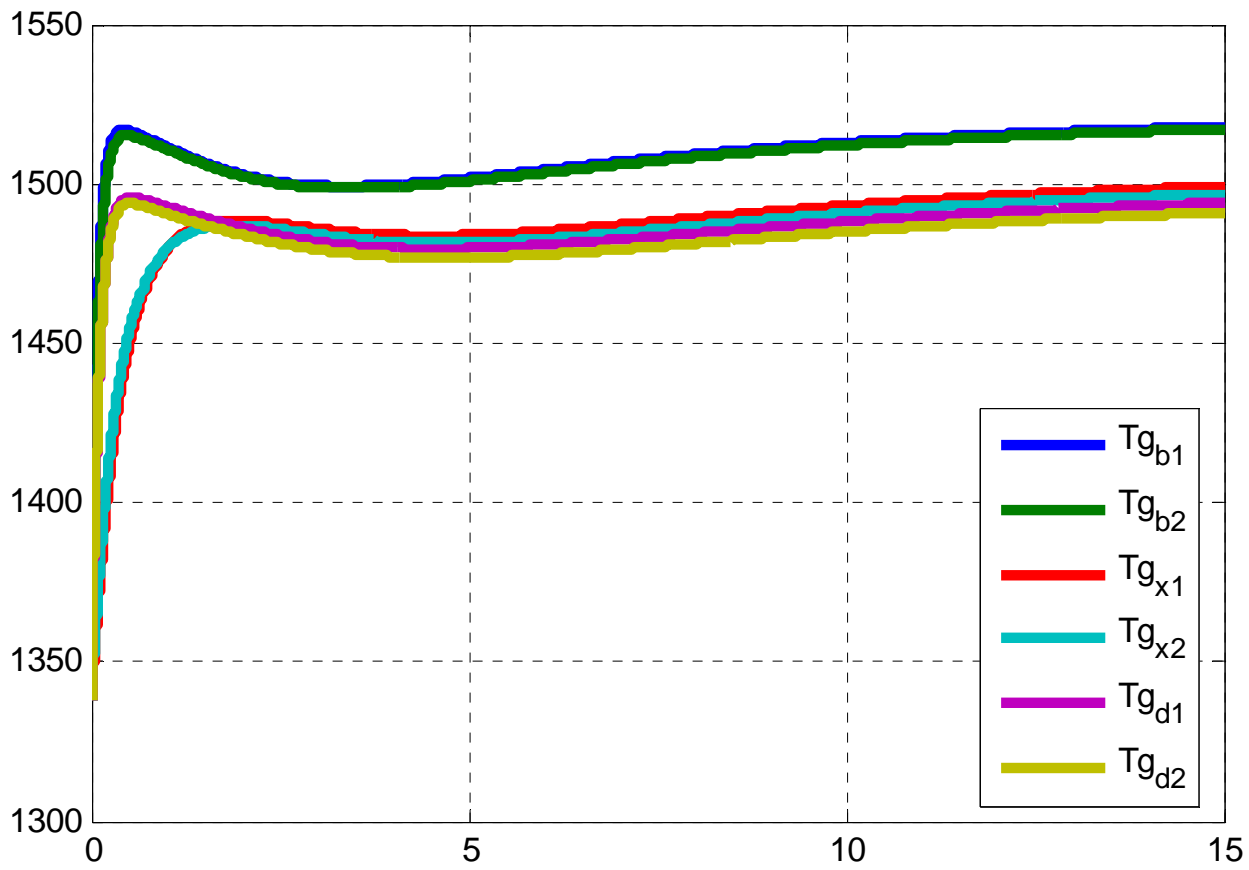

Figure 5.1-C: Profile Glass Temperatures during the Melt Cycle

The final glass temperatures at steady state are shown below.

\section{Table 5.1-E: Profile Glass Temperatures at Steady State}

\begin{tabular}{|c|c|c|c|}
\cline { 2 - 4 } \multicolumn{1}{c|}{} & \multicolumn{2}{c|}{ Temperatures (K) } & \multicolumn{1}{c|}{} \\
\cline { 2 - 4 } \multicolumn{1}{c|}{} & $\mathbf{1}$ & $\mathbf{2}$ & \% Difference \\
\hline $\mathrm{Tg}_{\beta}$ & 1518 & 1517 & 0.06 \\
\hline $\mathrm{Tg}_{\chi}$ & 1499 & 1497 & 0.13 \\
\hline $\mathrm{Tg}_{\delta}$ & 1494 & 1491 & 0.20 \\
\hline
\end{tabular}

Very little variation was present along the length of the furnace. The percent difference was small enough to consider the temperatures at a given height along the length of the furnace nearly equivalent. An assumption of equal temperatures along the length without symmetry is reasonable. The earlier assumption of equal temperatures 
along the width would have also been correct even if the model wasn't symmetrical along that axis. The lack of symmetry along the length proved nearly ineffective in generating longitudinal temperature variation, in the small furnaces studied here. This was very important since most furnaces are not symmetrical along either the length or width. This finding validates a model simplification that was initially considered unreasonable. The most significant temperature variance occurs along the height of the furnace.

\subsection{Control Schemes}

When modeling the end of the melt cycle for the presentation of temperature profiles, the controller used the temperature of $T g_{\chi^{2}}$ for feedback. This volume would be the volume of glass from which extraction would take place. It was desired to have the glass at the optimal temperature of $1500 \mathrm{~K}$. However, other volumes could have been used as feed back since the temperature variation between them and this volume was known from the earlier simulations. In industry, combustion gas temperature, crown temperature, predicted glass temperature, and refractory floor temperature have all been suggested as reasonable parameters on which to base control. It was decided that each of these control schemes should be examined.

A true full melt cycle was under examination for each control scheme. A furnace that just finished a batch and is empty and waiting for its next batch sits at a steady $1500 \mathrm{~K}$. A cold batch is added that has been in storage at ambient temperature (300K). Then the melt cycle begins. This cycle was represented by initializing the furnace 
structure and combustion gasses at $1500 \mathrm{~K}$ and, the glass melt at an initial temperature of $300 \mathrm{~K}$.

All of the volumes used for feedback were from side 2 since this was the side from which glass extraction occurs. A simulation has been run using the four volumes shown in Table 5.2-F as feedback and using their steady state temperature listed as the set point. In the table below, the steady state temperatures of each of the mentioned volumes are given from the earlier glass set point of $1500 \mathrm{~K}$.

\section{Table 5.2-A: Steady State Temperatures with} 1500K Set Point

\begin{tabular}{|c|c|}
\hline Volume & Temperature (K) \\
\hline $\mathrm{Tg}_{\chi_{2}}$ & 1500 \\
\hline $\mathrm{Ta}_{\alpha 2}$ & 1569 \\
\hline $\mathrm{Tc}_{\alpha 2}$ & 1503 \\
\hline $\mathrm{Tfl}_{\delta 2}$ & 1476 \\
\hline
\end{tabular}

The first simulation tested was the original controller which used the predicted glass temperature as feedback. The temperature in $T g_{\chi 2}$ was used for the controller. The controlled temperature was plotted over time. Fuel usage was plotted over time and a table listed the total fuel usage and the final temperature of $\operatorname{Tg}_{\chi^{2}}$ after 15 hours. These figures and table are shown below. 


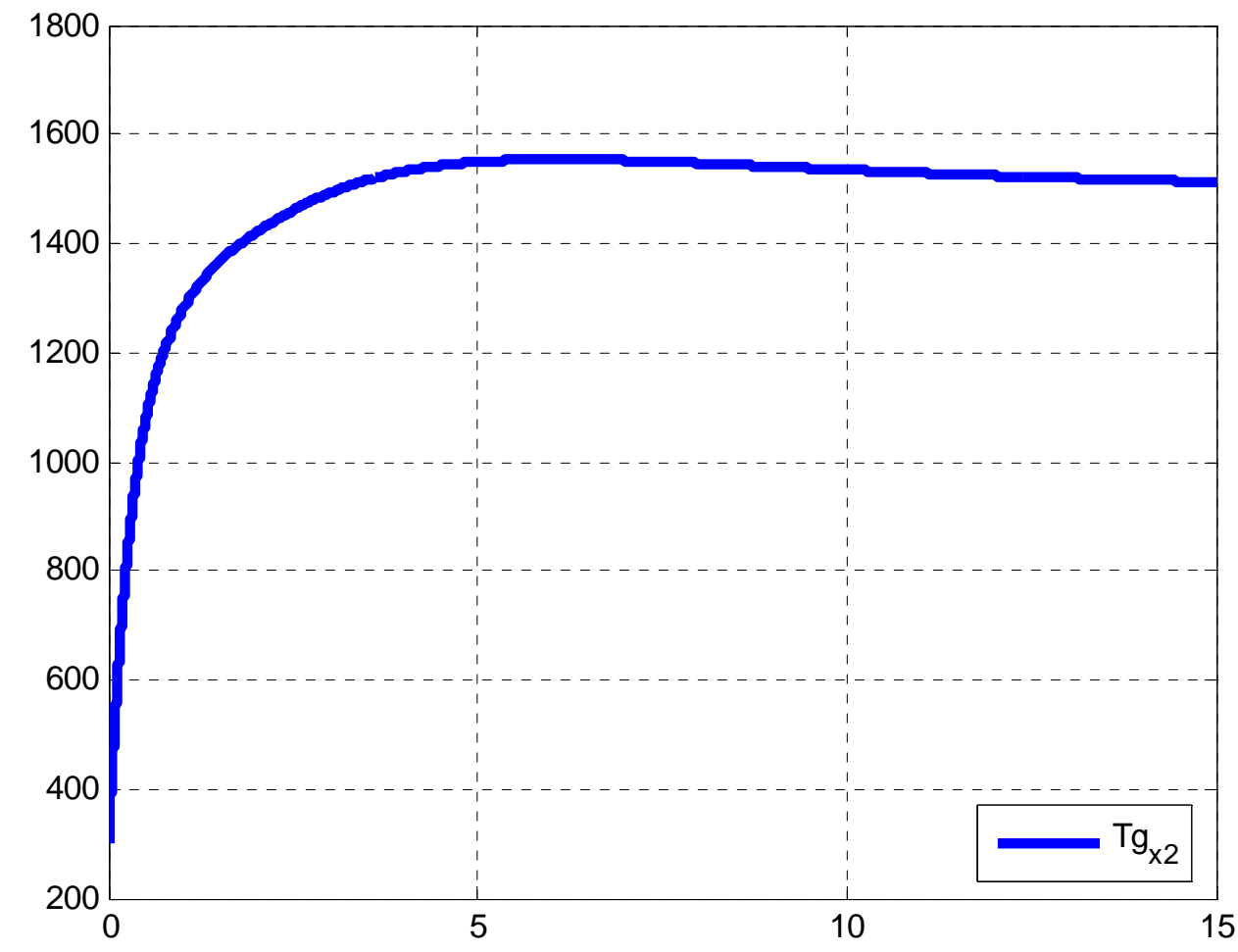

Figure 5.2-A: Feedback Glass Temperature during the Full Melt Cycle 


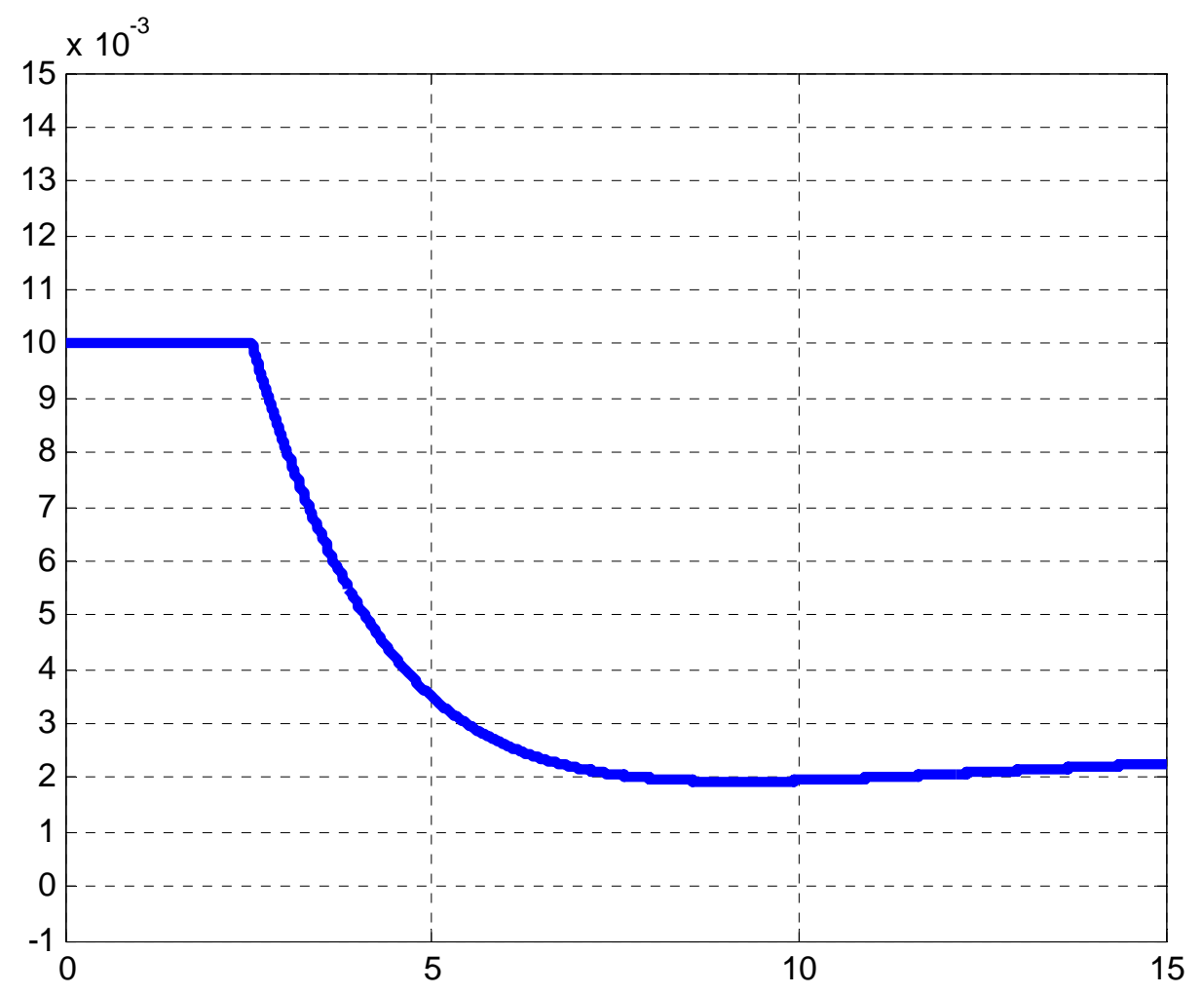

Figure 5.2-B: Fuel Rate during Operation with Glass Temperature Feedback

Table 5.2-B: Fuel Usage and Glass Temperature for Glass Feedback Controller

\begin{tabular}{|l|c|}
\hline Total Fuel Usage (kg) & 224.1 \\
\hline Final Glass Temperature (K) & 1513 \\
\hline Settling Time (hrs) & 7.5 \\
\hline
\end{tabular}

The second simulation tested was the combustion gas temperature feedback controller. The temperature in $\mathrm{Ta}_{a 2}$ was used for the controller. The controlled temperature was plotted over time. Fuel usage was plotted over time and a table listed 
the total fuel usage and the final temperature of $T g_{\chi^{2}}$ after 12 hours. These figures and table are shown below.

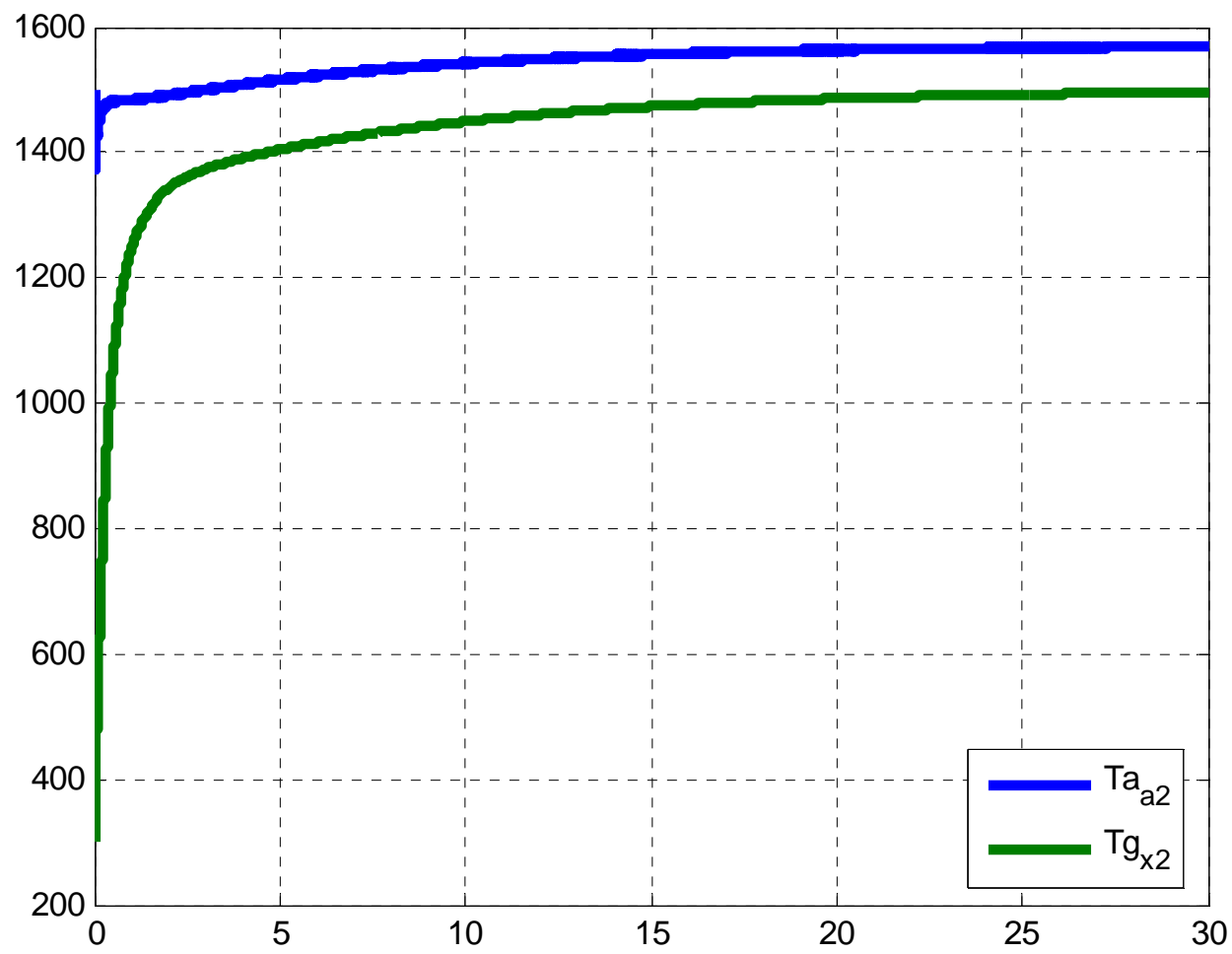

Figure 5.2-C: Feedback Gas Temperature during the Full Melt Cycle 


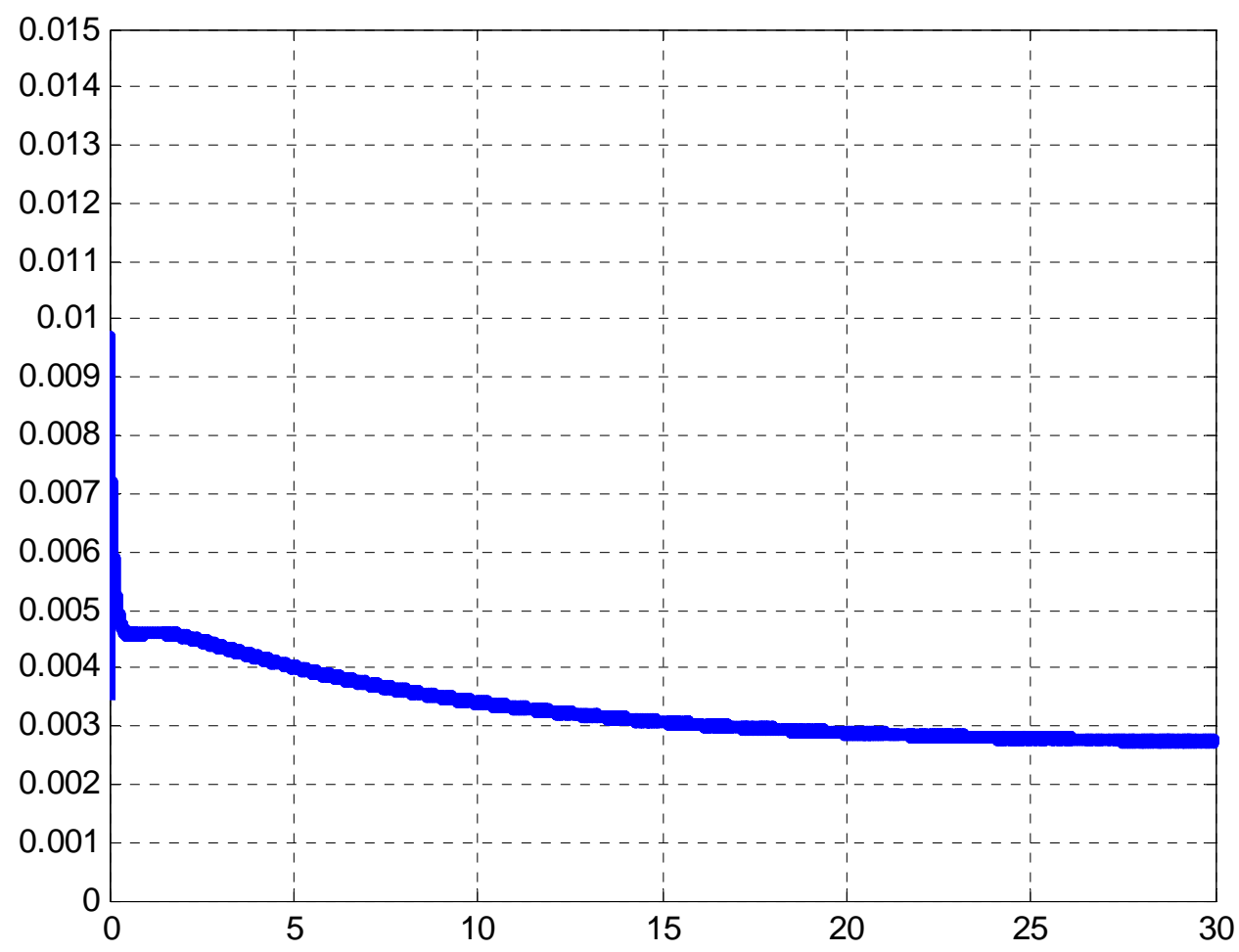

Figure 5.2-D: Fuel Rate during Operation with Gas Temperature Feedback

Table 5.2-C: Fuel Usage and Gas and Glass Temperature for Gas Feedback Controller

\begin{tabular}{|l|c|}
\hline Total Fuel Usage (kg) & 364.4 \\
\hline Final Glass Temperature (K) & 1496 \\
\hline Settling Time (hrs) & 30 \\
\hline
\end{tabular}

The third simulation tested was the crown temperature feedback controller. The temperature in $\mathrm{TC}_{a 2}$ was used for the controller. The controlled temperature was plotted over time. Fuel usage was plotted over time and a table listed the total fuel usage and the final temperature of TCa2 after 15 hours. These figures and table are shown below. 


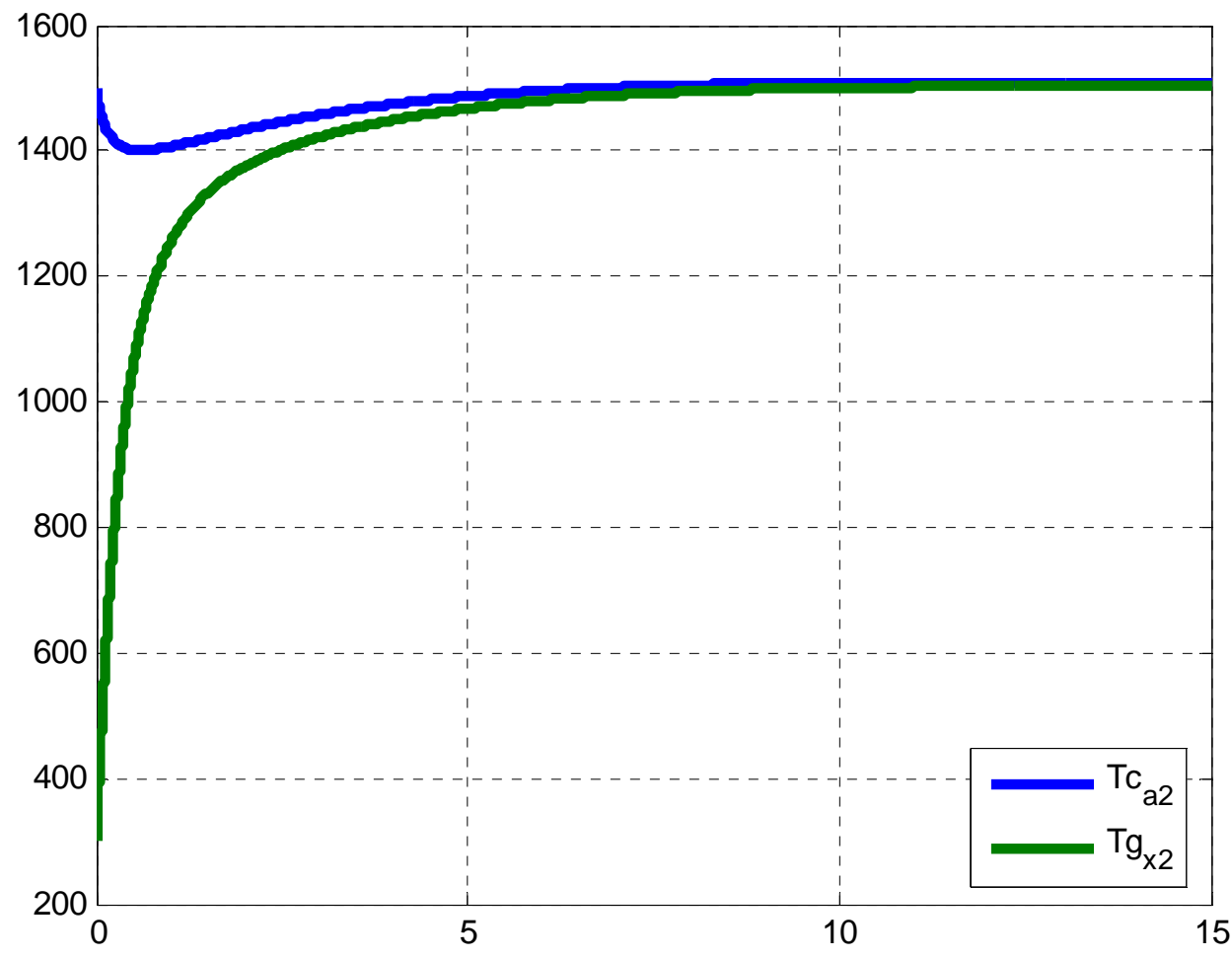

Figure 5.2-E: Feedback Crown Temperature during the Full Melt Cycle 


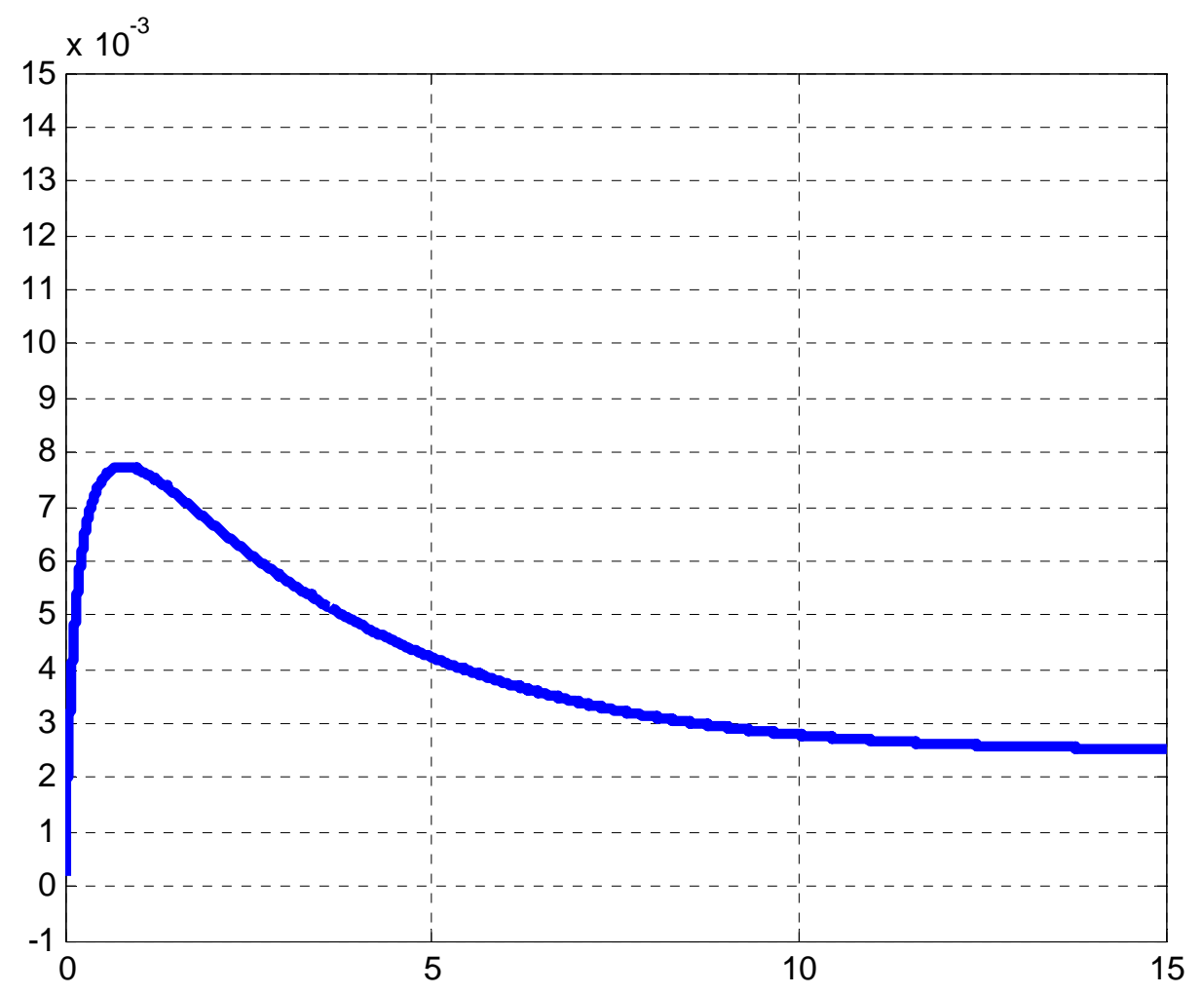

Figure 5.2-F: Fuel Rate during Operation with Crown Temperature Feedback

Table 5.2-D: Fuel Usage and Glass Temperature for Crown Feedback Controller

\begin{tabular}{|l|r|}
\hline Total Fuel Usage (kg) & 214.6 \\
\hline Final Glass Temperature (K) & 1502 \\
\hline Settling Time (hrs) & 10 \\
\hline
\end{tabular}

The final simulation tested was the floor temperature feedback controller. The temperature in $T f l_{\delta 2}$ was used for the controller. The controlled temperature was plotted over time. Fuel usage was plotted over time and a table listed the total fuel usage and the final temperature of $T f l_{\delta 2}$ after 15 hours. These figures and table are shown below. 


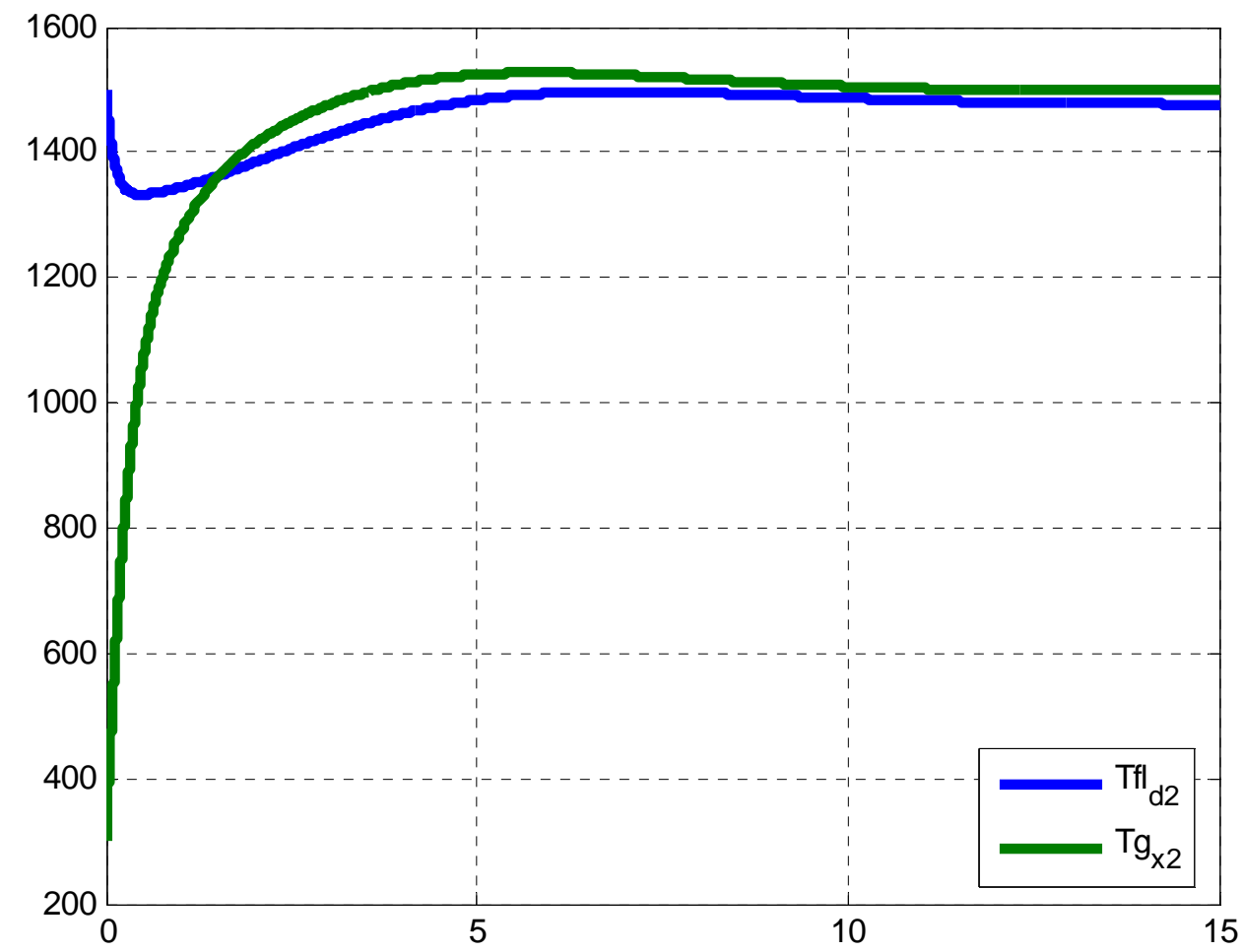

Figure 5.2-G: Feedback Floor Temperature during the Full Melt Cycle 


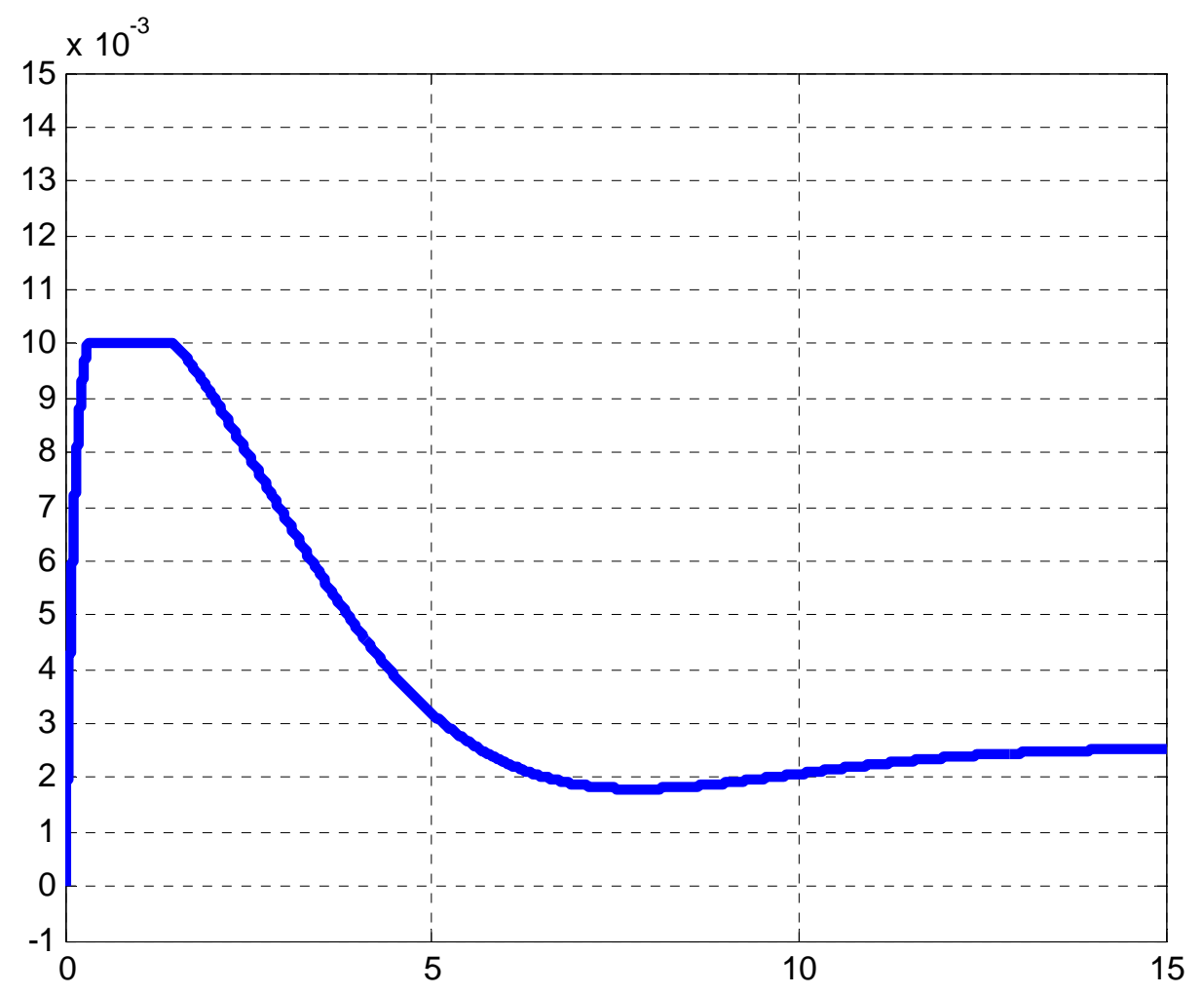

Figure 5.2-H: Fuel Rate during Operation with Floor Temperature Feedback

Table 5.2-E: Fuel Usage and Glass Temperature for Floor Feedback Controller

\begin{tabular}{|l|r|}
\hline Total Fuel Usage (kg) & 211.2 \\
\hline Final Glass Temperature (K) & 1500 \\
\hline Settling Time (hrs) & 10 \\
\hline
\end{tabular}

The best controller would have a good steady state glass temperature, a quick settling time, and a low total fuel usage. The final control scheme based on the furnace floor has the best performance. Since with this scheme, the fuel usage is the minimum 
and the settling time is as short as the crown and the steady state error is zero. This control scheme has been recommended in literature ${ }^{17}$ and these simulations suggested that it performed better than other common methods.

The crown feedback controller works very similarly to the floor feedback controller. The crown controller does not operate the furnace on high fire nearly as long as the floor feedback controller. The crown controller keeps the crown at a constant temperature and lets the glass heat up slowly. The crown is more directly influenced by the combustion gas temperatures and has a much smaller time constant than the glass and floor. This causes the crown to reach its stable temperature much earlier than the glass itself. This causes the controller to cut back the fuel causing the melt time to lengthen. An interesting result of this, however, is the reduction of inside temperatures of the furnace. The plots below show the crown, gas and front wall temperatures during the crown feedback and floor feedback controllers. 


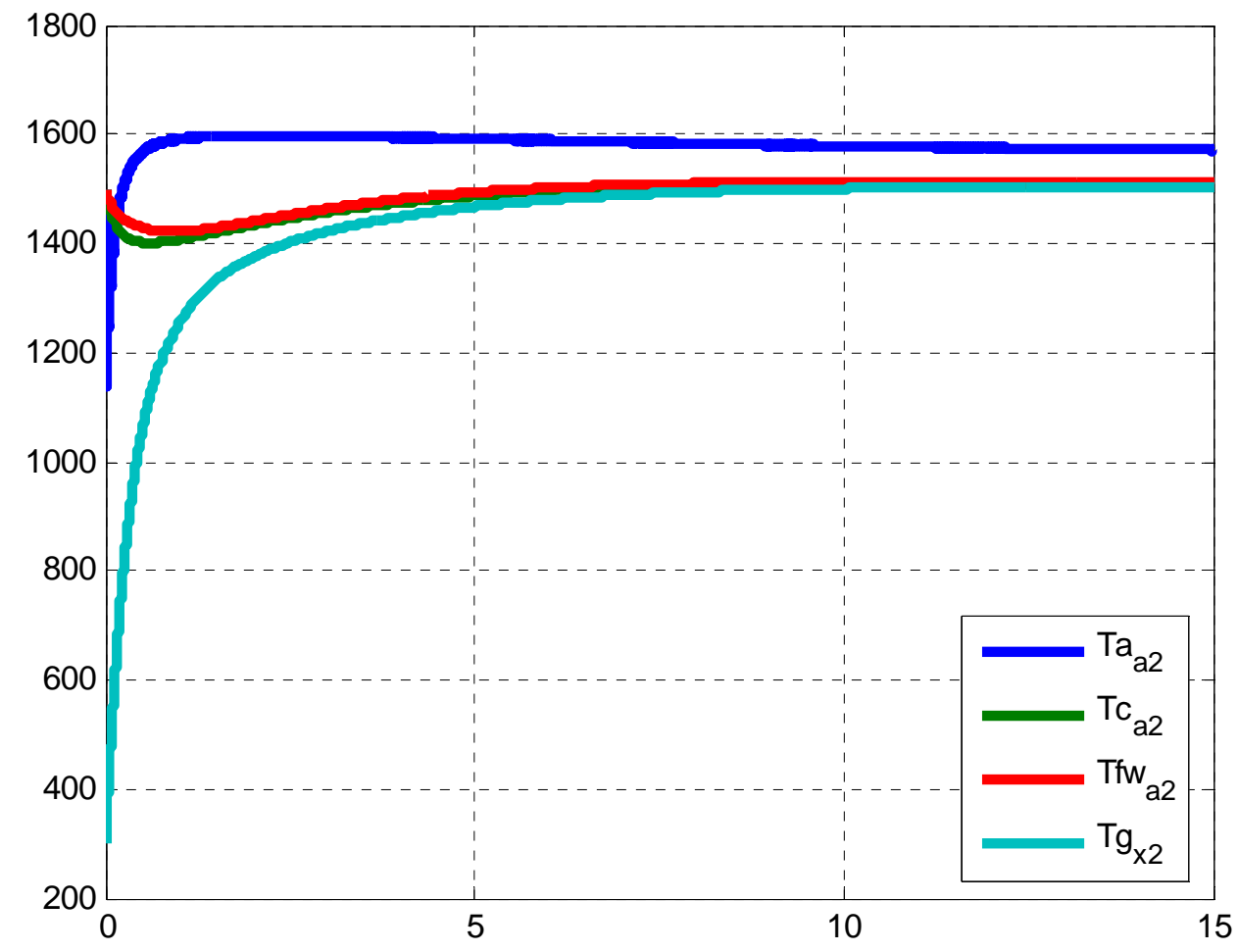

Figure 5.2-I: Feedback Crown Temperature and Others during the Full Melt Cycle 


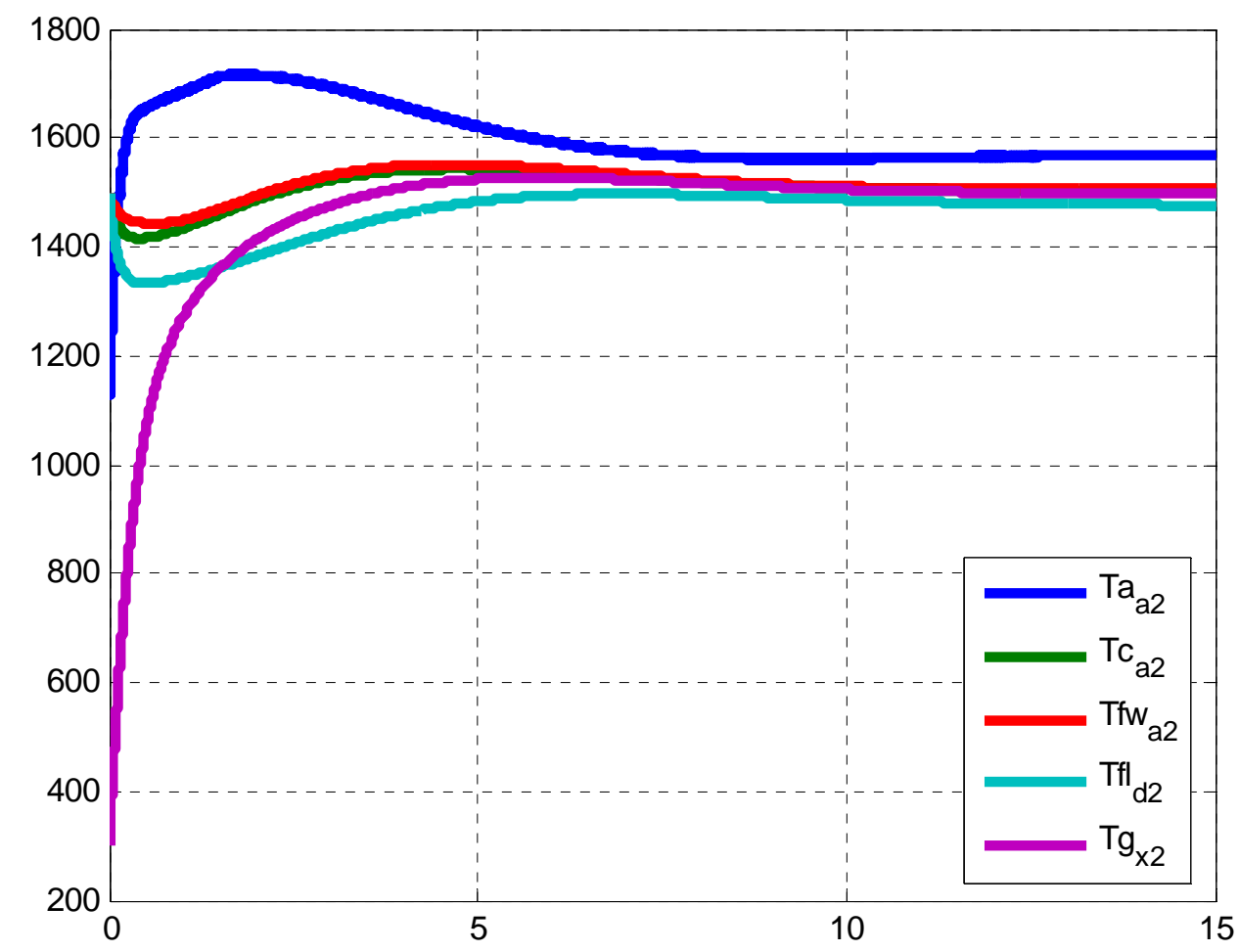

Figure 5.2-J: Feedback Floor Temperature and Others during the Full Melt Cycle

The inside combustion gas temperatures are reduced $100 \mathrm{~K}$ using a crown feedback controller. If inside temperatures were a concern to the operator, this control scheme would be useful with only a slight increase in fuel cost.

The purpose of this exploration is to facilitate more accurate and more economical melt cycles in a small glass furnace. Data have been shown to suggest the best controller approach is to use a floor temperature feedback controller. 


\subsection{Recommendation for Final Model for Application}

A state space model consisting of 24 state variables is not necessary for control. Some assumptions can be made to considerably reduce the number of state variables. The suggested final model for application would have the following assumptions:

- Each volume element in the model has a uniform temperature. Temperature gradients within the glass exist only in the vertical direction

- Heat input is calculated as a net input. Flame heat addition is calculated using $\mathrm{A} / \mathrm{F}$ ratio for $10 \%$ excess air and adiabatic flame temperatures. then the net losses from stack are subtracted to calculate a net heat input.

- Refractory temperatures would reflect the temperatures of the inner surface rather than the average temperature of the block. Air and glass temperatures represent the average temperature in the volume.

Five thermocouples would be used to measure input temperatures. Each thermo couple should be placed within the refractory at most 3-2 inches from the inner surface. The table below shows the location of each thermocouple and the temperatures it would represent. 


\section{Table 5.3-A: Thermocouple Locations for Application}

\begin{tabular}{|c|c|c|}
\hline $\begin{array}{c}\text { Thermocouple } \\
\text { Number }\end{array}$ & $\begin{array}{c}\text { Thermocouple } \\
\text { Position }\end{array}$ & $\begin{array}{c}\text { Temperatures } \\
\text { Assumed Equal }\end{array}$ \\
\hline$\# 1$ & Wall above glass & $\begin{array}{c}\text { All wall and crown } \\
\text { surfaces above the } \\
\text { glass }\end{array}$ \\
\hline$\# 2$ & Combustion gas & $\begin{array}{c}\text { All of the combustion } \\
\text { gases }\end{array}$ \\
\hline$\# 3$ & $\begin{array}{c}\text { Side wall near top half } \\
\text { of glass }\end{array}$ & $\begin{array}{c}\text { All wall surfaces at top } \\
\text { half of glass }\end{array}$ \\
\hline$\# 4$ & $\begin{array}{c}\text { Side wall near bottom } \\
\text { half of glass }\end{array}$ & $\begin{array}{c}\text { All wall surfaces at } \\
\text { bottom half of glass }\end{array}$ \\
\hline$\# 5$ & Floor & All floor temperatures \\
\hline
\end{tabular}

These five thermocouples would become the inputs for many of the original state variables. The control model would only consist of 3 unknown variables. These would be the temperatures of the three glass layers.

The differential equations for these glass volumes would be very similar to the original equations. The equations are shown below. 


$$
\begin{aligned}
& \boldsymbol{\beta} \\
& \begin{aligned}
\frac{d T g_{\beta}}{d t}= & -\frac{1}{C g_{\beta}}\left[\frac{O F_{\beta} A a_{\alpha}}{R a_{\alpha}}+\frac{(S F) O F_{\beta} A b w_{\alpha}}{R b w_{\alpha}}+\frac{O F_{\beta} A c_{\alpha}}{R c_{\alpha}}+\frac{(S F) O F_{\beta} A s w_{\alpha}}{R s w_{\alpha}}+\frac{(S F) O F_{\beta} A f w_{\alpha}}{R f w_{\alpha}}+\frac{A g_{\beta-\chi}}{R g_{\beta-\chi}}\right] T g_{\beta} \\
& +\frac{A g_{\beta-\chi}}{\left(C g_{\beta}\right) R g_{\beta-\chi}} T g_{\chi}+\frac{O F_{\beta} A a_{\alpha}}{\left(C g_{\beta}\right) R a_{\alpha}} T_{\# 2}+\frac{(S F) O F_{\beta} A b w_{\alpha}}{\left(C g_{\beta}\right) R b w_{\alpha}} T_{\# 1}+\frac{O F_{\beta} A c_{\alpha}}{\left(C g_{\beta}\right) R c_{\alpha}} T_{\# 1}+\frac{(S F) O F_{\beta} A s w_{\alpha}}{\left(C g_{\beta}\right) R s w_{\alpha}} T_{\# 1}+\frac{(S F) O F_{\beta} A f w_{\alpha}}{\left(C g_{\beta}\right) R f w_{\alpha}} T_{\# 1}
\end{aligned}
\end{aligned}
$$

$$
\begin{aligned}
\frac{d T g_{\chi}}{d t}= & \frac{A g_{\beta-\chi}}{\left(C g_{\chi}\right) R g_{\beta-\chi}} T g_{\beta}-\frac{1}{C g_{\chi}}\left[\frac{O F_{\chi} A a_{\alpha}}{R a_{\alpha}}+\frac{(S F) O F_{\chi} A b w_{\alpha}}{R b w_{\alpha}}+\frac{(S F) O F_{\chi} A s w_{\alpha}}{R s w_{\alpha}}+\frac{O F_{\chi} A c_{\alpha}}{R c_{\alpha}}+\frac{(S F) O F_{\chi} A f w_{\alpha}}{R f w_{\alpha}}\right. \\
& \left.+\frac{A g_{\beta-\chi}}{R g_{\beta-\chi}}+\frac{A s w_{\chi}}{R s w_{\chi}}+\frac{A b w_{\chi}}{R b w_{\chi}}+\frac{A g_{\chi-\delta}}{R g_{\chi-\delta}}\right] T g_{\chi}+\frac{A g_{\chi-\delta}}{\left(C g_{\chi}\right) R a_{\chi-\delta}} T g_{\delta}+\frac{O F_{\chi} A a_{\alpha}}{\left(C g_{\chi}\right) R a_{\alpha}} T_{\# 2}+\frac{(S F) O F_{\chi} A b w_{\alpha}}{\left(C g_{\chi}\right) R b w_{\alpha}} T_{\# 1} \\
& +\frac{O F_{\chi} A c_{\alpha}}{\left(C g_{\chi}\right) R c_{\alpha}} T_{\# 1}+\frac{(S F) O F_{\chi} A s w_{\alpha}}{\left(C g_{\chi}\right) R s w_{\alpha}} T_{\# 1}+\frac{(S F) O F_{\chi} A f w_{\alpha}}{\left(C g_{\chi}\right) R f w_{\alpha}} T_{\# 1}+\frac{A b w_{\chi}}{\left(C g_{\chi}\right) R b w_{\chi}} T_{\# 3}+\frac{A s w_{\chi}}{\left(C g_{\chi}\right) R s w_{\chi}} T_{\# 3}
\end{aligned}
$$




$$
\begin{aligned}
\frac{d T g_{\delta}}{d t}= & \frac{A g_{\chi-\delta}}{\left(C g_{\delta}\right) R g_{\chi-\delta}} T g_{\chi}-\frac{1}{C g_{\delta}}\left[\frac{O F_{\delta} A a_{\alpha}}{R a_{\alpha}}+\frac{(S F) O F_{\delta} A b w_{\alpha}}{R b w_{\alpha}}+\frac{(S F) O F_{\delta} A s w_{\alpha}}{R s w_{\alpha}}+\frac{O F_{\delta} A c_{\alpha}}{R c_{\alpha}}+\frac{(S F) O F_{\delta} A f w_{\alpha}}{R f w_{\alpha}}\right. \\
& \left.+\frac{A g_{\chi-\delta}}{R g_{\chi-\delta}}+\frac{A s w_{\delta}}{R s w_{\delta}}+\frac{A b w_{\delta}}{R b w_{\delta}}+\frac{A g_{\delta-\delta}}{R g_{\delta-\delta}}+\frac{A g_{\delta}}{R g_{\delta}}\right] T g_{\delta}+\frac{O F_{\delta} A a_{\alpha}}{\left(C g_{\delta}\right) R a_{\alpha}} T_{\# 2}+\frac{(S F) O F_{\delta} A b w_{\alpha}}{\left(C g_{\delta}\right) R b w_{\alpha}} T_{\# 1}+\frac{O F_{\delta} A c_{\alpha}}{\left(C g_{\delta}\right) R c_{\alpha}} T_{\# 1} \\
& +\frac{(S F) O F_{\delta} A s w_{\alpha}}{\left(C g_{\delta}\right) R s w_{\alpha}} T_{\# 1}+\frac{(S F) O F_{\delta} A f w_{\alpha}}{\left(C g_{\delta}\right) R f w_{\alpha}} T_{\# 1}+\frac{A s w_{\delta}}{\left(C g_{\delta}\right) R s w_{\delta}} T_{\# 4}+\frac{A b w_{\delta}}{\left(C g_{\delta}\right) R b w_{\delta}} T_{\# 4}+\frac{A g_{\delta}}{\left(C g_{\delta}\right) R a_{\delta}} T_{\# 5}
\end{aligned}
$$


In order to apply the model to a specific furnace, some calculations would be needed to adapt the model to the new furnace. Appendix D provides the values for areas, resistances and capacitances for the model used in this research. These values could be easily modified by adjusting the values of area, specific heat, density, thermal conductivity, and wall thickness for a different furnace.

The model provides flexibility to choose a variety of control schemes.

- Control of glass temperature at the surface $(\beta)$, middle $(\chi)$, or bottom $(\delta)$ layer

- Control of floor temperature

- Control of crown or air temperature

It is also possible to change control modes at will. The model/controller is supervisory and can merely provide a set point and feedback signal to the gas valve controller. Different modes might be advantageous for different parts of the melt cycle. Energy efficiency and glass quality will determine how the system is set up. 


\section{Conclusions and Recommendations}

\subsection{Conclusions}

A state space model has been developed to predict the temperatures of the furnace interior surfaces and the temperature of the glass melt at six locations in a small glass furnace. The model was simulated and validated with real furnace data. The state space model allows for multiple inputs to be used in order to improve glass temperature predictions. Using feedback from the floor temperature, a controller has been designed that is more efficient than a combustion gas, predictive glass temperature, or crown feedback controller.

The floor of the furnace has a very similar time constant as the glass melt that lies on top of it. A controller that adjusts fuel flow based on the floor temperature feedback responds the best in tests. The floor feedback controller uses $6.1 \%$ less fuel than the glass temperature predictive controller and $1.6 \%$ less fuel than the crown feedback controller.

Standard thermocouples, buried into the refractory, would be used to measure the input temperatures. Since the thermocouples are not exposed to the deteriorating combustion gas or glass their useful lives are extended beyond the life of an exposed thermocouple.

The simple design allows for a few calculations to personalize the model for the generic use with any glass furnace. The only alteration within the model 
needed between furnaces is the adjustment for different furnace dimensions. A simple calculation of volume areas and radiation shape factors should only take a few hours with the aid of Mills's ${ }^{19}$ radiation shape factor calculating program called "rad1". After these calculations are complete, the model can be controlled by the floor feedback controller after the gains are adjusted for optimal performance. The final system could be installed with only a minimal investment and would require less upkeep than current systems measuring combustion gas. 


\section{Bibliography}

1. "Check Burner Air to Fuel Ratios, Process Heat Tip Sheet \#2", U.S. Department of Energy, DOE/GO-102002-1552, May 2002, http://www.oit.doe.gov/bestpractices/process_heat/

2. Holladay, Andrea Rae (2005). Modeling and Control of a Small Glass Furnace, Master's Thesis, West Virginia University, [On-line Abstract]. Available: https://eidr.wvu.edu/files/4324/Holladay_Andrea_thesis.pdf

3. Tooley, Fay V., The Handbook of Glass Manufacture, V. 2, 3ed, Ashlee Publishing Co. Inc., New York, NY, 1984 ISBN 0-911993-21-5

4. Tooley, Fay V., The Handbook of Glass Manufacture, V. 1, 3ed, Ashlee Publishing Co. Inc., New York, NY, 1981 ISBN 0-911933-20-7

5. Bergen, Dr Paul van den. "Pot Furnace." http://member.melbpc. org.au/ gabpaul/furnace.html. January 31, 2007.

6. Fenton Art Glass Co. Williamstown, WV. http://www.fentonartglass.com/

7. Poolos, W. A., "Mathematical Modeling of Glassmelting Systems", American Ceramic Society Bulletin, vol. 83, Issue 1, January, 2004.

8. Chang, S.L., Golchert, B., Zhou, C. Q., "Computer Modeling of Glass Furnace Flow and Heat Transfer." Advances in Fusion and Processing of Glass III. Ceramic Transactions. Vol. 141. 2004.

9. Dzyuzer, V. Ya., Shvydkii, V. S., Kut'in, V. B., “ Mathematical Model of a Glass-melting Furnace with Horseshoe-shaped Flame", Glass \& Ceramics, Vol. 61, Issue 9-10, September, 2004.

10. Schill P., Trochta, M. "Mathematical Modeling of Batch Melting in a Glass Furnace." Advances in Fusion and Processing of Glass III. Ceramic Transactions. Vol. 141. 2004.

11. Dzhashitvo, V. E., Pankratov, V. M., Golikov, A. V., "Mathematical Model of Dynamic Heat and Mass-Exchange Processes in a Glass Making Furnace", Journal of Engineering Physics and Thermophysics, Vol. 76, No.5, 2003.

12. Choudhary, M. K., "Recent Advances in Mathematical Modeling of Flow and Heat Transfer Phenomena in Glass Furnaces", Journal of the American Ceramic Society, Vol. 85, No. 52002. 
13. Wei, Z., Lee, K., Zhou,Z., Hong, S. "Modeling of Advanced Melting Zone for Manufacturing of Optical Fibers" Journal of Manufacturing Science and Engineering, Vol. 126, November 2004.

14. Nixon, Steve W., "Recent Experience with Digital Process Control for a Glass Furnace and Forehearths", American Ceramic Society Bulletin, Vol. 61.1982.

15. Moon, U., Lee, K., "Multi-Loop Control of Temperature for TV Glass Furnace", IEEE Transactions on Control Systems Technology, Vol. 11, No.4, July, 2003.

16. Moon, U., Lee, K., "Hybrid Algorithm with Fuzzy System and Conventional PI Control for the Temperature Control of a TV Glass Furnace", Proceedings of the American Control Conference. Chicago, Illinois. June, 2000.

17. Wertz, V., Gevers, M., Simon, J.F., “Adaptive Control of the Temperature of a Glass Furnace." IFAC Adaptive Systems in Control and Signal Processing. Grenoble, France. 1992.

18. Verheijen, Oscar S., "Thermal and Chemical Behavior of Glass Forming Batches"-Eindhoven : Technische Universiteit Eindhoven, 2003 ISBN 90386-2555-3

19. Mills, A. F., Basic Heat and Mass Transfer. $2^{\text {nd }}$ Edition, Prentice Hall, Upper Saddle River, New Jersey, 1999.

20. "Monofrax CS-3 Alumina-Zirconia Silica (AZS) Fused Cast Refractory" Manufacturer's Literature available at http://monofrax.com/A3077CS3W.pdf, October, 25, 2005.

21. Shelby, James E., Introduction to Glass Science and Technology, Royal Society of Chemistry, Cambridge, UK, 1997

22. US Department of Energy , "Identifying Waste Heat Reduction Opportunities", www.eere.energy.gov/industry/bestpractices/ emsum05 identifying_waste heat_reduction.html, September 18, 2005.

23. Shackelford, James F., Alexander, W., Park, Jun S., CRC Materials Science and Engineering Handbook. $2^{\text {nd }}$ Edition, CRC Press, Inc., 1994. ISBN 0849342503.

24. 2001 ASHRAE Handbook Fundamentals, American Society of Heating, Refrigerating and Air-Conditioning Engineers, Inc., Atlanta, GA., 2001. ISBN 1-883413-87-7 


\section{Appendix A - State Variable Equations}

$\alpha 1$

$$
\begin{aligned}
\frac{d T a_{\alpha 1}}{d t}= & -\frac{1}{C a_{\alpha 1}}\left[\frac{A s w_{\alpha 1}}{R s w_{\alpha 1}}+\frac{A b w_{\alpha 1}}{R b w_{\alpha 1}}+\frac{A c_{\alpha 1}}{R c_{\alpha 1}}+\frac{A a_{\alpha 2}}{R a_{\alpha 2}}+\frac{O F_{\beta} A g_{\beta 1}}{R g_{\beta 1}}+\frac{(S F) O F_{\beta} A g_{\beta 2}}{R g_{\beta 2}}\right. \\
& \left.+\frac{O F_{\chi} A g_{\chi 1}}{R g_{\chi 1}}+\frac{(S F) O F_{\chi} A g_{\chi 2}}{R g_{\chi 2}}+\frac{O F_{\delta} A g_{\delta 1}}{R g_{\delta 1}}+\frac{(S F) O F_{\delta} A g_{\delta 2}}{R g_{\delta 2}} T a_{\alpha 1}+\frac{A b w_{\alpha 1}}{\left(C a_{\alpha 1}\right) R b w_{\alpha 1}} T b w_{\alpha 1}+\frac{A c_{\alpha 1}}{\left(C a_{\alpha 1}\right) R c_{\alpha 1}}\right] T c_{\alpha 1} \\
& +\frac{A s w_{\alpha 1}}{\left(C a_{\alpha 1}\right) R s w_{\alpha 1}} T s w_{\alpha 1}+\frac{A a_{\alpha 2}}{\left(C a_{\alpha 1}\right) R a_{\alpha a}} T a_{\alpha 2}+\frac{O F_{\beta} A g_{\beta 1}}{\left(C a_{\alpha 1}\right) R g_{\beta 1}} T g_{\beta 1}+\frac{(S F) O F_{\beta} A g_{\beta 2}}{\left(C a_{\alpha 1}\right) R g_{\beta 2}} T g_{\beta 2} \\
& +\frac{O F_{\chi} A g_{\chi 1}}{\left(C a_{\alpha 1}\right) R g_{\chi 1}} T g_{\chi 1}+\frac{(S F) O F_{\chi} A g_{\chi 2}}{\left(C a_{\alpha 1}\right) R g_{\chi 2}} T g_{\chi 2}+\frac{O F_{\delta} A g_{\delta 1}}{\left(C a_{\alpha 1}\right) R g_{\delta 1}} T g_{\delta 1}+\frac{(S F) O F_{\delta} A g_{\delta 2}}{\left(C a_{\alpha 1}\right) R g_{\delta 2}} T g_{\delta 2}+\frac{\dot{Q}}{C a_{\alpha 1}}
\end{aligned}
$$




$$
\begin{aligned}
\frac{d T b w_{\alpha 1}}{d t}= & \frac{A b w_{\alpha 1}}{\left(C b w_{\alpha 1}\right) R b w_{\alpha 1}} T a_{\alpha 1}-\frac{1}{C b w_{\alpha 1}}\left[\frac{A b w_{\alpha 1}}{R b w_{\alpha 1}}+\frac{A b w_{\alpha 1-\chi 1}}{R b w_{\alpha 1-\chi 1}}+\frac{A b w_{\alpha 1-o}}{R b w_{\alpha 1-o}}+\frac{(S F) O F_{\beta} A g_{\beta 1}}{R g_{\beta 1}}\right. \\
& \left.+\frac{(S F) O F_{\beta} A g_{\beta 2}}{R g_{\beta 2}}+\frac{(S F) O F_{\chi} A g_{\chi 1}}{R g_{\chi 1}}+\frac{(S F) O F_{\chi} A g_{\chi 2}}{R g_{\chi 2}}+\frac{(S F) O F_{\delta} A g_{\delta 1}}{R g_{\delta 1}}+\frac{(S F) O F_{\delta} A g_{\delta 2}}{R g_{\delta 2}}\right] T b w_{\alpha 1} \\
& +\frac{(S F) O F_{\beta} A g_{\beta 1}}{\left(C b w_{\alpha 1}\right) R g_{\beta 1}} T g_{\beta 1}+\frac{(S F) O F_{\beta} A g_{\beta 2}}{\left(C b w_{\alpha 1}\right) R g_{\beta 2}} T g_{\beta 2}+\frac{(S F) O F_{\chi} A g_{\chi 1}}{\left(C b w_{\alpha 1}\right) R g_{\chi 1}} T g_{\chi 1}+\frac{A b w_{\alpha 1-\chi 1}}{\left(C b w_{\alpha 1}\right) R b w_{\alpha 1-\chi 1}} T b w_{\chi 1} \\
& +\frac{(S F) O F_{\chi} A g_{\chi 2}}{\left(C b w_{\alpha 1}\right) R g_{\chi 2}} T g_{\chi 2}+\frac{(S F) O F_{\delta} A g_{\delta 1}}{\left(C b w_{\alpha 1}\right) R g_{\delta 1}} T g_{\delta 1}+\frac{(S F) O F_{\delta} A g_{\delta 2}}{\left(C b w_{\alpha 1}\right) R g_{\delta 2}} T g_{\delta 2}+\frac{A b w_{\alpha 1-o}}{\left(C b w_{\alpha 1}\right) R b w_{\alpha 1-o}} T o \\
\frac{d T c_{\alpha 1}=}{d t}= & \frac{A c_{\alpha 1}}{\left(C c_{\alpha 1}\right) R c_{\alpha 1}} T a_{\alpha 1}+-\frac{1}{C c_{\alpha 1}}\left[\frac{A c_{\alpha 1}}{R c_{\alpha 1}}+\frac{A c_{\alpha 1-\alpha 2}}{R c_{\alpha 1-\alpha 2}}+\frac{A c_{\alpha 1-o}}{R c_{\alpha 1-o}}+\frac{(S F) O F_{\beta} A g_{\beta 1}}{R g_{\beta 1}}\right. \\
+ & \left.\frac{(S F) O F_{\beta} A g_{\beta 2}}{R g_{\beta 2}}+\frac{(S F) O F_{\chi} A g_{\chi 1}}{R g_{\chi 1}}+\frac{(S F) O F_{\chi} A g_{\chi 2}}{R g_{\chi 2}}+\frac{(S F) O F_{\delta} A g_{\delta 1}}{R g_{\delta 1}}+\frac{(S F) O F_{\delta} A g_{\delta 2}}{R g_{\delta 2}}\right] T c_{\alpha 1}+\frac{A c_{\alpha 1-\alpha 2}}{\left(C c_{\alpha 1}\right) R c_{\alpha 1-\alpha 2}} T c_{\alpha 2} \\
+ & \frac{(S F) O F_{\beta} A g_{\beta 1}}{\left(C c_{\alpha 1}\right) R g_{\beta 1}} T g_{\beta 1}+\frac{(S F) O F_{\beta} A g_{\beta 2}}{\left(C c_{\alpha 1}\right) R g_{\beta 2}} T g_{\beta 2}+\frac{(S F) O F_{\chi} A g_{\chi 1}}{\left(C c_{\alpha 1}\right) R g_{\chi 1}} T g_{\chi 1}+\frac{(S F) O F_{\chi} A g_{\chi 2}}{\left(C c_{\alpha 1}\right) R g_{\chi 2}} T g_{\chi 2} \\
+ & \frac{(S F) O F_{\delta} A g_{\delta 1}}{\left(C c_{\alpha 1}\right) R g_{\delta 1}} T g_{\delta 1}+\frac{(S F) O F_{\delta} A g_{\delta 2}}{\left(C c_{\alpha 1}\right) R g_{\delta 2}} T g_{\delta 2}+\frac{A c_{\alpha 1-o}}{\left(C c_{\alpha 1}\right) R c_{\alpha 1-o}} T o
\end{aligned}
$$




$$
\begin{aligned}
\frac{d T s w_{\alpha 1}}{d t}= & \frac{A s w_{\alpha 1}}{\left(C s w_{\alpha 1}\right) R s w_{\alpha 1}} T a_{\alpha 1}+-\frac{1}{C s w_{\alpha 1}}\left[\frac{A s w_{\alpha 1}}{R s w_{\alpha 1}}+\frac{A s w_{\alpha 1-2}}{R s w_{\alpha 1-2}}+\frac{A s w_{\alpha 1-\chi 1}}{R s w_{\alpha 1-\chi 1}}+\frac{A s w_{\alpha 1-o}}{R s w_{\alpha 1-o}}+\frac{(S F) O F_{\beta} A g_{\beta 1}}{R g_{\beta 1}}\right. \\
& \left.+\frac{(S F) O F_{\beta} S F A g_{\beta 2}}{R g_{\beta 2}}+\frac{(S F) O F_{\chi} A g_{\chi 1}}{R g_{\chi 1}}+\frac{(S F) O F_{\chi} S F A g_{\chi 2}}{R g_{\chi 2}}+\frac{(S F) O F_{\delta} A g_{\delta 1}}{R g_{\delta 1}}+\frac{(S F) O F_{\delta} S F A g_{\delta 2}}{R g_{\delta 2}}\right] T s w_{\alpha 1} \\
& +\frac{A s w_{\alpha 1-2}}{\left(C s w_{\alpha 1}\right) R s w_{\alpha 1-2}} T s w_{\alpha 2}+\frac{(S F) O F_{\beta} A g_{\beta 1}}{\left(C s w_{\alpha 1}\right) R g_{\beta 1}} T g_{\beta 1}+\frac{(S F) O F_{\beta} A g_{\beta 2}}{\left(C s w_{\alpha 1}\right) R g_{\beta 2}} T g_{\beta 2}+\frac{(S F) O F_{\chi} A g_{\chi 1}}{\left(C s w_{\alpha 1}\right) R g_{\chi 1}} T g_{\chi 1} \\
& +\frac{A s w_{\alpha 1-\chi 1}}{\left(C s w_{\alpha 1}\right) R s w_{\alpha 1-\chi 1}} T s w_{\chi 1}+\frac{(S F) O F_{\chi} A g_{\chi 2}}{\left(C s w_{\alpha 1}\right) R g_{\chi 2}} T g_{\chi 2}+\frac{(S F) O F_{\delta} A g_{\delta 1}}{\left(C s w_{\alpha 1}\right) R g_{\delta 1}} T g_{\delta 1}+\frac{(S F) O F_{\delta} A g_{\delta 2}}{\left(C s w_{\alpha 1}\right) R g_{\delta 2}} T g_{\delta 2} \\
& +\frac{A s w_{\alpha 1-o}}{\left(C s w_{\alpha 1}\right) R s w_{\alpha 1-o}} T o
\end{aligned}
$$




\section{$\alpha 2$}

$$
\begin{aligned}
\frac{d T a_{\alpha 2}}{d t}= & \frac{A a_{\alpha 2}}{\left(C a_{\alpha 2}\right) R a_{\alpha a}} T a_{\alpha 1}-\frac{1}{C a_{\alpha 2}}\left[\frac{A a_{\alpha 2}}{R a_{\alpha 2}}+\frac{A s w_{\alpha 2}}{R s w_{\alpha 2}}+\frac{A f w_{\alpha 2}}{R f w_{\alpha 2}}+\frac{A c_{\alpha 2}}{R c_{\alpha 2}}+\frac{(S F) O F_{\beta} A g_{\beta 1}}{R g_{\beta 1}}+\frac{O F_{\beta} A g_{\beta 2}}{R g_{\beta 2}}\right. \\
& \left.+\frac{(S F) O F_{\chi} A g_{\chi 1}}{R g_{\chi 1}}+\frac{O F_{\chi} A g_{\chi 2}}{R g_{\chi 2}}+\frac{(S F) O F_{\delta} A g_{\delta 1}}{R g_{\delta 1}}+\frac{O F_{\delta} A g_{\delta 2}}{R g_{\delta 2}}\right] T a_{\alpha 2}+\frac{A c_{\alpha 2}}{\left(C a_{\alpha 2}\right) R c_{\alpha 2}} T c_{\alpha 2}+\frac{A s w_{\alpha 2}}{\left(C a_{\alpha 2}\right) R s w_{\alpha 2}} T s w_{\alpha 2} \\
& +\frac{A f w_{\alpha 2}}{\left(C a_{\alpha 2}\right) R f w_{\alpha 2}} T f w_{\alpha 1}+\frac{(S F) O F_{\beta} A g_{\beta 1}}{\left(C a_{\alpha 2}\right) R g_{\beta 1}} T g_{\beta 1}+\frac{O F_{\beta} A g_{\beta 2}}{\left(C a_{\alpha 2}\right) R g_{\beta 2}} T g_{\beta 2}+\frac{(S F) O F_{\chi} A g_{\chi 1}}{\left(C a_{\alpha 2}\right) R g_{\chi 1}} T g_{\chi 1} \\
& +\frac{O F_{\chi} A g_{\chi 2}}{\left(C a_{\alpha 2}\right) R g_{\chi 2}} T g_{\chi 2}+\frac{(S F) O F_{\delta} A g_{\delta 1}}{\left(C a_{\alpha 2}\right) R g_{\delta 1}} T g_{\delta 1}+\frac{O F_{\delta} A g_{\delta 2}}{\left(C a_{\alpha 2}\right) R g_{\delta 2}} T g_{\delta 2}
\end{aligned}
$$$$
\frac{d T c_{\alpha 2}}{d t}=\frac{A c_{\alpha 1-\alpha 2}}{\left(C c_{\alpha 2}\right) R c_{\alpha 1-\alpha 2}} T c_{\alpha 1}+\frac{A c_{\alpha 2}}{\left(C c_{\alpha 2}\right) R c_{\alpha 2}} T a_{\alpha 2}-\frac{1}{C c_{\alpha 2}}\left[\frac{A c_{\alpha 2}}{R c_{\alpha 2}}+\frac{A c_{\alpha 1-\alpha 2}}{R c_{\alpha 1-\alpha 2}}+\frac{A c_{\alpha 2-o}}{R c_{\alpha 2-o}}\right.
$$$$
\left.+\frac{(S F) O F_{\beta} A g_{\beta 1}}{R g_{\beta 1}}+\frac{(S F) O F_{\beta} A g_{\beta 2}}{R g_{\beta 2}}+\frac{(S F) O F_{\chi} A g_{\chi 1}}{R g_{\chi 1}}+\frac{(S F) O F_{\chi} A g_{\chi 2}}{R g_{\chi 2}}+\frac{(S F) O F_{\delta} A g_{\delta 1}}{R g_{\delta 1}}+\frac{(S F) O F_{\delta} A g_{\delta 2}}{R g_{\delta 2}}\right] T c_{\alpha 2}
$$$$
+\frac{(S F) O F_{\beta} A g_{\beta 1}}{\left(C c_{\alpha 2}\right) R g_{\beta 1}} T g_{\beta 1}+\frac{(S F) O F_{\beta} A g_{\beta 2}}{\left(C c_{\alpha 2}\right) R g_{\beta 2}} T g_{\beta 2}+\frac{(S F) O F_{\chi} A g_{\chi 1}}{\left(C c_{\alpha 2}\right) R g_{\chi 1}} T g_{\chi 1}+\frac{(S F) O F_{\chi} A g_{\chi 2}}{\left(C c_{\alpha 2}\right) R g_{\chi 2}} T g_{\chi 2}
$$$$
+\frac{(S F) O F_{\delta} A g_{\delta 1}}{\left(C c_{\alpha 2}\right) R g_{\delta 1}} T g_{\delta 1}+\frac{(S F) O F_{\delta} A g_{\delta 2}}{\left(C c_{\alpha 2}\right) R g_{\delta 2}} T g_{\delta 2}+\frac{A c_{\alpha 2-o}}{\left(C c_{\alpha 2}\right) R c_{\alpha 2-o}} T o
$$ 


$$
\begin{aligned}
\frac{d T f w_{\alpha 2}}{d t}= & \frac{A f w_{\alpha 2}}{\left(C f w_{\alpha 2}\right) R f w_{\alpha 2}} T a_{\alpha 2}-\frac{1}{C f w_{\alpha 2}}\left[\frac{A f w_{\alpha 2}}{R f w_{\alpha 2}}+\frac{A f w_{\alpha 2-\chi 2}}{R f w_{\alpha 2-\chi 2}}+\frac{A f w_{\alpha 2-o}}{R f w_{\alpha 2-o}}+\frac{(S F) O F_{\beta} A g_{\beta 1}}{R g_{\beta 1}}\right. \\
& \left.+\frac{(S F) O F_{\beta} A g_{\beta 2}}{R g_{\beta 2}}+\frac{(S F) O F_{\chi} A g_{\chi 1}}{R g_{\chi 1}}+\frac{(S F) O F_{\chi} A g_{\chi 2}}{R g_{\chi 2}}+\frac{(S F) O F_{\delta} A g_{\delta 1}}{R g_{\delta 1}}+\frac{(S F) O F_{\delta} A g_{\delta 2}}{R g_{\delta 2}}\right] T f w_{\alpha 2}+\frac{(S F) O F_{\beta} A g_{\beta 1}}{\left(C f w_{\alpha 2}\right) R g_{\beta 1}} T g_{\beta 1} \\
& +\frac{(S F) O F_{\beta} A g_{\beta 2}}{\left(C f w_{\alpha 2}\right) R g_{\beta 2}} T g_{\beta 2}+\frac{(S F) O F_{\chi} A g_{\chi 1}}{\left(C f w_{\alpha 2}\right) R g_{\chi 1}} T g_{\chi 1}+\frac{(S F) O F_{\chi} A g_{\chi 2}}{\left(C f w_{\alpha 2}\right) R g_{\chi 2}} T g_{\chi 2} \\
& +\frac{A f w_{\alpha 2-\chi 2}}{\left(C f w_{\alpha 2}\right) R f w_{\alpha 2-\chi 2}} T f w_{\chi 2}+\frac{(S F) O F_{\delta} A g_{\delta 1}}{\left(C f w_{\alpha 2}\right) R g_{\delta 1}} T g_{\delta 1}+\frac{(S F) O F_{\delta} A g_{\delta 2}}{\left(C f w_{\alpha 2}\right) R g_{\delta 2}} T g_{\delta 2}+\frac{A f w_{\alpha 2-o}}{\left(C f w_{\alpha 2}\right) R f w_{\alpha 2-o}} T o \\
\frac{d T s w_{\alpha 2}}{d t}= & \frac{A s w_{\alpha 1-2}}{\left(C s w_{\alpha 2}\right) R s w_{\alpha 1-2}} T s w_{\alpha 1}+\frac{A s w_{\alpha 2}}{\left(C s w_{\alpha 2}\right) R s w_{\alpha 2}} T a_{\alpha 2}-\frac{1}{C s w_{\alpha 1}}\left[\frac{A s w_{\alpha 2}}{R s w_{\alpha 2}}+\frac{A s w_{\alpha 1-2}}{R s w_{\alpha 1-2}}+\frac{A s w_{\alpha 2-\chi 2}}{R s w_{\alpha 2-\chi 2}}+\frac{(S F) O F_{\beta} A g_{\beta 1}}{R g_{\beta 1}}\right. \\
& \left.+\frac{(S F) O F_{\beta} A g_{\beta 2}}{R g_{\beta 2}}+\frac{(S F) O F_{\chi} A g_{\chi 1}}{R g_{\chi 1}}+\frac{(S F) O F_{\chi} A g_{\chi 2}}{R g_{\chi 2}}+\frac{(S F) O F_{\delta} A g_{\delta 1}}{R g_{\delta 1}}+\frac{(S F) O F_{\delta} A g_{\delta 2}}{R g_{\delta 2}}+\frac{A s w_{\alpha 2-o}}{R s w_{\alpha 2-o}}\right] T s w_{\alpha 2} \\
& +\frac{(S F) O F_{\beta} A g_{\beta 1}}{\left(C s w_{\alpha 2}\right) R g_{\beta 1}} T g_{\beta 1}+\frac{(S F) O F_{\beta} A g_{\beta 2}}{\left(C s w_{\alpha 2}\right) R_{\beta 2}} T g_{\beta 2}+\frac{(S F) O F_{\chi} A g_{\chi 1}}{\left(C s w_{\alpha 2}\right) R g_{\chi 1}} T g_{\chi 1}+\frac{(S F) O F_{\chi} A g_{\chi 2}}{\left(C s w_{\alpha 2}\right) R_{\chi 2}} T g_{\chi 2} \\
& +\frac{A s w_{\alpha 2-\chi 2}}{\left(C s w_{\alpha 2}\right) R s w_{\alpha 2-\chi 2}} T s w_{\chi 2}+\frac{(S F) O F_{\delta} A g_{\delta 1}}{\left(C s w_{\alpha 2}\right) R g_{\delta 1}} T g_{\delta 1}+\frac{(S F) O F_{\delta} A g_{\delta 2}}{\left(C s w_{\alpha 2}\right) R_{\delta 2}} T g_{\delta 2}+\frac{A s w_{\alpha 2-o}}{\left(C s w_{\alpha 2}\right) R s w_{\alpha 2-o}} T o
\end{aligned}
$$




\section{$\beta 1$}

$$
\begin{aligned}
\frac{d T g_{\beta 1}}{d t}= & \frac{O F_{\beta} A a_{\alpha 1}}{\left(C g_{\beta 1}\right) R a_{\alpha 1}} T a_{\alpha 1}+\frac{(S F) O F_{\beta} A b w_{\alpha 1}}{\left(C g_{\beta 1}\right) R b w_{\alpha 1}} T b w_{\alpha 1}+\frac{O F_{\beta} A c_{\alpha 1}}{\left(C g_{\beta 1}\right) R c_{\alpha 1}} T c_{\alpha 1}+\frac{(S F) O F_{\beta} A s w_{\alpha 1}}{\left(C g_{\beta 1}\right) R s w_{\alpha 1}} T s w_{\alpha 1} \\
& +\frac{(S F) O F_{\beta} A a_{\alpha 2}}{\left(C g_{\beta 1}\right) R a_{\alpha 2}} T a_{\alpha 2}+\frac{(S F) O F_{\beta} A c_{\alpha 2}}{\left(C g_{\beta 1}\right) R c_{\alpha 2}} T c_{\alpha 2}+\frac{(S F) O F_{\beta} A s w_{\alpha 2}}{\left(C g_{\beta 1}\right) R s w_{\alpha 2}} T s w_{\alpha 2}+\frac{(S F) O F_{\beta} A f w_{\alpha 2}}{\left(C g_{\beta 1}\right) R f w_{\alpha 2}} T f w_{\alpha 2} \\
& -\frac{1}{C g_{\beta 1}}\left[\frac{O F_{\beta} A a_{\alpha 1}}{R a_{\alpha 1}}+\frac{(S F) O F_{\beta} A a_{\alpha 2}}{R a_{\alpha 2}}+\frac{(S F) O F_{\beta} A b w_{\alpha 1}}{R b w_{\alpha 1}}+\frac{(S F) O F_{\beta} A s w_{\alpha 1}}{R s w_{\alpha 1}}+\frac{O F_{\beta} A c_{\alpha 1}}{R c_{\alpha 1}}\right. \\
& \left.+\frac{(S F) O F_{\beta} A f w_{\alpha 2}}{R f w_{\alpha 2}}+\frac{(S F) O F_{\beta} A s w_{\alpha 2}}{R s w_{\alpha 2}}+\frac{(S F) O F_{\beta} A c_{\alpha 2}}{R c_{\alpha 2}}+\frac{A g_{\beta 1-\chi 1}}{R g_{\beta 1-\chi 1}}\right] T g_{\beta 1}+\frac{A g_{\beta 1-\chi 1}}{\left(C g_{\beta 1}\right) R g_{\beta 1-\chi 1}} T g_{\chi 1}
\end{aligned}
$$

$\beta 2$

$$
\begin{aligned}
\frac{d T g_{\beta 2}}{d t}= & \frac{(S F) O F_{\beta} A a_{\alpha 1}}{\left(C g_{\beta 2}\right) R a_{\alpha 1}} T a_{\alpha 1}+\frac{(S F) O F_{\beta} A b w_{\alpha 1}}{\left(C g_{\beta 2}\right) R b w_{\alpha 1}} T b w_{\alpha 1}+\frac{(S F) O F_{\beta} A c_{\alpha 1}}{\left(C g_{\beta 2}\right) R c_{\alpha 1}} T c_{\alpha 1}+\frac{(S F) O F_{\beta} A s w_{\alpha 1}}{\left(C g_{\beta 2}\right) R s w_{\alpha 1}} T s w_{\alpha 1} \\
& +\frac{O F_{\beta} A a_{\alpha 2}}{\left(C g_{\beta 2}\right) R a_{\alpha 2}} T a_{\alpha 2}+\frac{O F_{\beta} A c_{\alpha 2}}{\left(C g_{\beta 2}\right) R c_{\alpha 2}} T c_{\alpha 2}+\frac{(S F) O F_{\beta} A s w_{\alpha 2}}{\left(C g_{\beta 2}\right) R s w_{\alpha 2}} T s w_{\alpha 2}+\frac{(S F) O F_{\beta} A f w_{\alpha 2}}{\left(C g_{\beta 2}\right) R f w_{\alpha 2}} T f w_{\alpha 2} \\
& -\frac{1}{C g_{\beta 2}}\left[\frac{O F_{\beta} A a_{\alpha 2}}{R a_{\alpha 2}}+\frac{(S F) O F_{\beta} A a_{\alpha 1}}{R a_{\alpha 1}}+\frac{(S F) O F_{\beta} A b w_{\alpha 1}}{R b w_{\alpha 1}}+\frac{(S F) O F_{\beta} A s w_{\alpha 1}}{R s w_{\alpha 1}}+\frac{(S F) O F_{\beta} A c_{\alpha 1}}{R c_{\alpha 1}}\right. \\
& \left.+\frac{(S F) O F_{\beta} A s w_{\alpha 2}}{R s w_{\alpha 2}}+\frac{(S F) O F_{\beta} A c_{\alpha 2}}{R c_{\alpha 2}}+\frac{(S F) O F_{\beta} A f w_{\alpha 2}}{R f w_{\alpha 2}}+\frac{A g_{\chi 2}}{R g_{\chi 2}}\right] T g_{\beta 2}+\frac{A g_{\chi 2}}{\left(C g_{\beta 2}\right) R a_{\chi 2}} T g_{\chi 2}
\end{aligned}
$$




$$
\begin{aligned}
\frac{d T g_{\chi 1}}{d t}= & \frac{O F_{\chi} A a_{\alpha 1}}{\left(C g_{\chi 1}\right) R a_{\alpha 1}} T a_{\alpha 1}+\frac{(S F) O F_{\chi} A b w_{\alpha 1}}{\left(C g_{\chi 1}\right) R b w_{\alpha 1}} T b w_{\alpha 1}+\frac{O F_{\chi} A c_{\alpha 1}}{\left(C g_{\chi 1}\right) R c_{\alpha 1}} T c_{\alpha 1}+\frac{(S F) O F_{\chi} A s w_{\alpha 1}}{\left(C g_{\chi 1}\right) R s w_{\alpha 1}} T s w_{\alpha 1} \\
& +\frac{(S F) O F_{\chi} A a_{\alpha 2}}{\left(C g_{\chi 1}\right) R a_{\alpha 2}} T a_{\alpha 2}+\frac{(S F) O F_{\chi} A c_{\alpha 2}}{\left(C g_{\chi 1}\right) R c_{\alpha 2}} T c_{\alpha 2}+\frac{(S F) O F_{\chi} A s w_{\alpha 2}}{\left(C g_{\chi 1}\right) R s w_{\alpha 2}} T s w_{\alpha 2}+\frac{(S F) O F_{\chi} A f w_{\alpha 2}}{\left(C g_{\chi 1}\right) R f w_{\alpha 2}} T f w_{\alpha 2} \\
& +\frac{A g_{\beta 1-\chi 1}}{\left(C g_{\chi 1}\right) R g_{\beta 1-\chi 1}} T g_{\beta 1}-\frac{1}{C g_{\chi 1}}\left[\frac{O F_{\chi} A a_{\alpha 1}}{R a_{\alpha 1}}+\frac{(S F) O F_{\chi} A a_{\alpha 2}}{R a_{\alpha 2}}+\frac{(S F) O F_{\chi} A b w_{\alpha 1}}{R b w_{\alpha 1}}+\frac{(S F) O F_{\chi} A s w_{\alpha 1}}{R s w_{\alpha 1}}\right. \\
& +\frac{O F_{\chi} A c_{\alpha 1}}{R c_{\alpha 1}}+\frac{(S F) O F_{\chi} A f w_{\alpha 2}}{R f w_{\alpha 2}}+\frac{(S F) O F_{\chi} A s w_{\alpha 2}}{R s w_{\alpha 2}}+\frac{(S F) O F_{\chi} A c_{\alpha 2}}{R c_{\alpha 2}}+\frac{A g_{\beta 1-\chi 1}}{R g_{\beta 1-\chi 1}}+\frac{A s w_{\chi 1}}{R s w_{\chi 1}} \\
& \left.+\frac{A b w_{\chi 1}}{R b w_{\chi 1}}+\frac{A g_{\chi 1-\chi 2}}{R g_{\chi 1-\chi 2}}+\frac{A g_{\chi 1-\delta 1}}{R g_{\chi 1-\delta 1}}\right] T g_{\chi 1}+\frac{A b w_{\chi 1}}{\left(C g_{\chi 1}\right) R b w_{\chi 1}} T b w_{\chi 1}+\frac{A s w_{\chi 1}}{\left(C g_{\chi 1}\right) R s w_{\chi 1}} T s w_{\chi 1} \\
& +\frac{A g_{\chi 1-\chi 2}}{\left(C g_{\chi 1}\right) R g_{\chi 1-\chi 2}} T g_{\chi 2}+\frac{A g_{\chi 1-\delta 1}}{\left(C g_{\chi 1}\right) R a_{\chi 1-\delta 1}} T g_{\delta 1} \\
\frac{d T b w_{\chi 1}}{d t}= & \frac{A b w_{\alpha 1-\chi 1}}{\left(C b w_{\chi 1}\right) R b w_{\alpha 1-\chi 1}} T b w_{\alpha 1}+\frac{A b w_{\chi 1}}{\left(C b w_{\chi 1}\right) R b w_{\chi 1}} T g_{\chi 1}-\frac{1}{C b w_{\chi 1}}\left[\frac{A b w_{\chi 1}}{R b w_{\chi 1}}\right. \\
& \left.+\frac{A b w_{\alpha 1-\chi 1}}{R b w_{\alpha 1-\chi 1}}+\frac{A b w_{\chi 1}-\delta 1}{R b w_{\chi 1-\delta 1}}+\frac{A b w_{\chi 1-o}}{R b w_{\chi 1-o}}\right] T b w_{\chi 1}+\frac{A b w_{\chi 1}-\delta 1}{\left(C b w_{\chi 1}\right) R b w_{\chi 1-\delta 1}} T b w_{\delta 1} \\
& +\frac{A b w_{\chi 1-o}}{\left(C b w_{\chi 1}\right) R b w_{\chi 1-o}} T o
\end{aligned}
$$




$$
\begin{aligned}
\frac{d T s w_{\chi 1}}{d t}= & \frac{A s w_{\alpha 1-\chi 1}}{\left(C s w_{\chi 1}\right) R s w_{\alpha 1-\chi 1}} T s w_{\alpha 1}+\frac{A s w_{\chi 1}}{\left(C s w_{\chi 1}\right) R s w_{\chi 1}} T g_{\chi 1}-\frac{1}{C s w_{\chi 1}}\left[\frac{A s w_{\chi 1}}{R s w_{\chi 1}}\right. \\
& \left.+\frac{A s w_{\alpha 1-\chi 1}}{R s w_{\alpha 1-\chi 1}}+\frac{A s w_{\chi 1-\chi 2}}{R s w_{\chi 1-\chi 2}}+\frac{A s w_{\chi 1-\delta 1}}{R s w_{\chi 1-\delta 1}}+\frac{A s w_{\chi 1-o}}{R s w_{\chi 1-o}}\right] T s w_{\chi 1}+\frac{A s w_{\chi 1-\chi 2}}{\left(C s w_{\chi 1}\right) R s w_{\chi 1-\chi 2}} T s w_{\chi 2} \\
& +\frac{A s w_{\chi 1-\delta 1}}{\left(C s w_{\chi 1}\right) R s w_{\chi 1-\delta 1}} T s w_{\delta 1}+\frac{A s w_{\chi 1-o}}{\left(C s w_{\chi 1}\right) R s w_{\chi 1-o}} T o
\end{aligned}
$$

\section{$\chi^{2}$}

$$
\begin{aligned}
\frac{d T g_{\chi 2}}{d t}= & \frac{(S F) O F_{\chi} A a_{\alpha 1}}{\left(C g_{\beta 2}\right) R a_{\alpha 1}} T a_{\alpha 1}+\frac{(S F) O F_{\chi} A b w_{\alpha 1}}{\left(C g_{\beta 2}\right) R b w_{\alpha 1}} T b w_{\alpha 1}+\frac{(S F) O F_{\chi} A c_{\alpha 1}}{\left(C g_{\beta 2}\right) R c_{\alpha 1}} T c_{\alpha 1}+\frac{(S F) O F_{\chi} A s w_{\alpha 1}}{\left(C g_{\beta 2}\right) R s w_{\alpha 1}} T s w_{\alpha 1} \\
& +\frac{O F_{\chi} A a_{\alpha 2}}{\left(C g_{\beta 2}\right) R a_{\alpha 2}} T a_{\alpha 2}+\frac{O F_{\chi} A c_{\alpha 2}}{\left(C g_{\beta 2}\right) R c_{\alpha 2}} T c_{\alpha 2}+\frac{(S F) O F_{\chi} A s w_{\alpha 2}}{\left(C g_{\beta 2}\right) R s w_{\alpha 2}} T s w_{\alpha 2}+\frac{(S F) O F_{\chi} A f w_{\alpha 2}}{\left(C g_{\beta 2}\right) R f w_{\alpha 2}} T f w_{\alpha 2} \\
& +\frac{A g_{\beta 2-\chi 2}}{\left(C g_{\chi 2}\right) R g_{\beta 2-\chi 2}} T g_{\beta 2}+\frac{A g_{\chi 1-\chi 2}}{\left(C g_{\chi 2}\right) R g_{\chi 1-\chi 2}} T g_{\chi 1}-\frac{1}{C g_{\chi 2}}\left[\frac{O F_{\chi} A a_{\alpha 2}}{R a_{\alpha 2}}+\frac{(S F) O F_{\chi} A a_{\alpha 1}}{R a_{\alpha 1}}\right. \\
& +\frac{(S F) O F_{\chi} A b w_{\alpha 1}}{R b w_{\alpha 1}}+\frac{(S F) O F_{\chi} A s w_{\alpha 1}}{R s w_{\alpha 1}}+\frac{(S F) O F_{\chi} A c_{\alpha 1}}{R c_{\alpha 1}}+\frac{(S F) O F_{\chi} A s w_{\alpha 2}}{R s w_{\alpha 2}}+\frac{(S F) O F_{\chi} A c_{\alpha 2}}{R c_{\alpha 2}} \\
& \left.+\frac{(S F) O F_{\chi} A f w_{\alpha 2}}{R f w_{\alpha 2}}+\frac{A g_{\chi 1-\chi 2}}{R g_{\chi 1-\chi 2}}+\frac{A g_{\beta 2-\chi 2}}{R g_{\beta 2-\chi 2}}+\frac{A s w_{\chi 2}}{R s w_{\chi 2}}+\frac{A f w_{\chi 2}}{R f w_{\chi 2}}+\frac{A g_{\delta 2}}{R g_{\delta 2}}\right] T g_{\chi 2} \\
& +\frac{A s w_{\chi 2}}{\left(C g_{\chi 2}\right) R s w_{\chi 2}} T s w_{\chi 2}+\frac{A f w_{\chi 2}}{\left(C g_{\chi 2}\right) R f w_{\chi 2}} T f w_{\chi 2}+\frac{A g_{\delta 2}}{\left(C g_{\chi 2}\right) R a_{\delta 2}} T g_{\delta 2}
\end{aligned}
$$




$$
\begin{aligned}
& \frac{d T s w_{\chi 2}}{d t}=\frac{A s w_{\alpha 2-\chi^{2}}}{\left(C s w_{\chi 2}\right) R s w_{\alpha 2-\chi^{2}}} T s w_{\alpha 2}+\frac{A s w_{\chi 1-\chi^{2}}}{\left(C s w_{\chi 2}\right) R s w_{\chi 1-\chi^{2}}} T s w_{\chi 1} \\
& +\frac{A s w_{\chi^{2}}}{\left(C s w_{\chi^{2}}\right) R s w_{\chi^{2}}} T g_{\chi^{2}}-\frac{1}{C s w_{\chi^{2}}}\left[\frac{A s w_{\chi^{2}}}{R s w_{\chi^{2}}}+\frac{A s w_{\chi 1-\chi^{2}}}{R s w_{\chi 1-\chi^{2}}}+\frac{A s w_{\alpha 2-\chi^{2}}}{R s w_{\alpha 2-\chi^{2}}}\right. \\
& \left.+\frac{A s w_{\chi 2-\delta 2}}{R s w_{\chi 2-\delta 2}}+\frac{A s w_{\chi 2-o}}{R s w_{\chi 2-o}}\right] T s w_{\delta 2}+\frac{A s w_{\chi 2-\delta 2}}{\left(C s w_{\chi 2}\right) R s w_{\chi 2-\delta 2}} T s w_{\delta 2}+\frac{A s w_{\chi 2-o}}{\left(C s w_{\chi 2}\right) R s w_{\chi 2-o}} T o \\
& \frac{d T f w_{\chi^{2}}}{d t}=\frac{A f w_{\alpha 2-\chi^{2}}}{\left(C f w_{\chi^{2}}\right) R f w_{\alpha 2-\chi^{2}}} T f w_{\alpha 2}+\frac{A f w_{\chi^{2}}}{\left(C f w_{\chi^{2}}\right) R f w_{\chi^{2}}} T g_{\chi^{2}}-\frac{1}{C f w_{\chi^{2}}}\left[\frac{A f w_{\chi^{2}}}{R f w_{\chi^{2}}}\right. \\
& \left.+\frac{A f w_{\alpha 2-\chi^{2}}}{R f w_{\alpha 2-\chi^{2}}}+\frac{A f w_{\chi 2-\delta 2}}{R f w_{\chi^{2-\delta 2}}}+\frac{A f w_{\chi 2-o}}{R f w_{\chi^{2-o}}}\right] T f w_{\chi^{2}}+\frac{A f w_{\chi 2-\delta 2}}{\left(C f w_{\chi^{2}}\right) R f w_{\chi^{2-\delta 2}}} T f w_{\delta 2}+\frac{A f w_{\chi 2-o}}{\left(C f w_{\chi^{2}}\right) R f w_{\chi^{2-o}}} T o
\end{aligned}
$$




\section{反 1}

$$
\begin{aligned}
\frac{d T g_{\delta 1}}{d t}= & \frac{O F_{\delta} A a_{\alpha 1}}{\left(C g_{\delta 1}\right) R a_{\alpha 1}} T a_{\alpha 1}+\frac{(S F) O F_{\delta} A b w_{\alpha 1}}{\left(C g_{\delta 1}\right) R b w_{\alpha 1}} T b w_{\alpha 1}+\frac{O F_{\delta} A c_{\alpha 1}}{\left(C g_{\delta 1}\right) R c_{\alpha 1}} T c_{\alpha 1} \\
& +\frac{(S F) O F_{\delta} A s w_{\alpha 1}}{\left(C g_{\delta 1}\right) R s w_{\alpha 1}} T s w_{\alpha 1}+\frac{(S F) O F_{\delta} A a_{\alpha 2}}{\left(C g_{\delta 1}\right) R a_{\alpha 2}} T a_{\alpha 2}+\frac{(S F) O F_{\delta} A c_{\alpha 2}}{\left(C g_{\delta 1}\right) R c_{\alpha 2}} T c_{\alpha 2}+\frac{(S F) O F_{\delta} A s w_{\alpha 2}}{\left(C g_{\delta 1}\right) R s w_{\alpha 2}} T s w_{\alpha 2} \\
& +\frac{(S F) O F_{\delta} A f w_{\alpha 2}}{\left(C g_{\delta 1}\right) R f w_{\alpha 2}} T f w_{\alpha 2}+\frac{A g_{\chi 1-\delta 1}}{\left(C g_{\delta 1}\right) R g_{\chi 1-\delta 1}} T g_{\chi 1}-\frac{1}{C g_{\delta 1}}\left[\frac{O F_{\delta} A a_{\alpha 1}}{R a_{\alpha 1}}+\frac{(S F) O F_{\delta} A a_{\alpha 2}}{R a_{\alpha 2}}\right. \\
& +\frac{(S F) O F_{\delta} A b w_{\alpha 1}}{R b w_{\alpha 1}}+\frac{(S F) O F_{\delta} A s w_{\alpha 1}}{R s w_{\alpha 1}}+\frac{O F_{\delta} A c_{\alpha 1}}{R c_{\alpha 1}}+\frac{(S F) O F_{\delta} A f w_{\alpha 2}}{R f w_{\alpha 2}}+\frac{(S F) O F_{\delta} A s w_{\alpha 2}}{R s w_{\alpha 2}}+\frac{(S F) O F_{\delta} A c_{\alpha 2}}{R c_{\alpha 2}} \\
& \left.+\frac{A g_{\chi 1-\delta 1}}{R g_{\chi 1-\delta 1}}+\frac{A s w_{\delta 1}}{R s w_{\delta 1}}+\frac{A b w_{\delta 1}}{R b w_{\delta 1}}+\frac{A g_{\delta 1-\delta 2}}{R g_{\delta 1-\delta 2}}+\frac{A g_{\delta 1}}{R g_{\delta 1}}\right] T g_{\delta 1}+\frac{A s w_{\delta 1}}{\left(C g_{\delta 1}\right) R s w_{\delta 1}} T s w_{\delta 1}+\frac{A b w_{\delta 1}}{\left(C g_{\delta 1}\right) R b w_{\delta 1}} T b w_{\delta 1} \\
+ & \frac{A g_{\delta 1}}{\left(C g_{\delta 1}\right) R a_{\delta 1}} T f l_{\delta 1}+\frac{A g_{\delta 1-\delta 2}}{\left(C g_{\delta 1}\right) R g_{\delta 1-\delta 2}} T g_{\delta 2} \\
\frac{d T b w_{\delta 1}}{d t}= & \frac{A b w_{\chi 1-\delta 1}}{\left(C b w_{\delta 1}\right) R b w_{\chi 1-\delta 1}} T b w_{\chi 1}+\frac{A b w_{\delta 1}}{\left(C b w_{\delta 1}\right) R b w_{\delta 1}} T g_{\delta 1} \\
& -\frac{1}{C b w_{\delta 1}}\left[\frac{A b w_{\delta 1}}{R b w_{\delta 1}}+\frac{A b w_{\chi 1-\delta 1}}{R b w_{\chi 1-\delta 1}}+\frac{A b w_{\delta 1-o}}{R b w_{\delta 1-o}}\right] T b w_{\delta 1}+\frac{A b w_{\delta 1-o}}{\left(C b w_{\delta 1}\right) R b w_{\delta 1-o}} T o
\end{aligned}
$$




$$
\begin{aligned}
\frac{d T s w_{\delta 1}}{d t} & =\frac{A s w_{\chi 1-\delta 1}}{\left(C s w_{\delta 1}\right) R s w_{\chi 1-\delta 1}} T s w_{\chi 1}+\frac{A s w_{\delta 1}}{\left(C s w_{\delta 1}\right) R s w_{\delta 1}} T g_{\delta 1} \\
& -\frac{1}{C s w_{\delta 1}}\left[\frac{A s w_{\delta 1}}{R s w_{\delta 1}}+\frac{A s w_{\chi 1-\delta 1}}{R s w_{\chi 1-\delta 1}}+\frac{A s w_{\delta 1-\delta 2}}{R s w_{\delta 1-\delta 2}}+\frac{A s w_{\delta 1-o}}{R s w_{\delta 1-o}}\right] T s w_{\delta 1} \\
& +\frac{A s w_{\delta 1-\delta 2}}{\left(C s w_{\delta 1}\right) R s w_{\delta 1-\delta 2}} T s w_{\delta 2}+\frac{A s w_{\delta 1-o}}{\left(C s w_{\delta 1}\right) R s w_{\delta 1-o}} T o \\
\frac{d T f l_{\delta 1}}{d t}= & \frac{A f l_{\delta 1}}{\left(C f l_{\delta 1}\right) R f l_{\delta 1}} T g_{\delta 1}-\frac{1}{C f l_{\delta 1}}\left[\frac{A f l_{\delta 1}}{R f l_{\delta 1}}+\frac{A f l_{\delta 1-\delta 2}}{R f l_{\delta 1-\delta 2}}+\frac{A f l_{\delta 1-o}}{R f l_{\delta 1-o}}\right] T f l_{\delta 1} \\
& +\frac{A f l_{\delta 1-\delta 2}}{\left(C f l_{\delta 1}\right) R f l_{\delta 1-\delta 2}} T f w_{\delta 2}+\frac{A f l_{\delta 1-o}}{\left(C f l_{\delta 1}\right) R f l_{\delta 1-o}} T o
\end{aligned}
$$




\section{反 2}

$$
\begin{aligned}
\frac{d T g_{\delta 2}}{d t}= & \frac{(S F) O F_{\delta} A a_{\alpha 1}}{\left(C g_{\beta 2}\right) R a_{\alpha 1}} T a_{\alpha 1}+\frac{(S F) O F_{\delta} A b w_{\alpha 1}}{\left(C g_{\beta 2}\right) R b w_{\alpha 1}} T b w_{\alpha 1}+\frac{(S F) O F_{\delta} A c_{\alpha 1}}{\left(C g_{\beta 2}\right) R c_{\alpha 1}} T c_{\alpha 1} \\
& +\frac{(S F) O F_{\delta} A s w_{\alpha 1}}{\left(C g_{\beta 2}\right) R s w_{\alpha 1}} T s w_{\alpha 1}+\frac{O F_{\delta} A a_{\alpha 2}}{\left(C g_{\beta 2}\right) R a_{\alpha 2}} T a_{\alpha 2}+\frac{O F_{\delta} A c_{\alpha 2}}{\left(C g_{\beta 2}\right) R c_{\alpha 2}} T c_{\alpha 2}+\frac{(S F) O F_{\delta} A s w_{\alpha 2}}{\left(C g_{\beta 2}\right) R s w_{\alpha 2}} T s w_{\alpha 2} \\
& +\frac{(S F) O F_{\delta} A f w_{\alpha 2}}{\left(C g_{\beta 2}\right) R f w_{\alpha 2}} T f w_{\alpha 2}+\frac{A g_{\chi 2-\delta 2}}{\left(C g_{\varepsilon 2}\right) R g_{\chi 2-\delta 2}} T g_{\chi 2}+\frac{A g_{\delta 1-\delta 2}}{\left(C g_{\delta 2}\right) R g_{\delta 1-\delta 2}} T g_{\delta 1} \\
& -\frac{1}{C g_{\delta 2}}\left[\frac{O F_{\delta} A a_{\alpha 2}}{R a_{\alpha 2}}+\frac{(S F) O F_{\delta} A a_{\alpha 1}}{R a_{\alpha 1}}+\frac{(S F) O F_{\delta} A b w_{\alpha 1}}{R b w_{\alpha 1}}+\frac{(S F) O F_{\delta} A s w_{\alpha 1}}{R s w_{\alpha 1}}+\frac{(S F) O F_{\delta} A c_{\alpha 1}}{R c_{\alpha 1}}\right. \\
& +\frac{(S F) O F_{\delta} A s w_{\alpha 2}}{R s w_{\alpha 2}}+\frac{(S F) O F_{\delta} A c_{\alpha 2}}{R c_{\alpha 2}}+\frac{(S F) O F_{\delta} A f w_{\alpha 2}}{R f w_{\alpha 2}}+\frac{A g_{\delta 1-\delta 2}}{R g_{\delta 1-\delta 2}}+\frac{A g_{\chi 2-\delta 2}}{R g_{\chi 2-\delta 2}}+\frac{A s w_{\delta 2}}{R s w_{\delta 2}} \\
& \left.+\frac{A f w_{\delta 2}}{R f w_{\delta 2}}+\frac{A f l_{\delta 2}}{R f l_{\delta 2}}\right] T g_{\delta 2}+\frac{A s w_{\delta 2}}{\left(C g_{\delta 2}\right) R s w_{\delta 2}} T s w_{\delta 2}+\frac{A f w_{\delta 2}}{\left(C g_{\delta 2}\right) R f w_{\delta 2}} T f w_{\delta 2}+\frac{A f l_{\delta 2}}{\left(C g_{\delta 2}\right) R f l_{\delta 2}} T f l_{\delta 2} \\
\frac{d T s w_{\delta 2}}{d t}= & \frac{A s w_{\chi 2-\delta 2}}{\left(C s w_{\delta 2}\right) R s w_{\chi 2-\delta 2}} T s w_{\chi 2}+\frac{A s w_{\delta 1-\delta 2}}{\left(C s w_{\delta 2}\right) R s w_{\delta 1-\delta 2}} T s w_{\delta 1} \\
& +\frac{A s w_{\delta 2}}{\left(C s w_{\delta 2}\right) R s w_{\delta 2}} T g_{\delta 2}-\frac{1}{C s w_{\delta 2}}\left[\frac{A s w_{\delta 2}}{R s w_{\delta 2}}+\frac{A s w_{\delta 1-\delta 2}}{R s w_{\delta 1-\delta 2}}+\frac{A s w_{\chi 2-\delta 2}}{R s w_{\chi 2-\delta 2}}+\frac{A s w_{\delta 2-o}}{R s w_{\delta 2-o}}\right] T s w_{\delta 2} \\
& +\frac{A s w_{\delta 2-o}}{\left(C s w_{\delta 2}\right) R s w_{\delta 2-o}} T o
\end{aligned}
$$




$$
\begin{aligned}
\frac{d T f w_{\delta 2}}{d t}= & \frac{A f w_{\chi 2-\delta 2}}{\left(C f w_{\delta 2}\right) R f w_{\chi 2-\delta 2}} T f w_{\chi 2}+\frac{A f w_{\delta 2}}{\left(C f w_{\delta 2}\right) R f w_{\delta 2}} T g_{\delta 2} \\
& -\frac{1}{C f w_{\delta 2}}\left[\frac{A f w_{\delta 2}}{R f w_{\delta 2}}+\frac{A f w_{\chi 2-\delta 2}}{R f w_{\chi 2-\delta 2}}+\frac{A f w_{\delta 2-o}}{R f w_{\delta 2-o}}\right] T f w_{\delta 2}+\frac{A f w_{\delta 2-o}}{\left(C f w_{\delta 2}\right) R f w_{\delta 2-o}} T o \\
\frac{d T f l_{\delta 2}}{d t}= & \frac{A f l_{\delta 1-\delta 2}}{\left(C f l_{\delta 2}\right) R f w_{\delta 1-\delta 2}} T f l_{\delta 1}+\frac{A f l_{\delta 2}}{\left(C f l_{\delta 2}\right) R f l_{\delta 2}} T g_{\delta 2} \\
& -\frac{1}{C f l_{\delta 2}}\left[\frac{A f l_{\delta 2}}{R f l_{\delta 2}}+\frac{A f l_{\delta 1-\delta 2}}{R f l_{\delta 1-\delta 2}}+\frac{A f l_{\varepsilon 2-o}}{R f l_{\delta 2-o}}\right] T f l_{\delta 2}+\frac{A f l_{\delta 2-o}}{\left(C f l_{\delta 2}\right) R f l_{\delta 2-o}} T o
\end{aligned}
$$




\section{Appendix B - State Matrices}

Table 6.1-A: Matrix A First Twelve Columns

\begin{tabular}{|c|c|c|c|c|c|c|c|c|c|c|c|}
\hline $3.05 \mathrm{E}+01$ & $4.20 \mathrm{E}-01$ & $8.40 \mathrm{E}-01$ & 5.64E-01 & $2.78 \mathrm{E}+01$ & 0 & 0 & 0 & $1.51 \mathrm{E}-01$ & $3.25 \mathrm{E}-03$ & $1.26 \mathrm{E}-01$ & 0 \\
\hline $1.09 \mathrm{E}-04$ & $-2.82 \mathrm{E}-04$ & 0 & 0 & 0 & 0 & 0 & 0 & $1.76 \mathrm{E}-05$ & $8.14 \mathrm{E}-07$ & $1.47 \mathrm{E}-05$ & $6.58 \mathrm{E}-05$ \\
\hline $1.09 \mathrm{E}-04$ & 0 & $-3.49 \mathrm{E}-04$ & 0 & 0 & $7.88 \mathrm{E}-05$ & 0 & 0 & $2.38 \mathrm{E}-05$ & $4.31 \mathrm{E}-06$ & $1.98 \mathrm{E}-05$ & 0 \\
\hline $1.09 \mathrm{E}-04$ & 0 & 0 & $-3.70 \mathrm{E}-04$ & 0 & 0 & 7.90E-05 & 0 & $1.80 \mathrm{E}-05$ & $1.94 \mathrm{E}-06$ & $1.50 \mathrm{E}-05$ & 0 \\
\hline $5.56 \mathrm{E}+01$ & 0 & 0 & 0 & $-5.88 \mathrm{E}+01$ & 8.19E-01 & $5.51 \mathrm{E}-01$ & 8.40E-01 & $1.75 \mathrm{E}-02$ & $1.47 \mathrm{E}-01$ & $1.46 \mathrm{E}-02$ & 0 \\
\hline 0 & 0 & $1.61 \mathrm{E}-04$ & 0 & $1.09 \mathrm{E}-04$ & $-4.15 \mathrm{E}-04$ & 0 & 0 & 8.83E-06 & $1.62 \mathrm{E}-05$ & 7.36E-06 & 0 \\
\hline 0 & 0 & 0 & $1.62 \mathrm{E}-04$ & $1.09 \mathrm{E}-04$ & 0 & $-4.44 \mathrm{E}-04$ & 0 & $3.98 \mathrm{E}-06$ & $1.44 \mathrm{E}-05$ & $3.32 \mathrm{E}-06$ & 0 \\
\hline 0 & 0 & 0 & 0 & $1.09 \mathrm{E}-04$ & 0 & 0 & $-2.47 \mathrm{E}-04$ & $1.39 \mathrm{E}-05$ & 5.33E-05 & 0 & 0 \\
\hline $7.20 \mathrm{E}-04$ & $3.24 \mathrm{E}-04$ & 8.74E-04 & $4.44 \mathrm{E}-04$ & $4.17 \mathrm{E}-05$ & $1.58 \mathrm{E}-04$ & $4.80 \mathrm{E}-05$ & 4.59E-05 & $-3.46 \mathrm{E}-03$ & 0 & 8.00E-04 & 0 \\
\hline $3.10 \mathrm{E}-05$ & 2.99E-05 & $3.17 \mathrm{E}-04$ & $9.56 \mathrm{E}-05$ & 7.02E-04 & $5.81 \mathrm{E}-04$ & $3.48 \mathrm{E}-04$ & $3.53 \mathrm{E}-04$ & 0 & $-3.24 \mathrm{E}-03$ & $7.81 \mathrm{E}-04$ & 0 \\
\hline $4.95 \mathrm{E}-05$ & $2.23 \mathrm{E}-05$ & $6.01 \mathrm{E}-05$ & $3.06 \mathrm{E}-05$ & $2.87 \mathrm{E}-06$ & $1.09 \mathrm{E}-05$ & $3.30 \mathrm{E}-06$ & $3.16 \mathrm{E}-06$ & 6.61E-05 & 0 & $-7.96 \mathrm{E}-04$ & $1.35 \mathrm{E}-04$ \\
\hline 0 & $2.70 \mathrm{E}-04$ & 0 & 0 & 0 & 0 & 0 & 0 & 0 & 0 & $3.64 \mathrm{E}-04$ & $-7.46 \mathrm{E}-04$ \\
\hline 0 & 0 & 0 & 2.71E-04 & 0 & 0 & 0 & 0 & 0 & 0 & $3.66 \mathrm{E}-04$ & 0 \\
\hline $2.19 \mathrm{E}-06$ & $2.11 \mathrm{E}-06$ & $2.23 \mathrm{E}-05$ & $6.74 \mathrm{E}-06$ & $4.96 \mathrm{E}-05$ & $4.10 \mathrm{E}-05$ & $2.45 \mathrm{E}-05$ & 2.49E-05 & 0 & $6.61 \mathrm{E}-05$ & 2.01E-04 & 0 \\
\hline 0 & 0 & 0 & 0 & 0 & 0 & 2.71E-04 & 0 & 0 & 0 & 0 & 0 \\
\hline 0 & 0 & 0 & 0 & 0 & 0 & 0 & $2.70 \mathrm{E}-04$ & 0 & 0 & 0 & 0 \\
\hline $2.21 \mathrm{E}-04$ & $9.98 \mathrm{E}-05$ & 2.69E-04 & $1.37 \mathrm{E}-04$ & $1.28 \mathrm{E}-05$ & $4.87 \mathrm{E}-05$ & $1.48 \mathrm{E}-05$ & $1.41 \mathrm{E}-05$ & 0 & 0 & $1.32 \mathrm{E}-04$ & 0 \\
\hline 0 & 0 & 0 & 0 & 0 & 0 & 0 & 0 & 0 & 0 & 0 & $1.06 \mathrm{E}-04$ \\
\hline 0 & 0 & 0 & 0 & 0 & 0 & 0 & 0 & 0 & 0 & 0 & 0 \\
\hline 0 & 0 & 0 & 0 & 0 & 0 & 0 & 0 & 0 & 0 & 0 & 0 \\
\hline $9.76 \mathrm{E}-06$ & $9.43 \mathrm{E}-06$ & $9.98 \mathrm{E}-05$ & $3.01 \mathrm{E}-05$ & $2.21 \mathrm{E}-04$ & $1.83 \mathrm{E}-04$ & $1.10 \mathrm{E}-04$ & $1.11 \mathrm{E}-04$ & 0 & 0 & 0 & 0 \\
\hline 0 & 0 & 0 & 0 & 0 & 0 & 0 & 0 & 0 & 0 & 0 & 0 \\
\hline 0 & 0 & 0 & 0 & 0 & 0 & 0 & 0 & 0 & 0 & 0 & 0 \\
\hline 0 & 0 & 0 & 0 & 0 & 0 & 0 & 0 & 0 & 0 & 0 & 0 \\
\hline
\end{tabular}




\begin{tabular}{|c|c|c|c|c|c|c|c|c|c|c|c|}
\hline 0 & $2.71 \mathrm{E}-03$ & 0 & 0 & $5.63 \mathrm{E}-01$ & 0 & 0 & 0 & $1.21 \mathrm{E}-02$ & 0 & 0 & 0 \\
\hline 0 & $6.78 \mathrm{E}-07$ & 0 & 0 & $6.56 \mathrm{E}-05$ & 0 & 0 & 0 & $3.03 \mathrm{E}-06$ & 0 & 0 & 0 \\
\hline 0 & $3.59 \mathrm{E}-06$ & 0 & 0 & $8.85 \mathrm{E}-05$ & 0 & 0 & 0 & $1.60 \mathrm{E}-05$ & 0 & 0 & 0 \\
\hline $6.59 \mathrm{E}-05$ & $1.61 \mathrm{E}-06$ & 0 & 0 & $6.70 \mathrm{E}-05$ & 0 & 0 & 0 & $7.20 \mathrm{E}-06$ & 0 & 0 & 0 \\
\hline 0 & $1.23 \mathrm{E}-01$ & 0 & 0 & $6.51 \mathrm{E}-02$ & 0 & 0 & 0 & $5.49 \mathrm{E}-01$ & 0 & 0 & 0 \\
\hline 0 & $1.35 \mathrm{E}-05$ & 0 & 0 & $3.29 \mathrm{E}-05$ & 0 & 0 & 0 & $6.04 \mathrm{E}-05$ & 0 & 0 & 0 \\
\hline 0 & $1.20 \mathrm{E}-05$ & $6.59 \mathrm{E}-05$ & 0 & $1.48 \mathrm{E}-05$ & 0 & 0 & 0 & $5.37 \mathrm{E}-05$ & 0 & 0 & 0 \\
\hline 0 & 0 & 0 & $6.58 \mathrm{E}-05$ & 0 & 0 & 0 & 0 & 0 & 0 & 0 & 0 \\
\hline 0 & 0 & 0 & 0 & 0 & 0 & 0 & 0 & 0 & 0 & 0 & 0 \\
\hline 0 & 0 & 0 & 0 & 0 & 0 & 0 & 0 & 0 & 0 & 0 & 0 \\
\hline $1.81 \mathrm{E}-04$ & $9.82 \mathrm{E}-05$ & 0 & 0 & $1.32 \mathrm{E}-04$ & 0 & 0 & 0 & 0 & 0 & 0 & 0 \\
\hline 0 & 0 & 0 & 0 & 0 & $1.06 \mathrm{E}-04$ & 0 & 0 & 0 & 0 & 0 & 0 \\
\hline$-8.26 \mathrm{E}-04$ & $\begin{array}{ll}40 \\
\end{array}$ & $7.92 \mathrm{E}-05$ & 0 & 0 & 0 & $1.06 \mathrm{E}-04$ & 0 & 0 & 0 & 0 & 0 \\
\hline 0 & $-1.03 \mathrm{E}-03$ & $31.81 \mathrm{E}-04$ & $2.76 \mathrm{E}-04$ & 0 & 0 & 0 & 0 & $1.32 \mathrm{E}-04$ & 0 & 0 & 0 \\
\hline $1.63 \mathrm{E}-04$ & $3.66 \mathrm{E}-04$ & $-9.11 \mathrm{E}-04$ & 0 & 0 & 0 & 0 & 0 & 0 & $1.06 \mathrm{E}-04$ & 0 & 0 \\
\hline 0 & 3.64E-04 & 0 & $-7.46 \mathrm{E}-04$ & & 0 & 0 & 0 & 0 & 0 & $1.06 \mathrm{E}-04$ & 0 \\
\hline 0 & 0 & 0 & 0 & $-2.47 \mathrm{E}-03$ & $31.35 \mathrm{E}-04$ & $1.82 \mathrm{E}-04$ & $1.11 \mathrm{E}-03$ & 9.83E-05 & 0 & 0 & 0 \\
\hline 0 & 0 & 0 & 0 & $3.64 \mathrm{E}-04$ & $-4.76 \mathrm{E}-04$ & 0 & 0 & 0 & 0 & 0 & 0 \\
\hline $1.06 \mathrm{E}-04$ & 0 & 0 & 0 & $3.66 \mathrm{E}-04$ & 0 & $-5.56 \mathrm{E}-04$ & 40 & 0 & 7.92E-05 & 0 & 0 \\
\hline 0 & 0 & 0 & 0 & $3.65 \mathrm{E}-04$ & 0 & 0 & $-4.08 \mathrm{E}-04$ & 0 & 0 & 0 & $3.87 \mathrm{E}-05$ \\
\hline 0 & $1.32 \mathrm{E}-04$ & 0 & 0 & $2.01 \mathrm{E}-04$ & 0 & 0 & 0 & $-2.67 \mathrm{E}-03$ & $1.81 \mathrm{E}-04$ & $2.76 \mathrm{E}-04$ & $1.11 \mathrm{E}-03$ \\
\hline 0 & 0 & $1.06 \mathrm{E}-04$ & 0 & 0 & 0 & $1.63 \mathrm{E}-04$ & 0 & $3.66 \mathrm{E}-04$ & $-6.40 \mathrm{E}-04$ & & 0 \\
\hline 0 & 0 & 0 & $1.06 \mathrm{E}-04$ & 0 & 0 & 0 & 0 & $3.64 \mathrm{E}-04$ & 0 & $-4.76 \mathrm{E}-04$ & \\
\hline 0 & 0 & 0 & 0 & 0 & 0 & 0 & $1.61 \mathrm{E}-04$ & $3.65 \mathrm{E}-04$ & 0 & 0 & $-5.31 \mathrm{E}-04$ \\
\hline
\end{tabular}


Table 6.1-C: Matrix B

\begin{tabular}{|l|l|}
\hline 5 & 0 \\
\hline 0 & $5.25 \mathrm{E}-06$ \\
\hline 0 & $5.25 \mathrm{E}-06$ \\
\hline 0 & $5.24 \mathrm{E}-06$ \\
\hline 0 & 0 \\
\hline 0 & $5.25 \mathrm{E}-06$ \\
\hline 0 & $5.25 \mathrm{E}-06$ \\
\hline 0 & $5.25 \mathrm{E}-06$ \\
\hline 0 & 0 \\
\hline 0 & 0 \\
\hline 0 & 0 \\
\hline 0 & $5.24 \mathrm{E}-06$ \\
\hline 0 & $5.26 \mathrm{E}-06$ \\
\hline 0 & 0 \\
\hline 0 & $5.26 \mathrm{E}-06$ \\
\hline 0 & $5.24 \mathrm{E}-06$ \\
\hline 0 & 0 \\
\hline 0 & $5.24 \mathrm{E}-06$ \\
\hline 0 & $5.26 \mathrm{E}-06$ \\
\hline 0 & $5.25 \mathrm{E}-06$ \\
\hline 0 & 0 \\
\hline 0 & $5.26 \mathrm{E}-06$ \\
\hline 0 & $5.24 \mathrm{E}-06$ \\
\hline 0 & $5.25 \mathrm{E}-06$ \\
\hline & \\
\hline
\end{tabular}


Matrix C

First Twelve Columns

Table 6.1-D: Matrix C First Twelve Columns

\begin{tabular}{|l|l|l|l|l|l|l|l|l|l|l|l|l|}
\hline 0 & 0 & 0 & 0 & 0 & 0 & 0 & 0 & 0 & 0 & 0 & 0 \\
\hline 0 & 0 & 0 & 0 & 1 & 0 & 0 & 0 & 0 & 0 & 0 & 0 \\
\hline 0 & 0 & 0 & 0 & 0 & 0 & 0 & 0 & 0 & 1 & 0 & 0 \\
\hline 0 & 0 & 0 & 0 & 0 & 0 & 0 & 0 & 0 & 0 & 0 & 0 \\
\hline 0 & 0 & 0 & 0 & 0 & 0 & 0 & 0 & 0 & 0 & 0 & 0 \\
\hline 0 & 0 & 0 & 0 & 0 & 0 & 0 & 0 & 0 & 0 & 0 & 0 \\
\hline
\end{tabular}

Second Twelve Columns

Table 6.1-E: Matrix C Second Twelve Columns

\begin{tabular}{|l|l|l|l|l|l|l|l|l|l|l|l|}
\hline 0 & 1 & 0 & 0 & 0 & 0 & 0 & 0 & 0 & 0 & 0 & 0 \\
\hline 0 & 0 & 0 & 0 & 0 & 0 & 0 & 0 & 0 & 0 & 0 & 0 \\
\hline 0 & 0 & 0 & 0 & 0 & 0 & 0 & 0 & 0 & 0 & 0 & 0 \\
\hline 0 & 1 & 0 & 0 & 0 & 0 & 0 & 0 & 0 & 0 & 0 & 0 \\
\hline 0 & 0 & 0 & 0 & 0 & 0 & 0 & 0 & 1 & 0 & 0 & 0 \\
\hline 0 & 0 & 0 & 0 & 0 & 0 & 0 & 0 & 0 & 0 & 0 & 1 \\
\hline
\end{tabular}


Matrix D

\section{Table 6.1-F: Matrix D}

\begin{tabular}{|l|l|}
\hline 0 & 0 \\
\hline 0 & 0 \\
\hline 0 & 0 \\
\hline 0 & 0 \\
\hline 0 & 0 \\
\hline 0 & 0 \\
\hline
\end{tabular}

The arrangement of $\mathrm{C}$ and $\mathrm{D}$ is for an output of the following six temperatures:
1) $\operatorname{Tg}_{x^{2}}$ - for the controller
2) $\mathrm{Ta}_{\alpha 2}$ - for display
3) $\operatorname{Tg}_{\beta 2}$ - for display
4) $\operatorname{Tg}_{\chi_{2}}$ - for display
5) $\operatorname{Tg}_{\delta 2}$ - for display
6) $\mathrm{Tfl}_{\delta 2}-$ for display 


\section{Appendix C - Model Plots and Tables}

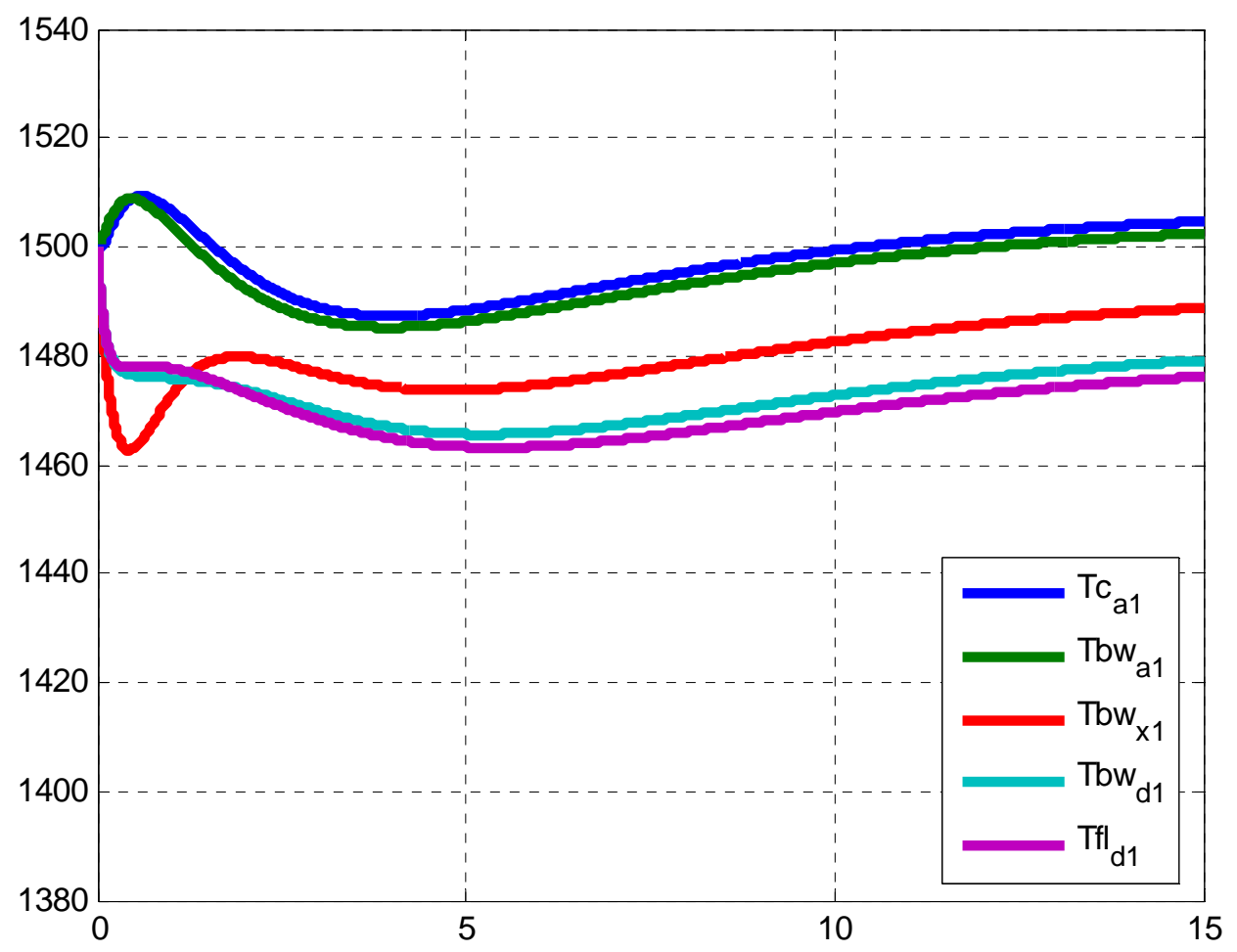

Figure 6.1-A: Back Profile Temperatures during the Melt Cycle

Table 6.1-A: Back Profile Temperatures at Steady State

\begin{tabular}{|c|c|}
\hline Location & $\begin{array}{c}\text { Temperature } \\
(\mathbf{K})\end{array}$ \\
\hline $\mathrm{Tc}_{\alpha 1}$ & 1505 \\
\hline $\mathrm{Tbw}_{\alpha 1}$ & 1504 \\
\hline $\mathrm{Tbw}_{1}$ & 1489 \\
\hline $\mathrm{Tbw}_{\delta 1}$ & 1479 \\
\hline $\mathrm{Tfl}_{\delta 1}$ & 1476 \\
\hline
\end{tabular}




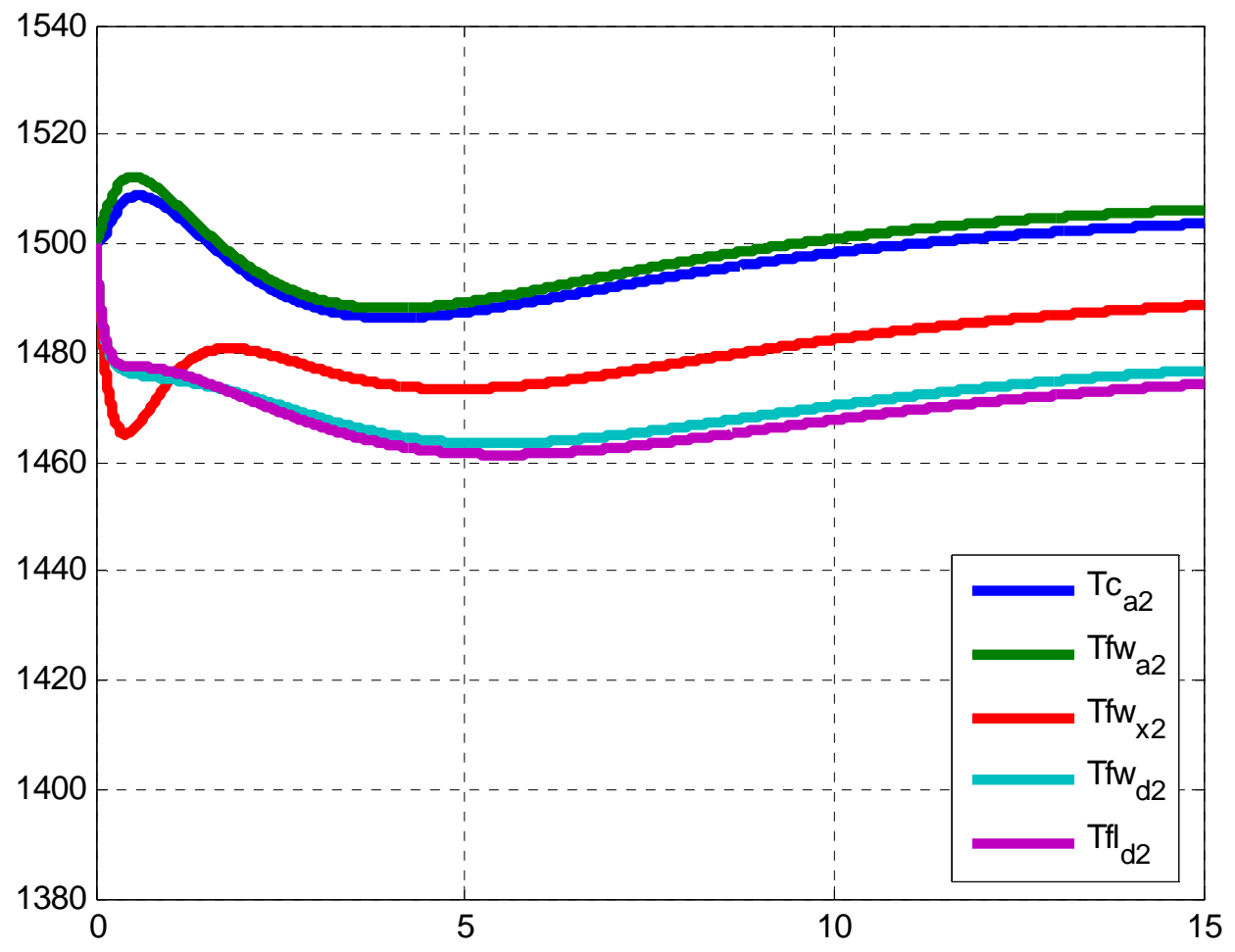

Figure 6.1-B: Front Profile Temperatures during the Melt Cycle

Table 6.1-B: Front Profile Temperatures at Steady State

\begin{tabular}{|c|c|}
\hline Location & $\begin{array}{c}\text { Temperature } \\
(\mathbf{K})\end{array}$ \\
\hline $\mathrm{Tc}_{\alpha 2}$ & 1504 \\
\hline $\mathrm{Tfw}_{\alpha 2}$ & 1506 \\
\hline $\mathrm{Tfw}_{2}$ & 1489 \\
\hline $\mathrm{Tfw}_{\delta 2}$ & 1477 \\
\hline $\mathrm{Tfl}_{\delta 2}$ & 1474 \\
\hline
\end{tabular}




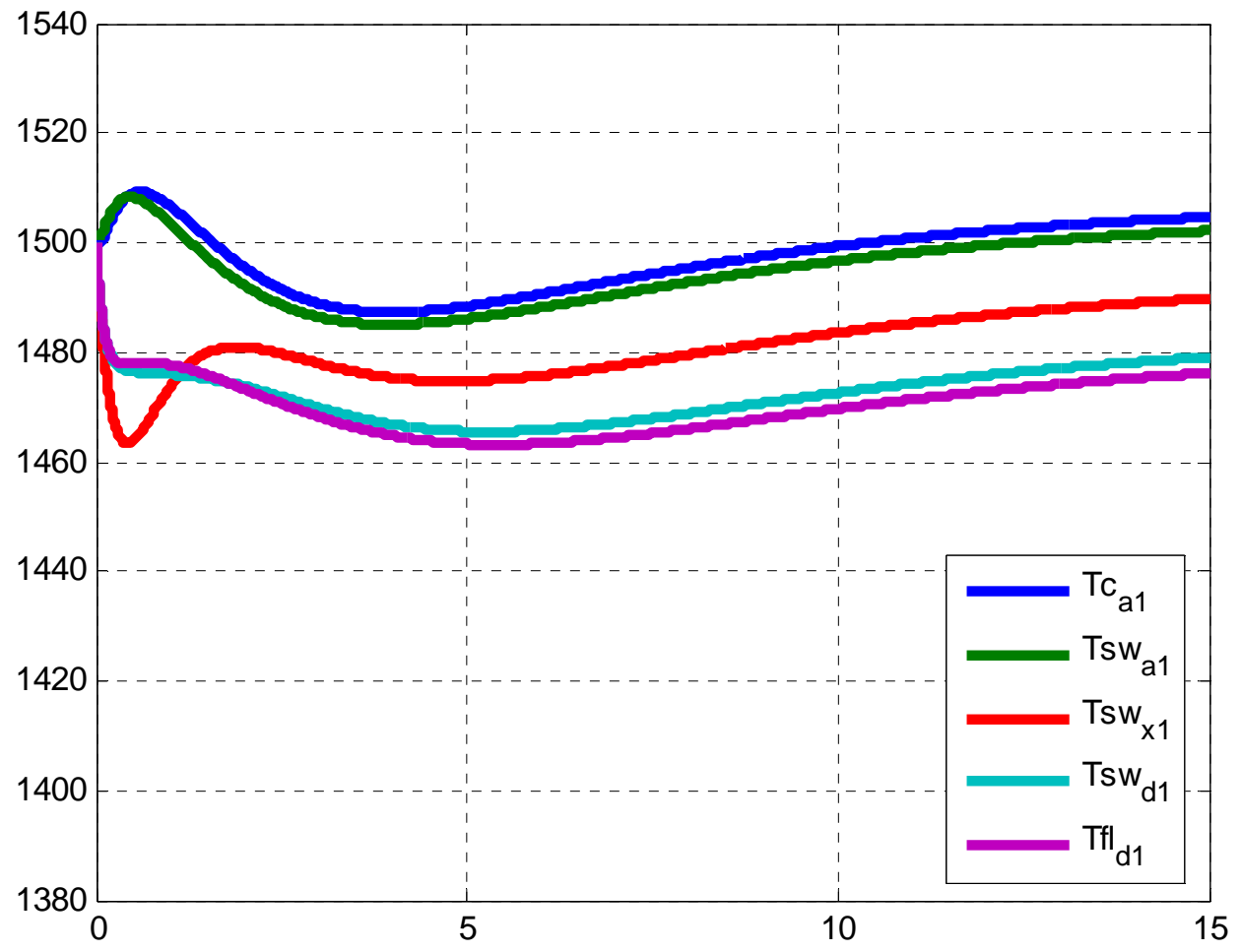

Figure 6.1-C: Side Profile Temperatures near the Flame during the Melt Cycle

Table 6.1-C: Side Profile Temperatures near the Flame at Steady State

\begin{tabular}{|c|c|}
\hline Location & $\begin{array}{c}\text { Temperature } \\
(\mathbf{K})\end{array}$ \\
\hline $\mathrm{Tc}_{\alpha 1}$ & 1505 \\
\hline $\mathrm{Tsw}_{\alpha 1}$ & 1502 \\
\hline $\mathrm{Tsw}_{1}$ & 1490 \\
\hline $\mathrm{Tsw}_{\delta 1}$ & 1479 \\
\hline $\mathrm{Tfl}_{\delta 1}$ & 1476 \\
\hline
\end{tabular}




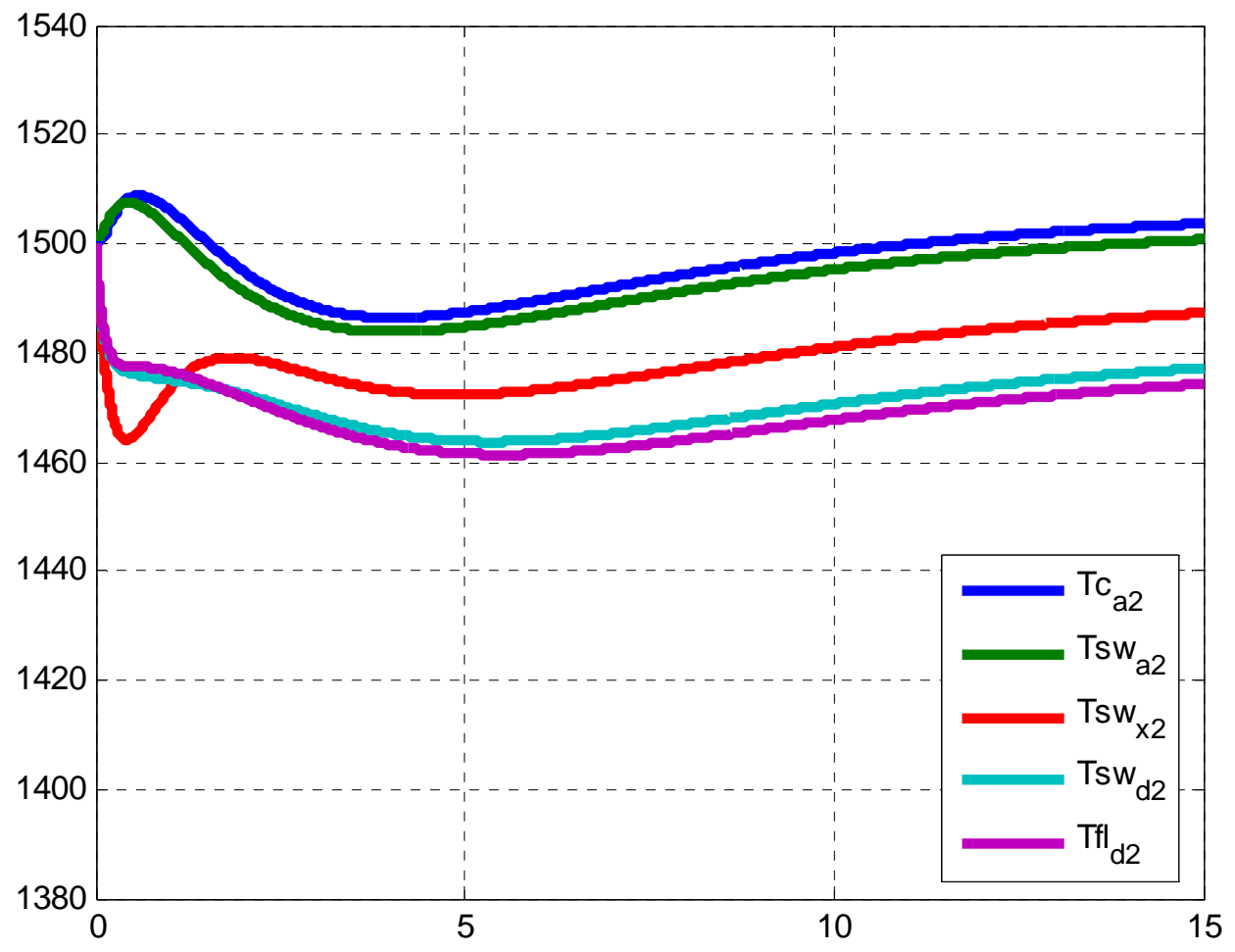

Figure 6.1-D: Side Profile Temperatures away from the Flame during the Melt Cycle

Table 6.1-D: Side Profile Temperatures away from the Flame at Steady State

\begin{tabular}{|c|c|}
\hline Location & $\begin{array}{c}\text { Temperature } \\
(\mathbf{K})\end{array}$ \\
\hline $\mathrm{Tc}_{\alpha 2}$ & 1504 \\
\hline $\mathrm{Tsw}_{\alpha 2}$ & 1501 \\
\hline $\mathrm{Tsw}_{2}$ & 1487 \\
\hline $\mathrm{Tsw}_{\delta 2}$ & 1477 \\
\hline $\mathrm{Tfw}_{\delta 2}$ & 1474 \\
\hline
\end{tabular}




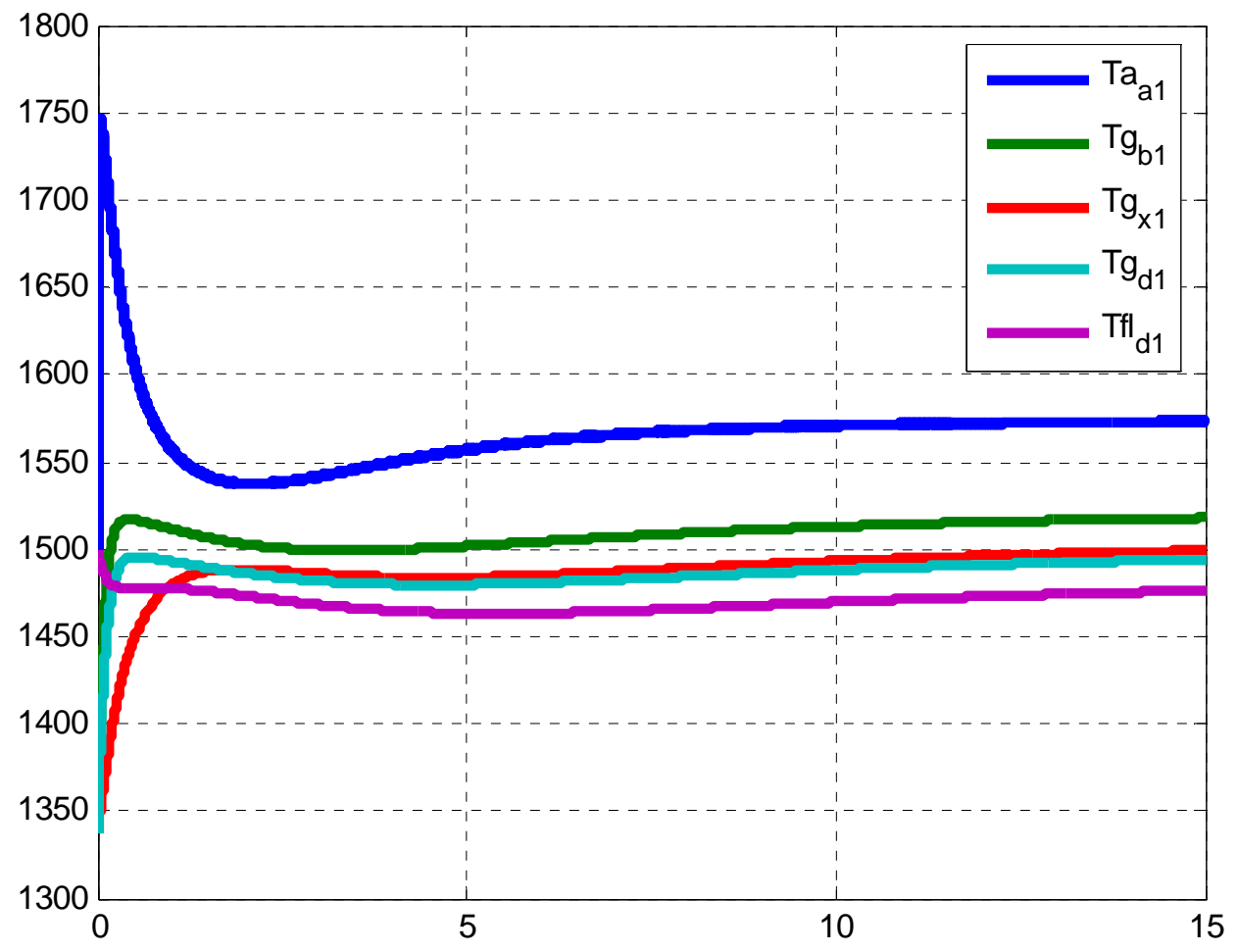

Figure 6.1-E: Glass Temperatures near the Flame during the Melt Cycle

Table 6.1-E: Glass Temperatures near the Flame at Steady State

\begin{tabular}{|c|c|}
\hline Location & $\begin{array}{c}\text { Temperature } \\
(\mathbf{K})\end{array}$ \\
\hline $\mathrm{Ta}_{\alpha 1}$ & 1573 \\
\hline $\mathrm{Tg}_{\beta 1}$ & 1518 \\
\hline $\mathrm{Tg}_{\chi 1}$ & 1499 \\
\hline $\mathrm{Tg}_{\delta 1}$ & 1494 \\
\hline $\mathrm{Tfl}_{\delta 1}$ & 1476 \\
\hline
\end{tabular}




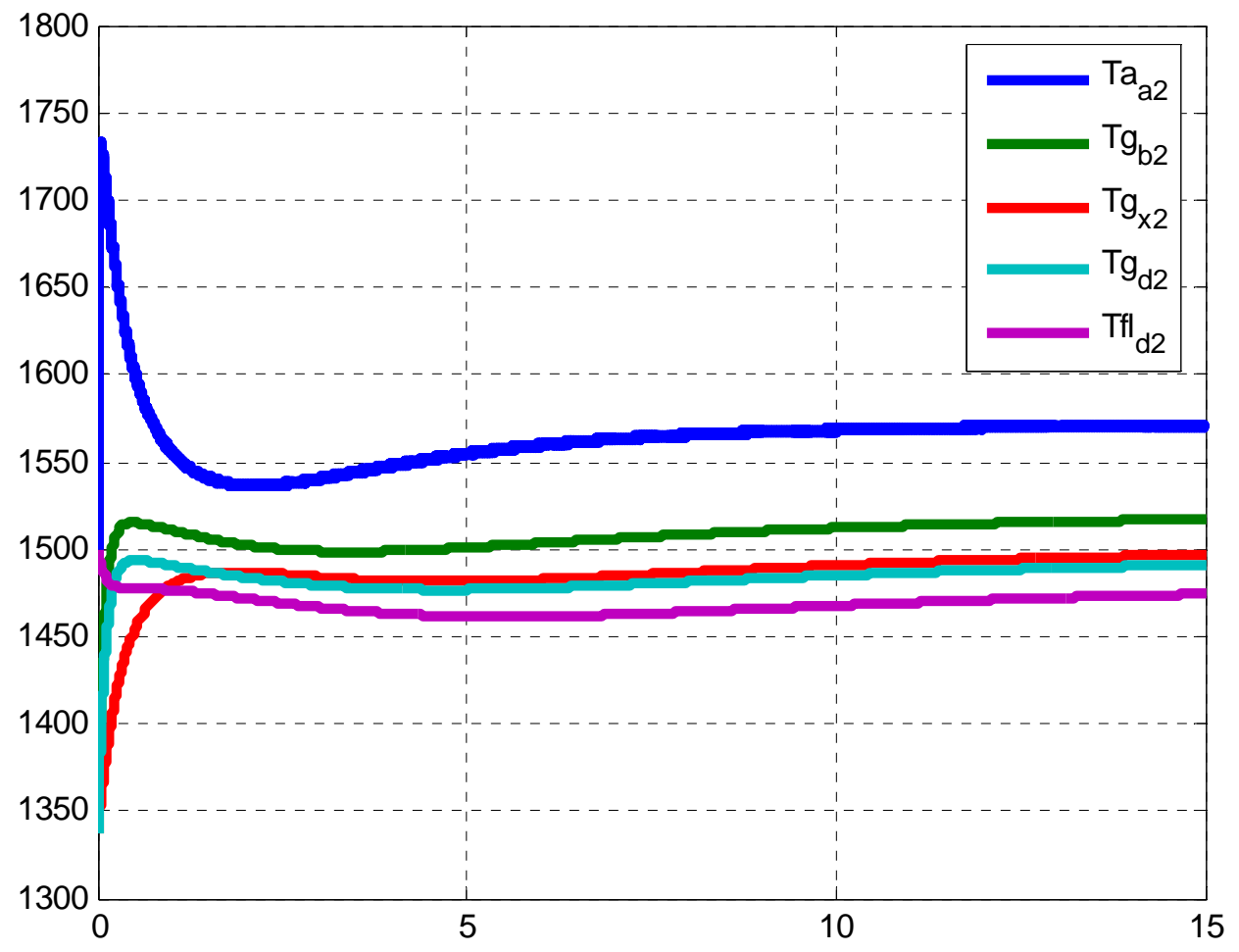

Figure 6.1-F: Glass Temperatures away from the Flame during the Melt Cycle

Table 6.1-F: Glass Temperatures away from the Flame at Steady State

\begin{tabular}{|c|c|}
\hline Location & $\begin{array}{c}\text { Temperature } \\
(\mathbf{K})\end{array}$ \\
\hline $\mathrm{Ta}_{\alpha 2}$ & 1570 \\
\hline $\mathrm{Tg}_{\beta 2}$ & 1517 \\
\hline $\mathrm{Tg}_{\chi 2}$ & 1497 \\
\hline $\mathrm{Tg}_{\delta 2}$ & 1491 \\
\hline $\mathrm{Tfl}_{\delta 2}$ & 1475 \\
\hline
\end{tabular}




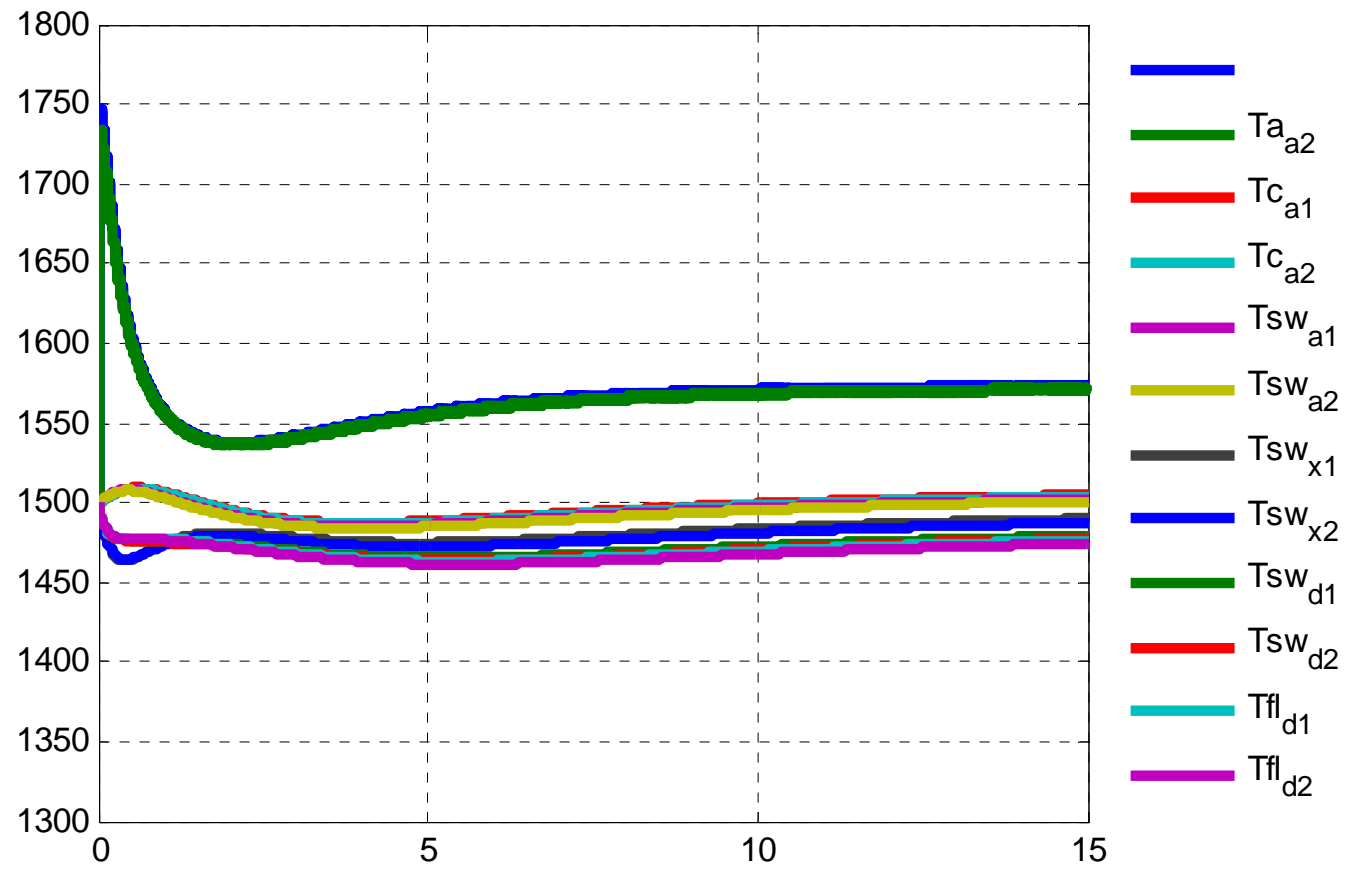

Figure 6.1-G: Profile Temperatures during the Melt Cycle

Table 6.1-G: Profile Temperatures at Steady State

\begin{tabular}{|c|c|c|c|}
\cline { 2 - 4 } \multicolumn{1}{c|}{} & \multicolumn{2}{c|}{$\begin{array}{c}\text { Temperatures } \\
\text { (K) }\end{array}$} & \multicolumn{1}{c}{} \\
\cline { 2 - 4 } \multicolumn{1}{c|}{} & $\mathbf{1}$ & $\mathbf{2}$ & \% Difference \\
\hline $\mathbf{T a}_{\boldsymbol{\alpha}}$ & 1573 & 1570 & 0.19 \\
\hline $\mathbf{T c}_{\boldsymbol{\alpha}}$ & 1505 & 1504 & 0.07 \\
\hline $\mathbf{T s w}_{\boldsymbol{\alpha}}$ & 1502 & 1501 & 0.07 \\
\hline $\mathbf{T s w}_{\boldsymbol{y y y}}$ & 1490 & 1487 & 0.20 \\
\hline $\mathbf{T s w}_{\boldsymbol{\delta}}$ & 1479 & 1477 & 0.14 \\
\hline $\mathbf{T f l}_{\boldsymbol{\delta}}$ & 1476 & 1475 & 0.07 \\
\hline
\end{tabular}




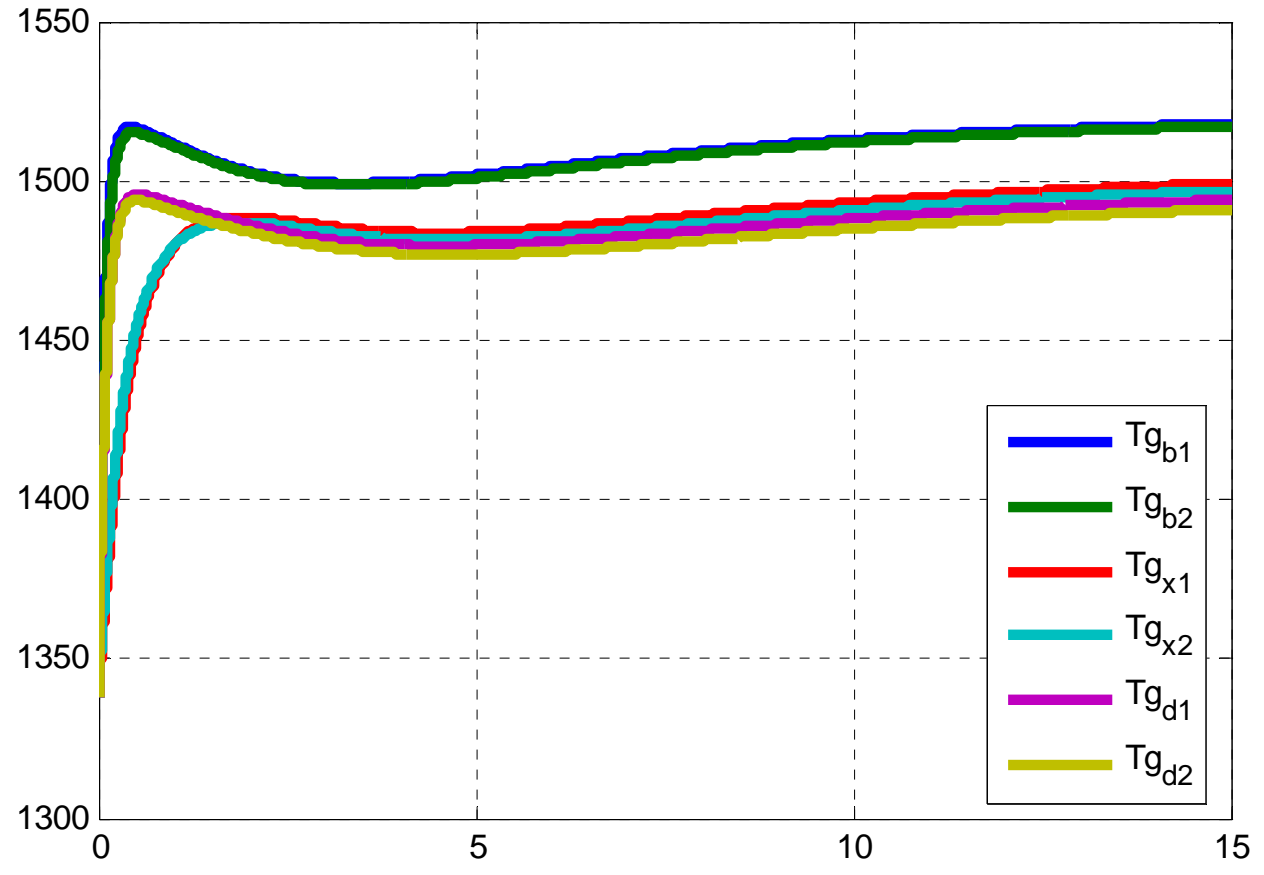

Figure 6.1-H: Profile Glass Temperatures during the Melt Cycle

Table 6.1-H: Profile Glass Temperatures at Steady State

\begin{tabular}{|c|c|c|c|}
\cline { 2 - 4 } \multicolumn{1}{c|}{} & \multicolumn{2}{c|}{ Temperatures (K) } & \multicolumn{1}{c|}{} \\
\cline { 2 - 4 } \multicolumn{1}{c|}{} & $\mathbf{1}$ & $\mathbf{2}$ & \% Difference \\
\hline $\mathrm{Tg}_{\beta}$ & 1518 & 1517 & 0.06 \\
\hline $\mathrm{Tg}_{\chi}$ & 1499 & 1497 & 0.13 \\
\hline $\mathrm{Tg}_{\delta}$ & 1494 & 1491 & 0.20 \\
\hline
\end{tabular}




\section{Appendix D - Application Model Coefficients}

Table 6.1-A: Table of Areas and Shape

Factors for Application

\begin{tabular}{|c|c|c|c|c|}
\hline Volume 1 & Volume 2 & $\begin{array}{c}\text { Area of Contact } \\
\left(\mathbf{m}^{\mathbf{2}}\right)\end{array}$ & Shape Factor & $\mathbf{S F}^{*} \mathbf{A}$ \\
\hline $\mathrm{a}_{\alpha}$ & $\mathrm{g}_{\beta}$ & 1.688 & 1 & 1.688 \\
\hline $\mathrm{bw}_{\alpha}$ & $\mathrm{g}_{\beta}$ & 0.563 & 0.281 & 0.158 \\
\hline $\mathrm{c}_{\alpha}$ & $\mathrm{g}_{\beta}$ & 1.688 & 1 & 1.688 \\
\hline $\mathrm{sw}_{\alpha}$ & $\mathrm{g}_{\beta}$ & 1.125 & 0.2963 & 0.333 \\
\hline $\mathrm{fw}_{\alpha}$ & $\mathrm{g}_{\beta}$ & 0.369 & 0.281 & 0.104 \\
\hline $\mathrm{g}_{\beta}$ & $\mathrm{g}_{\chi}$ & 1.688 & 1 & 1.688 \\
\hline $\mathrm{g}_{\chi}$ & $\mathrm{sw}_{\chi}$ & 0.231 & 1 & 0.231 \\
\hline $\mathrm{g}_{\chi}$ & $\mathrm{bw} \chi$ & 0.137 & 1 & 0.137 \\
\hline $\mathrm{g}_{\chi 1}$ & $\mathrm{~g}_{\delta 1}$ & 1.688 & 1 & 1.688 \\
\hline $\mathrm{g}_{\chi}$ & $\mathrm{fw}_{\chi}$ & 0.137 & 1 & 0.137 \\
\hline $\mathrm{g}_{\delta}$ & $\mathrm{sw}_{\delta}$ & 0.231 & 1 & 0.231 \\
\hline $\mathrm{g}_{\delta}$ & $\mathrm{bw}_{\delta}$ & 0.137 & 1 & 0.137 \\
\hline $\mathrm{g}_{\delta}$ & $\mathrm{fl}_{\delta}$ & 1.688 & 1 & 1.688 \\
\hline $\mathrm{g}_{\delta}$ & $\mathrm{fw}_{\delta}$ & 0.137 & 1 & 0.137 \\
\hline
\end{tabular}


Table 6.1-B: Table of Masses, Specific Heats, and Capacitances for Application

\begin{tabular}{|c|c|c|c|c|c|}
\hline $\begin{array}{c}\text { Volume } \\
\text { Name }\end{array}$ & $\begin{array}{c}\text { Volume } \\
\left(\mathbf{m}^{3}\right)\end{array}$ & $\begin{array}{c}\text { Density } \\
\left(\mathbf{k g} / \mathbf{m}^{\mathbf{3}} \mathbf{)}\right.\end{array}$ & $\begin{array}{c}\text { Mass } \\
(\mathbf{k g})\end{array}$ & $\begin{array}{c}\text { Specific } \\
\mathbf{H e a t} \\
(\mathbf{k J} / \mathbf{k g} * \mathbf{K})\end{array}$ & $\begin{array}{c}\text { Capacitance } \\
\mathbf{( k J / k g})\end{array}$ \\
\hline $\mathrm{bw}_{\alpha}$ & 0.172 & 3810 & 654 & 1.18 & 771.72 \\
\hline $\mathrm{c}_{\alpha 1}$ & 0.51 & 3810 & 1943.1 & 1.18 & 2292.858 \\
\hline $\mathrm{sw}_{\alpha}$ & 0.344 & 3810 & 1310.64 & 1.18 & 1546.555 \\
\hline $\mathrm{fw}_{\alpha}$ & 0.172 & 3810 & 655.32 & 1.18 & 773.2776 \\
\hline $\mathrm{g}_{\beta}$ & 0.021 & 2430 & 51.03 & 1.24 & 63.2772 \\
\hline $\mathrm{g}_{\chi 1}$ & 0.251 & 2430 & 609.93 & 1.24 & 756.3132 \\
\hline $\mathrm{bw}_{\chi}$ & 0.418 & 381 & 159.258 & 1.18 & 187.9244 \\
\hline $\mathrm{sw}_{\chi}$ & 0.083 & 3810 & 316.23 & 1.18 & 373.1514 \\
\hline $\mathrm{fw}_{\chi}$ & 0.042 & 3810 & 160.02 & 1.18 & 188.8236 \\
\hline $\mathrm{g}_{\delta 1}$ & 0.251 & 2430 & 609.93 & 1.24 & 756.3132 \\
\hline $\mathrm{bw}_{\delta}$ & 0.042 & 3810 & 160.02 & 1.18 & 188.8236 \\
\hline $\mathrm{sw}_{\delta}$ & 0.083 & 3810 & 316.23 & 1.18 & 373.1514 \\
\hline $\mathrm{fl}_{\delta}$ & 0.51 & 3810 & 1943.1 & 1.18 & 2292.858 \\
\hline $\mathrm{fw}_{\delta}$ & 0.042 & 3810 & 160.02 & 1.18 & 188.8236 \\
\hline
\end{tabular}

Table 6.1-C: Mass, Specific Heat, and Capacitance for Gas Volume for Application

\begin{tabular}{|c|c|c|c|c|c|c|c|}
\hline $\begin{array}{c}\text { Volume } \\
\text { Name }\end{array}$ & $\begin{array}{c}\text { Pressure } \\
\left(\mathbf{N} / \mathbf{m}^{\mathbf{2}}\right)\end{array}$ & $\begin{array}{c}\text { Volume } \\
\left(\mathbf{m}^{\mathbf{3}}\right)\end{array}$ & $\begin{array}{c}\text { Gas } \\
\text { Constant }\end{array}$ & $\begin{array}{c}\text { Temperature } \\
(\mathbf{K})\end{array}$ & $\begin{array}{c}\text { Mass } \\
(\mathbf{k g})\end{array}$ & $\begin{array}{c}\text { Specific } \\
\mathbf{H} \mathbf{H} / \mathbf{k g} * \mathbf{K})\end{array}$ & $\begin{array}{c}\text { Capacitance } \\
(\mathbf{k J} / \mathbf{k g})\end{array}$ \\
\hline $\mathrm{a}_{\alpha}$ & 101325 & 1.031 & 274.57 & 1300 & 0.293 & 1.025 & 0.3 \\
\hline
\end{tabular}


Table 6.1-D: Heat Transfer Resistances between Different Materials for Application

\begin{tabular}{|c|c|}
\hline Resistance & $\begin{array}{c}\text { Value } \\
\left(\mathbf{m}^{2} \mathbf{K} / \mathbf{k W}\right)\end{array}$ \\
\hline Raw & 6.7 \\
\hline Rag & 6.7 \\
\hline Rgw & 2 \\
\hline Rwo & 139 \\
\hline
\end{tabular}

Table 6.1-E: Table of Resistances between Glass Volumes for Application

\begin{tabular}{|c|c|c|c|c|}
\hline $\begin{array}{c}\text { Volume } \\
\mathbf{1}\end{array}$ & $\begin{array}{c}\text { Volume } \\
\mathbf{2}\end{array}$ & $\begin{array}{c}\mathbf{K} \\
(\mathbf{k W} / \mathbf{m K})\end{array}$ & $\begin{array}{c}\text { Distance } \\
\mathbf{( m )}\end{array}$ & $\begin{array}{l}\text { Resistance } \\
\left(\mathbf{m}^{\mathbf{2}} \mathbf{K} / \mathbf{k W}\right)\end{array}$ \\
\hline $\mathrm{g}_{\beta}$ & $\mathrm{g}_{\chi}$ & 1.2 & 0.075 & 0.063 \\
\hline $\mathrm{g}_{\chi}$ & $\mathrm{g}_{\delta}$ & 1.2 & 0.15 & 0.125 \\
\hline
\end{tabular}

